\title{
$A C$ and DC Hybrid Distribution Grids with Solar Integration: Architecture, Stabilization and Cost Assessment
}

DOE SETO Project Final Report

Energy Systems Division 


\section{About Argonne National Laboratory}

Argonne is a U.S. Department of Energy laboratory managed by UChicago Argonne, LLC

under contract DE-AC02-06CH11357. The Laboratory's main facility is outside Chicago, at 9700 South Cass Avenue, Lemont, Illinois 60439. For information about Argonne

and its pioneering science and technology programs, see www.anl.gov.

\section{DOCUMENT AVAILABILITY}

Online Access: U.S. Department of Energy (DOE) reports produced after 1991 and a growing number of pre-1991 documents are available free at OSTI.GOV (http://www.osti.gov/), a service of the US Dept. of Energy's Office of Scientific and Technical Information.

Reports not in digital format may be purchased by the public from the National Technical Information Service (NTIS):

U.S. Department of Commerce

National Technical Information Service

5301 Shawnee Rd

Alexandria, VA 22312

www.ntis.gov

Phone: (800) 553-NTIS (6847) or (703) 605-6000

Fax: (703) 605-6900

Email: orders@ntis.gov

Reports not in digital format are available to DOE and DOE contractors from the Office of Scientific and Technical Information (OSTI):

U.S. Department of Energy

Office of Scientific and Technical Information

P.O. Box 62

Oak Ridge, TN 37831-0062

www.osti.gov

Phone: (865) 576-8401

Fax: (865) 576-5728

Email: reports@osti.gov 


\section{AC and DC Hybrid Distribution Grids with Solar Integration: Architecture, Stabilization and Cost Assessment}

DOE SETO Project Final Report

prepared by

Dongbo Zhao

Energy Systems Division, Argonne National Laboratory

December 2020 
Project Title: $\quad A C$ and DC Hybrid Distribution Grids with Solar Integration: Architecture, Stabilization and Cost Assessment

Project Period: $\quad 1$ Oct $2018-30$ Sept 2020

Project Budget: $\quad \$ 826,000$

Submission Date: $\quad 30$ October 2020

Recipient: $\quad$ Argonne National Laboratory

Address: $\quad 9700$ S Cass Ave, Lemont, IL 60439

Agreement Number: $\quad$ Lab Call FY19-21 34225

Awarding Agency: DOE EERE SETO

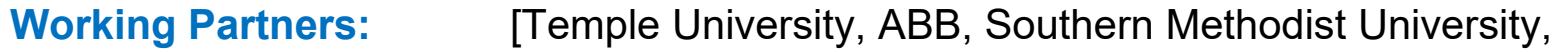
Illinois Institute of Technology, University of Texas - Austin]

Principal Investigator: Dongbo Zhao

Principal Energy System Scientist

Phone: (630)252-4307

Email: dongbo.zhao@anl.gov 


\section{Executive Summary}

In this project, a holistic analysis of architecture, stabilization, and cost/efficiency analysis in hybrid AC and DC distribution grids are conducted. Particularly, versatile and costefficient multiport converters are developed to not only integrate solar sources and other DERs in DC grids, but also facilitate the interactive operation of DC sub-grids and conventional AC distribution grids. Meanwhile, a universal and extended impedancebased stabilization approach with a decentralized and adaptive virtual impedance loop is developed in hybrid AC and DC distribution grids, which comprehensively covers the active stabilization of DC sections, AC sections, and interface inverters interlinking both $A C$ and DC sections. Furthermore, to quantitatively evaluate the cost and efficiency of hybrid $A C$ and $D C$ distribution grids and quantify the improvement of hybrid $A C$ and $D C$ grids over conventional pure AC grids, the project team develops an alpha-version tool to monitor and calculate the efficiency and cost of the DC, AC, or hybrid AC and DC grids.

\section{Table of Contents}

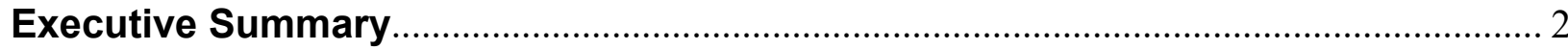

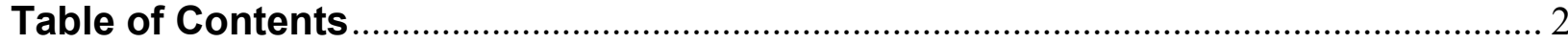

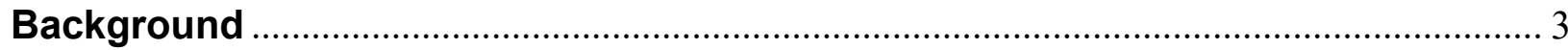

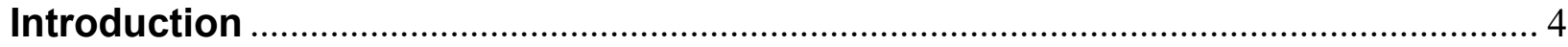

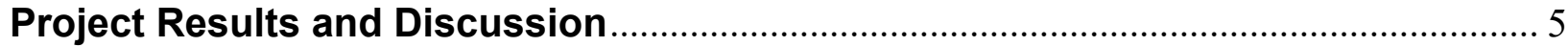

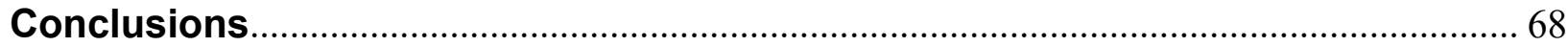

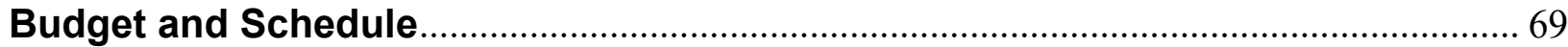

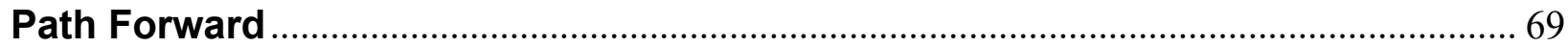

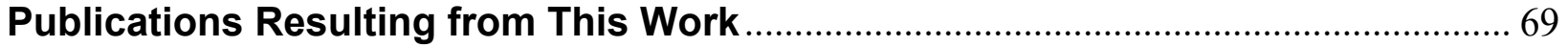

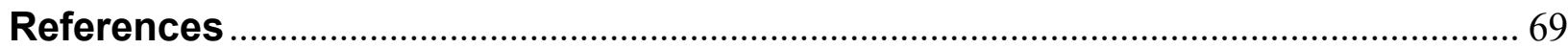




\section{Background}

Increasing penetration of inverter-based resources challenges modern distribution systems with insufficient inertia and increasing generation intermittency. To mitigate the impacts of operational uncertainties, the concept of distribution grids was proposed for effectively integrating distributed energy resources (DERs) and enhancing grid operational performance. In the past years, AC distribution grids have been extensively studied, given that conventional grids are implemented based upon AC electricity [1]. Meanwhile, with increasing penetration of DC-coupled resources (e.g., photovoltaics [PVs], battery energy storage, etc.), the technology frontier of DC distribution grids has been significantly advanced that enables a hybrid architecture with both AC and DC resources (i.e., hybrid AC and DC distribution grids [2]).

In the literature, the planning and operations of $A C / D C$ distribution systems have been extensively studied in the past decades [3]-[7]. Nevertheless, most of those existing system-level studies are established on an uncleared engineering basis. The definitions or problems such as the architecture and stability of the hybrid AC/DC are not well-solved nor well-established. Apart from the planning and operation studies of AC/DC distribution systems, some efforts have been put into the protection system development [8]-[10] and the control system development [1], [11]-[12].

The challenges, issues, and solutions in AC distribution protection after the integration of DERs have been discussed in many papers. The issues include misoperation of directional protection, mis-tripping of recloser or breakers, fuse fatigue, and sympathetic tripping [13]-[15]. The reason is recognized as the fault current distribution is no longer deterministic in fault current direction and magnitude, which varies with changing penetration levels and network configurations. Adaptive protection is said to calculate and implement appropriate protection settings at various operation conditions [16]-[17] and thus is one protection solution used by most researchers. Challenges in "fuse saving" in AC distribution after DERs and solar PV integration are studied [18]-[19]. However, not many studies can be found on the protection coordination of hybrid $\mathrm{AC}$ and $\mathrm{DC}$ distribution systems with solar PV integration.

Control systems development of the hybrid AC/DC system is another challenge since hybrid $A C$ and $D C$ distribution grids have relatively complex operational dynamics due to the hybrid and inverter dominated configuration. Therefore, it is critical and also challenging for small-signal stability analysis compared to conventional power grids. In [11], the small-signal modeling of a hybrid AC and DC distribution grid is presented, focusing on $A C$ distribution feeders, DC feeders, and interlink converters between common $A C$ and DC buses. Meanwhile, synthetic droop characteristics for regulating interlink converters are implemented to control the power exchange between AC and DC distribution grids. Further, in [12], the modeling and control of inverter dominated AC distribution grids is studied in detail to conduct small-signal analysis, providing a feasible solution for understanding the small-signal system of AC distribution grids. However, the existing control systems for AC/DC hybrid system only focus more on particular sections, a complete solution covering various control functions and all the corresponding sections is still missing.

Besides, the techno-economic study is also critical for the realization of hybrid AC/DC systems. The sizing, locating, installation and operation related economic analyses for 
hybrid AC/DC systems have been presented in the literature [20]-[22]. However, the whole life cycle cost and benefit analyses are not studied in the literature.

By leveraging with existing literature, this project first developed a multiport converter that enabling the hybrid AC/DC distribution system. Different from the existing control system development, the control system considered in this project is a holistic control system for the general AC/DC grid. Besides, the computation complexity and the system stability margin quantification problem are also considered in the process of control system development. Finally, comprehensive cost-benefit analyses are carried out by considering the installation and operational cost as well as the life cycle of the energy storage system.

\section{Introduction}

This project and the research thrusts therein are designed to tackle the obstacles with respect to the key development and integration efforts of hybrid $A C$ and $D C$ distribution grids with solar energy. The innovation of this project can be concluded as (1) performs comprehensive benefit analyses of the hybrid AC/DC distribution system considering the potential benefits on system voltage, harmonic minimization, and loss reduction; (2) develops a holistic small-signal model for the general hybrid AC/DC distribution system and the corresponding generalized control algorithm for hybrid AC/DC system; (3) develops an alpha version tool for cost-benefit analysis and performs a life cycle cost analysis for the hybrid AC/DC system with solar power and energy stage facility. A milestone summary is concluded in Table 1.

Apart from the milestone listed in the TWP, our team member also investigates the protection problems and potential solutions with hybrid AC/DC distribution systems in the context of the fuse saving concept. The issues in hybrid AC and DC protection coordination because of solar PV integration are analyzed. Root causes and potential solutions in control and protection are analyzed and discussed. One solution using fault current limiting is given and explained.

Table 1. Milestone Table of the Project

\begin{tabular}{|c|l|c|c|c|}
\hline No. & \multicolumn{1}{|c|}{ Description } & Start & End & Status \\
\hline 1 & $\begin{array}{l}\text { Implement the baseline model of a hybrid AC and DC grid in } \\
\text { MATLAB/Simulink with dedicated interface inverters, which } \\
\text { should include 1 AC sub-section, 1 DC sub-section, solar } \\
\text { sources and batteries, and solar penetration level should be } \\
\text { adjustable between 0 to 100\%. MATLAB/Simulink software } \\
\text { environment will be used to verify the developed model } \\
\text { components and required penetration level. }\end{array}$ & $10 / 01 / 2018$ & $12 / 31 / 2018$ & $100 \%$ \\
\hline 2 & $\begin{array}{l}\text { Based on the baseline model developed in Task 1, } \\
\text { implement a complete impedance model of hybrid AC and } \\
\text { DC grids, covering: 1) AC sub-section, 2) DC sub-section } \\
\text { and 3) interfaces between AC and DC common buses, and } \\
\text { the relative error between the impedance model and the } \\
\text { baseline model (developed in Task 1) is limited to 5\% by } \\
\text { comparing the model differences in the frequency domain. }\end{array}$ & $10 / 01 / 2018$ & $03 / 31 / 2019$ & $100 \%$ \\
\hline
\end{tabular}


Lab Call FY19-21 34225

$A C$ and DC hybrid distribution grids with solar integration: architecture, stabilization and cost assessment

Dongbo Zhao

\begin{tabular}{|c|l|l|l|l|}
\hline 3 & $\begin{array}{l}\text { Implement the multiport converters in both DC subsection } \\
\text { (Case I) and AC subsection (Case II) in MATLAB/Simulink } \\
\text { with component power loss profile embedded, and the } \\
\text { efficiency of the developed multiport converters will be over } \\
\text { 95\%, which is demonstrated by comparing the total input } \\
\text { power and total output power of each multiport converter. }\end{array}$ & $01 / 01 / 2019$ & $06 / 30 / 2019$ & $100 \%$ \\
\hline 4 & $\begin{array}{l}\text { Formulate and calculate the acquisition/investment cost and } \\
\text { O\&M cost of hybrid AC and DC grids of the baseline system. }\end{array}$ & $01 / 01 / 2019$ & $06 / 30 / 2019$ & $100 \%$ \\
\hline 5 & $\begin{array}{l}\text { Conduct experimental tests of the developed multiport } \\
\text { converters and demonstrate that the converter efficiency is } \\
\text { over 95\%. }\end{array}$ & $07 / 01 / 2019$ & $12 / 31 / 2019$ & $100 \%$ \\
\hline 6 & $\begin{array}{l}\text { Develop the impedance-based stability criteria and virtual- } \\
\text { impedance-based active stabilization approach to enhance } \\
\text { the stability margin by 20\%. }\end{array}$ & $04 / 01 / 2019$ & $12 / 31 / 2019$ & $100 \%$ \\
\hline 7 & $\begin{array}{l}\text { Calculate the energy conversion efficiency from operation } \\
\text { simulation using the baseline system. }\end{array}$ & $01 / 01 / 2019$ & $12 / 31 / 2019$ & $100 \%$ \\
\hline 8 & $\begin{array}{l}\text { Scenario analysis and impact analysis of cost and energy } \\
\text { conversion efficiency using the test case developed. }\end{array}$ & $07 / 01 / 2019$ & $12 / 31 / 2019$ & $100 \%$ \\
\hline 9 & $\begin{array}{l}\text { Assess the performance of various cases including the } \\
\text { system with multiple DC links for their steady state voltages, } \\
\text { and the system with AC/DC sections connected to the main } \\
\text { AC grid. }\end{array}$ & $10 / 01 / 2019$ & $09 / 30 / 2020$ & $100 \%$ \\
\hline
\end{tabular}

\section{Project Results and Discussion}

\section{Task 1 Develop the multiport converter in AC and DC distribution grids}

Subtask 1.1 Implement a baseline hybrid AC and DC grid in MATLAB/Simulink, which includes dedicated inverters interfacing solar source, battery, AC common bus and DC common bus, respectively. This baseline case will also be used in Task 2 for stability analysis.

Subtask 1.2 Identify the potential approaches to aggregate neighboring dedicated inverters. Two approaches of aggregation should be provided, with one implemented in the DC sub-section (Case I) and one implemented in the AC sub-section (Case II).

Subtask 1.3 Implement the aggregated multiport converter in Case I and Case II in MATLAB/Simulink and conduct simulation tests.

The switching model diagram of the developed multiport converter for hybrid AC/DC application is shown in Fig. 1.1, which is made by an interlinking converter that connects AC common bus and DC common bus through an LCL filter and transformer. In the DC section, two DC-DC boost converters are connected to the common DC bus, where the solar source is connected to a unidirectional boost converter and battery management is done by a bidirectional boost converter. This model is developed in MATLAB/Simulink and it is used in AC/DC microgrid. 


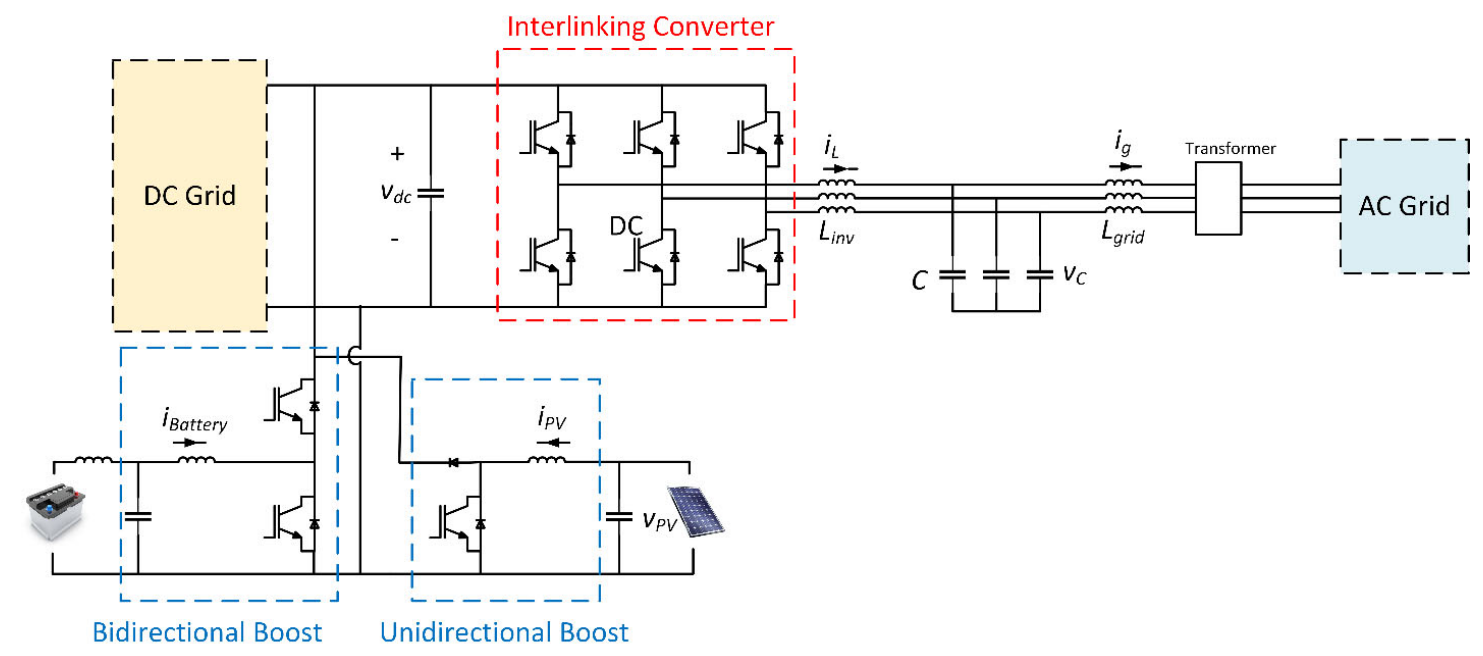

Fig. 1.1. Switching model of multiport converter.

The controller for the interlinking converter is shown in Fig. 1.2. The proposed controller uses a common dc bus, i.e. $v_{d c}$, and grid frequency $\left(\omega_{g}\right)$ for controlling active power control and $\mathrm{AC}$ voltage magnitude for reactive power compensation. Coefficients for controlling active power flow, i.e. $m_{v d c}$ and $m_{\omega}$, are selected based on converter power rating, DC voltage limits, and frequency support from DC microgrid. The droop coefficient in reactive power loop, i.e. $\mathrm{m}_{\mathrm{q}}$, is based on maximum available reactive power $\left(\mathrm{Q}_{\max }\right)$, and location of DC subgrid in the developed hybrid AC/DC microgrid and magnitude of the measured voltage at the point of connection to $A C$ common bus is used for setting reactive power reference by a PI controller.

$$
Q_{\text {max }}=\sqrt{S_{\text {rating }}-P_{\text {meas }}}
$$

In (1.1), S Sating is the interlinking converter power rating and $P_{\text {meas }}$ is measured active power, and $\mathrm{Q}_{\max }$ is maximum reactive power that can be provided by the interlinking converter. The generated references for current in $d$ and $q$ axes are given to the wellknown current controller that generates modulation references for PWM.

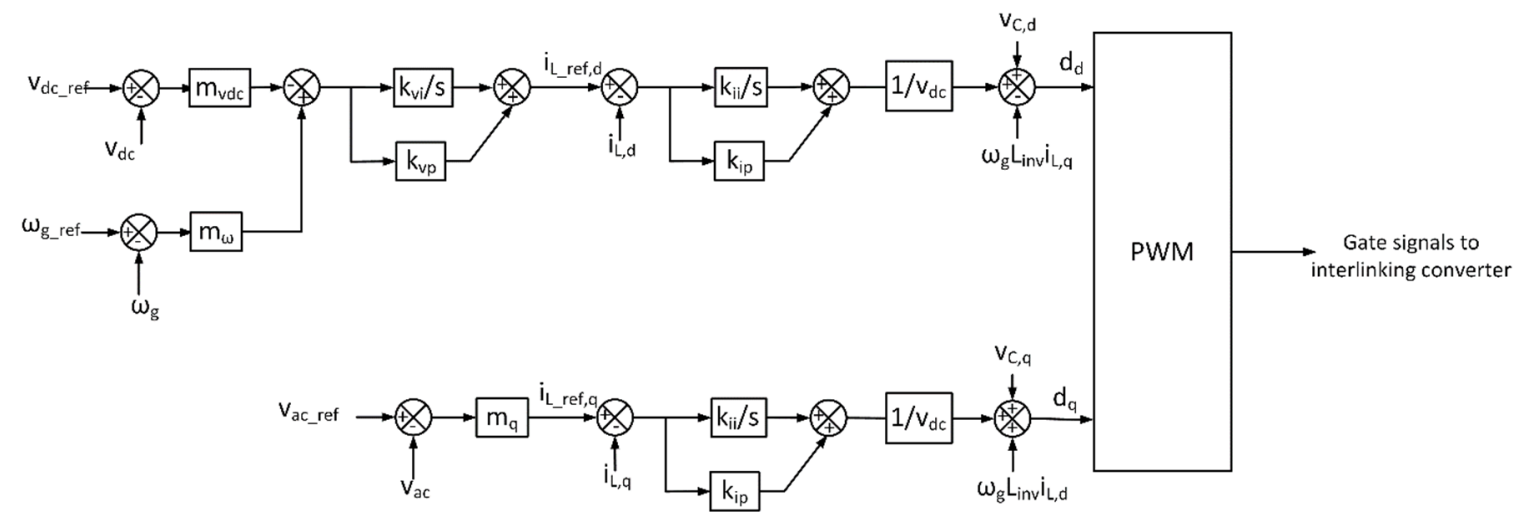

Fig. 1.2. Interlinking converter control diagram.

The unidirectional boost converter between the common DC link and PV array in Fig. 1.3 is responsible for injecting maximum available PV power to the grid by applying P\&O maximum power point tracking (MPPT) algorithm. 


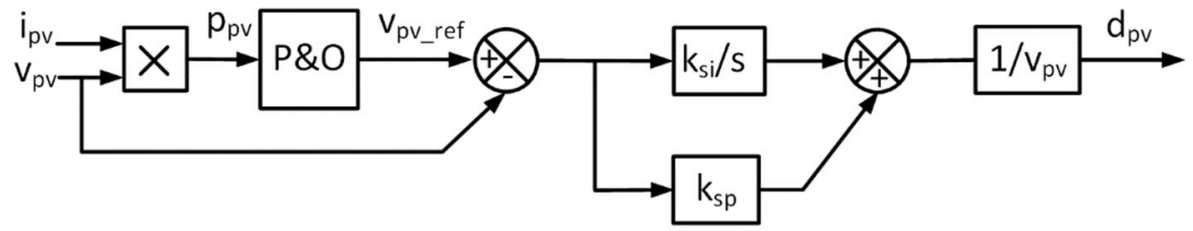

Fig. 1.3. MPPT control via boost converter.

After the development of the Simulink model of the multiport converter system, a baseline hybrid AC/DC microgrid is simulated in MATLAB/Simulink, which includes one DC subgrid and one AC subgrid. In the baseline model, the AC section of the IEEE 34 node test feeder is kept as the original model, and an additional DC section is connected to node 828 . This system is connected to a three-phase $24.9 \mathrm{kV}, 60 \mathrm{~Hz}$ grid at node 800 as shown in Fig. 1.4 and parameters of the system are provided in Table 1.1. In DC section nodes that are shown by Z, I, P are constant impedance, constant current, and constant power loads, respectively.

Table 1.1. Baseline hybrid AC/DC system

\begin{tabular}{|c|c|}
\hline Parameter & Value \\
\hline AC gird voltage & $24.9 \mathrm{kV}$ \\
\hline DC grid voltage & $40 \mathrm{kV}$ \\
\hline AC Load & $1.8 \mathrm{MW}, 0.3 \mathrm{MVar}$ \\
\hline Maximum Interlinking converter rating & $1 \mathrm{MVA}$ \\
\hline Maximum Solar panel capacity & $1 \mathrm{MW}$ \\
\hline DC Load & $0.6 \mathrm{MW}$ \\
\hline
\end{tabular}

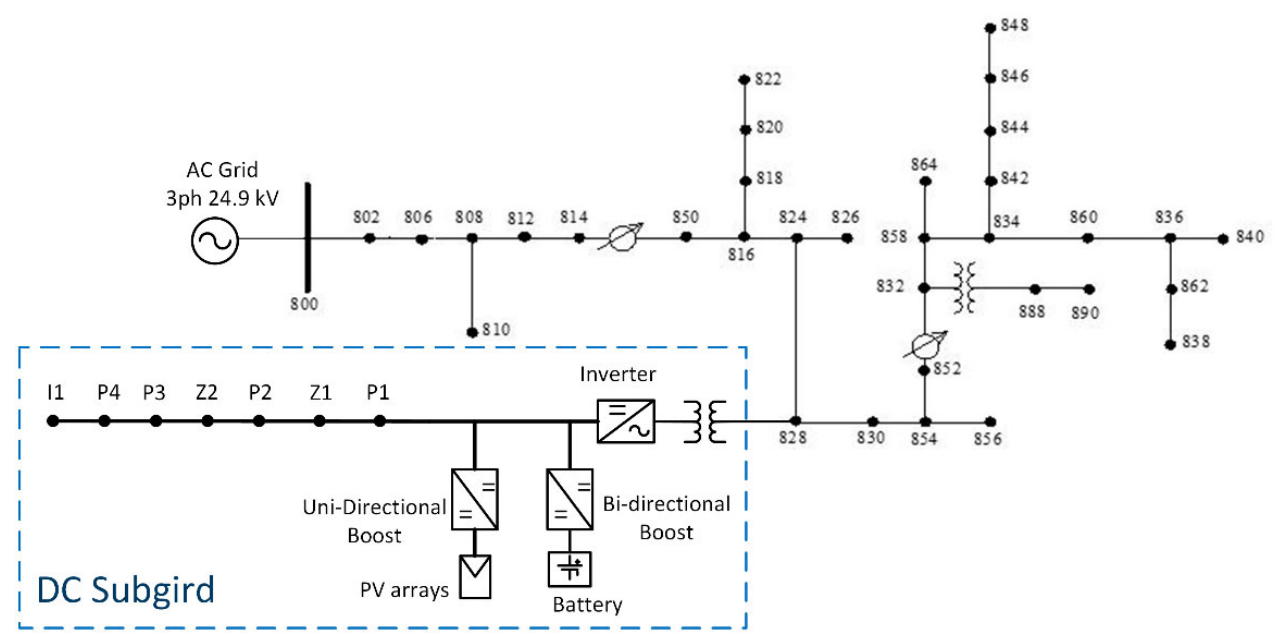

Fig. 1.4. Baseline model of hybrid AC/DC grid.

The ANSI C 84.1 defines $90 \%$ to $105 \%$ of the nominal voltage as the acceptable voltage range for utilization in range $A$. For verifying the ability of the control system in keeping the voltage regulated, according to the ANSI limits, first the nominal voltage of AC grid at three different load conditions is simulated for the original IEEE 34 node test feeder. In Fig. 1.5, the per-unit rms voltages at all nodes are sketched for two loading conditions. In this model, two regulating transformers with a 120:122 turn ratio are placed between 
nodes $814-850$, and $852-832$. Also, there are two shunt capacitors at nodes 844 and 848 . In the $100 \%$ load case, the shunt capacitors are connected to the system, otherwise the voltages at the neighboring nodes drop below $85 \%$. In Fig. 1.5(a) rms voltage at all nodes remain in the standard range for $100 \%$ load condition. For the $20 \%$ load condition, shunt capacitors should be disconnected, otherwise the rms voltage at nodes near the shunt capacitors exceeds $105 \%$ of the nominal voltage limit. In Fig. 1.5(b) value of rms voltage at some nodes violates the ANSI C84.1 upper limit. This violation occurs at the nodes after the regulator where 1.05 p.u. voltage is increased to a higher value.

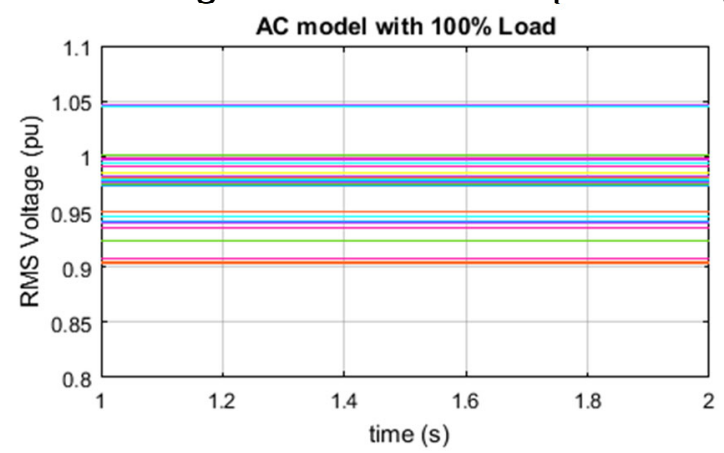

(a)

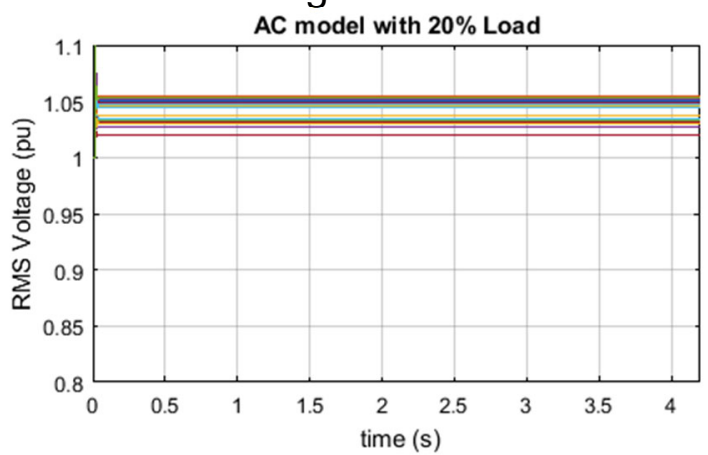

(b)

Fig. 1.5. (a) RMS voltage at all nodes in IEEE 34 bus system with $100 \%$ load. (b) RMS voltage at all nodes in IEEE 34 bus system with $20 \%$ load.

For controlling the AC microgrid voltage, the controller uses node 828 voltage measurement. The upper and lower limit for voltage of this node should be set according to light load and full load condition in the AC system, respectively. Based on this observation, the voltage at node 828 acceptable range is 0.975 to 1.03 p.u. and reactive power compensation by interlinking converter should follow equation (1.1).

In the first case, both AC subgrid and DC subgrid are working with $100 \%$ loading condition and PV's power generation is zero, and it is considered that the battery cannot provide power regarding the state of charge. Here, all the DC grid load power is provided by the AC grid and the volt-var converter injects reactive power to the AC grid to keep AC voltage regulated. Figs. 1.6 and 1.7(a) show the rms voltage at AC side, DC voltage, and active and reactive power that the interlinking converter received from the AC grid. In this condition, the reactive power injection reaches the maximum reactive power limit of the interlinking converter, i.e. $800 \mathrm{kVAr}$, and the voltage limit is followed at all nodes. The voltage at node 828 is 0.985 p.u. However, it should be noticed if the DC or AC load increase even $10 \%$, the voltage will be violated at some AC nodes like 848 or 849 , which are located at the end of the feeder. This issue happens because the extra load is added to the system while the existing line cannot handle extra load and it causes extra power loss on the line. The measured voltages at DC grid nodes are kept around 1 p.u.

In the second case, all loads in AC and DC subgrids are reduced to $50 \%$ of their nominal value and PV is generating $800 \mathrm{~kW}$ power. Like the original IEEE 34 model simulation, shunt capacitors are disconnected from nodes 844 and 848 . The results for the second case are shown in Figs. 1.8 and 1.7(b). Injected reactive power to the AC grid is very low and $500 \mathrm{~kW}$ is injected from the DC grid to the AC grid while the voltage at both AC and DC subgrids are following ANSI limits. 
$A C$ and DC hybrid distribution grids with solar integration: architecture, stabilization and cost assessment

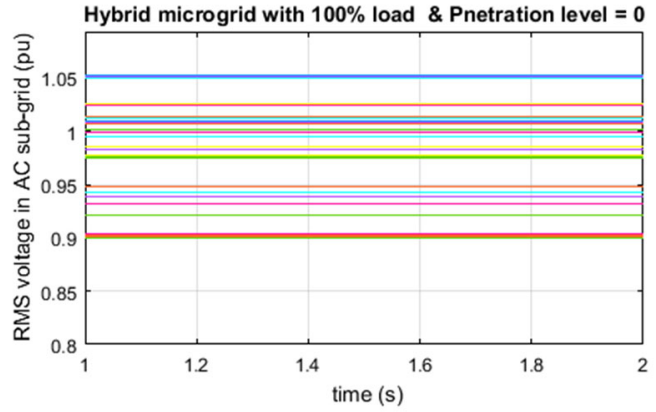

(a)

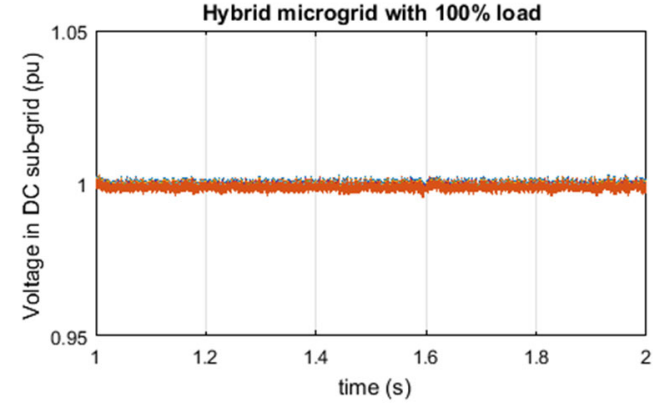

(b)

Fig. 1.6. Hybrid AC/DC microgrid results with $100 \%$ load and zero PV penetration level (a) RMS voltage at all AC nodes. (b) Voltage at all DC nodes.
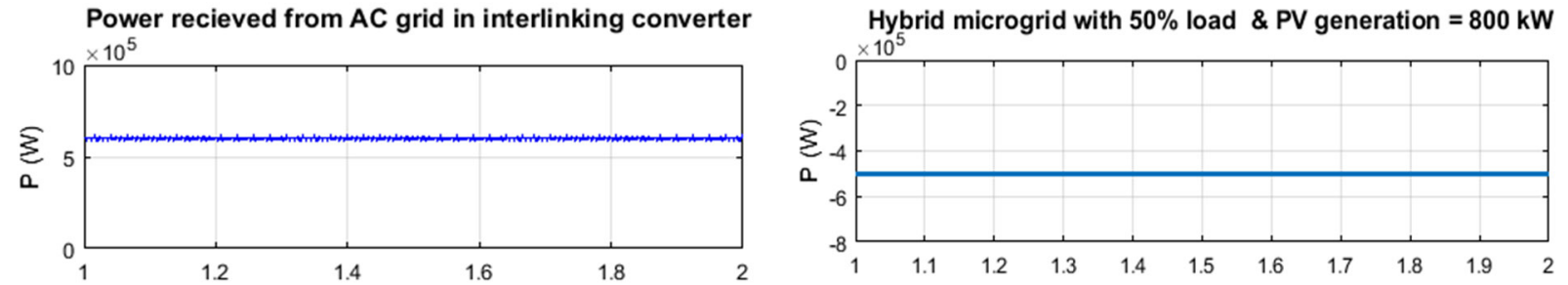

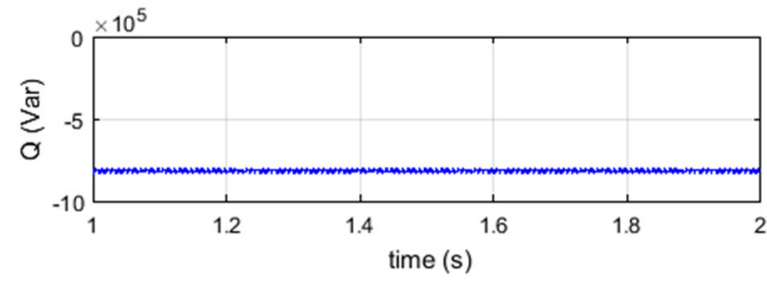

(a)

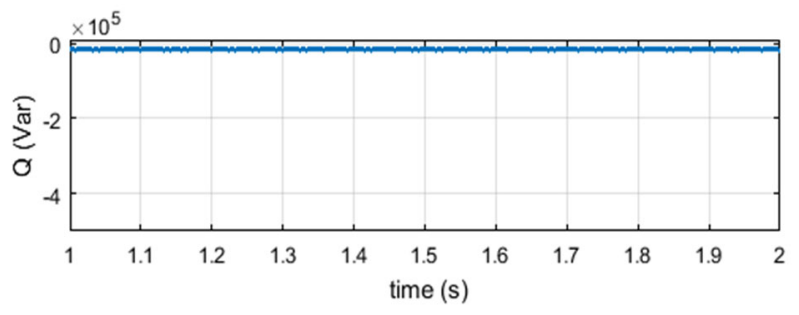

(b)

Fig. 1.7. Active and reactive power injection from AC grid to DC grid. (a) $100 \%$ load. (b) $50 \%$ load

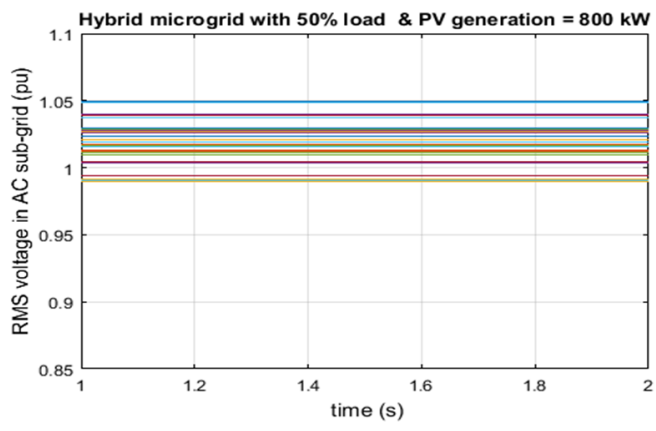

(a)

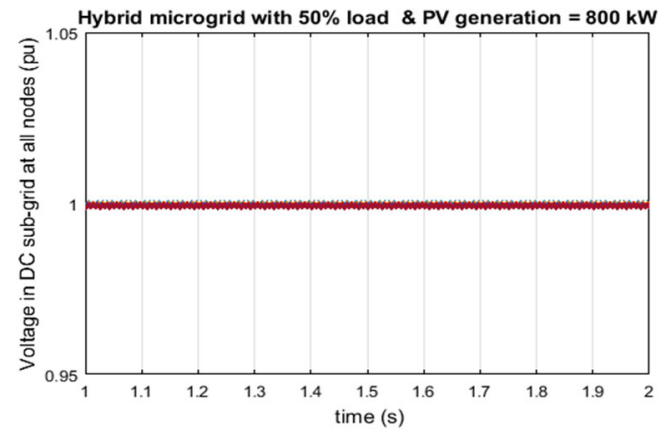

(b)

Fig. 1.8. Hybrid AC/DC microgrid results with $50 \%$ load and zero PV penetration level (a) RMS voltage at all AC nodes. (b) Voltage at all DC nodes.

As can be seen in the full load condition, the voltage is near the boundary limit and a huge amount of reactive power should be injected into the gird. The overvoltage also happens at very light load conditions where reactive power should be absorbed from the grid. In these conditions, if the load increases (or be decreased in light load case), the ANSI limits will be violated. There are a few solutions to overcome this problem including using an interlinking converter with higher power ratings, placing the DC subgrid near the 
AC grid at node 800 , adding reactive power compensators like STATCOM at the end of feeder nodes. Also, battery energy storage can act according to the voltage limits, but the battery management system should consider the state of the charge of the battery.

Subtask 1.4 Build the scale-down multiport converter prototype, and conduct the tests of the multiport converters at full load, half load, and low load conditions in UT-Austin's lab. Subtask 1.5 Identify the cost and efficiency improvement in Case I and Case II in comparison with the baseline case developed in Subtask 1.1.

A scaled-down single-phase multiport converter was designed and developed for testing $A C$ and DC hybrid microgrid. This multiport converter has two DC ports, one AC port, and one intermediate DC port. Two DC ports can be used to connect energy resources such as PV arrays and batteries. Power conversion from PV/battery to the AC grid goes through three stages, which are boost converter, isolated bidirectional DC-DC converter, and single-phase grid-tied inverter. The isolated DC/DC converter is used to enhance the safety of the system and to reduce the common-mode current for the PV panels. In Fig. 1.9, different stages of the multiport converter system are shown. PV panel will be connected to the common DC bus, with a boost converter like the battery management converter in Fig. 1.9(b). This multiport converter is able to transfer power in both directions, so it can absorb power from the grid when PV and battery cannot provide DC load power, or transfer power from the DC side to the AC side according to power requirements.

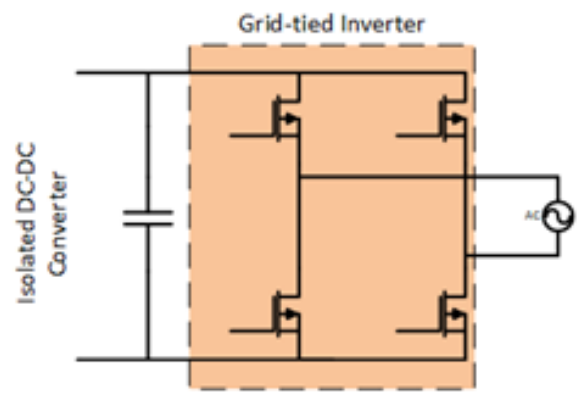

(a)

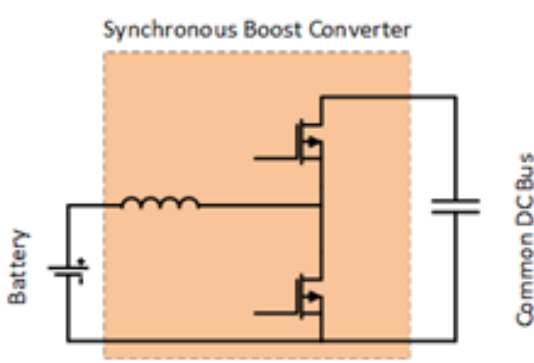

(b)

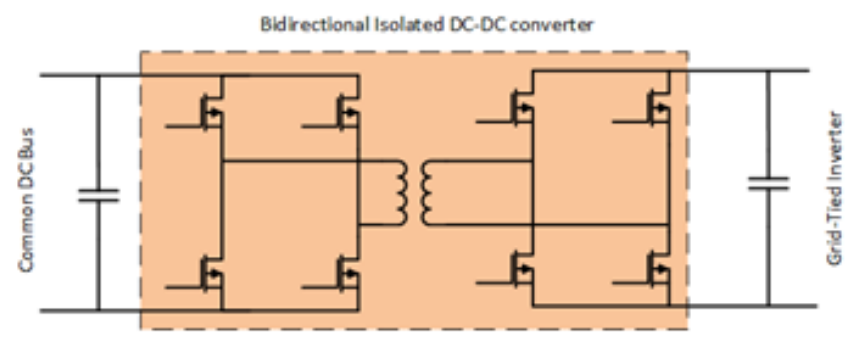

(c)

Fig. 1.9. (a) Grid-tied inverter. (b) Battery management converter. (c) Isolated dc-dc converter

To meet higher than 95\% efficiency requirements of the project, advanced SiliconCarbide ( $\mathrm{SiC}$ ) power MOSFETs are used in all converters. In addition to the power stages, two local control boards are designed and implemented, where one board is controlling boost rectifiers and common DC bus side of the isolated DC-DC converter and the other board is controlling grid-tied inverter and grid side of the isolated DC-DC converter. 
The entire multiport converter system with DC-DC converters and grid-tied inverter is shown in Fig. 1.10. The power loss in the multiport converter is dependent on the operating point of each converter. The total power loss is determined by:

$$
P_{\text {total_loss }}=P_{\text {boost_PV }}+P_{\text {boost_Battery }}+P_{D A B}+P_{\text {inverter }}+P_{\text {filter }}
$$

The power loss in each DC/DC or AC/DC converter is caused by MOSFET's loss, magnetic component's loss, and ESR loss of capacitors. The power loss in MOSFET is caused by conduction, switching, and driver losses. The other noticeable power loss that affects the efficiency of the converter is in magnetic components, including boost inductor and isolated DC/DC converter transformer.

Table 1.2. Notable Specification of the Scaled-down Multiport Converter System

\begin{tabular}{|l|l|}
\hline Description & Value \\
\hline Maximum Achievable Power & $10 \mathrm{~kW}$ \\
\hline Maximum AC Voltage & $480 \mathrm{Vrms}$ \\
\hline Maximum common DC bus voltage & $800 \mathrm{~V}$ \\
\hline Boost input voltage & $300 \mathrm{~V}$ \\
\hline Switching frequency & $40 \mathrm{kHz}$ \\
\hline Peak efficiency & $97.2 \%$ \\
\hline
\end{tabular}

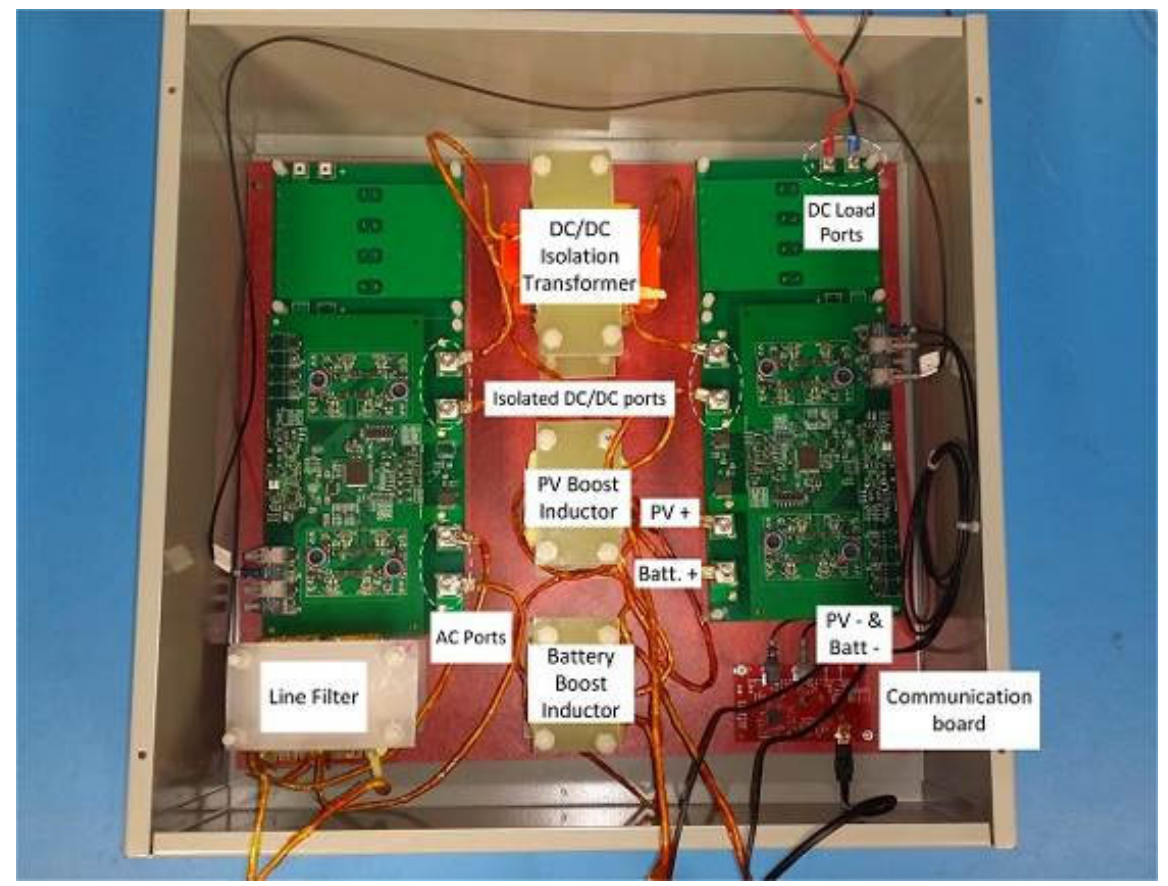

Fig. 1.10. Developed multiport converter.

In the following, two different test scenarios are considered to verify higher than $95 \%$ efficiency of the multiport converter. In the first case scenario, all the generated power by the PV panel is delivered to the gird. In this case, the battery neither injects nor stores power. Therefore only gate driver loss of this converter has an effect on the total efficiency. As shown in Fig. 1.11(a), the peak efficiency of the multiport converter is $97.2 \%$, and the efficiency of the converter from light load to full load is higher than $95 \%$. In the second case scenario, half of the injected power that is delivered to the AC grid is shared equally between battery and PV panel. In this case, the switching loss will be higher, while half of the current passes through the PV's boost converter and the other 
half is conducted by the battery's boost converter and conduction loss will be lower. The efficiency curve for this case is shown in Fig. 1.12(b) where the peak efficiency is higher than $97 \%$ and as the first case, the light load to full load test shows higher than $95 \%$ efficiency.

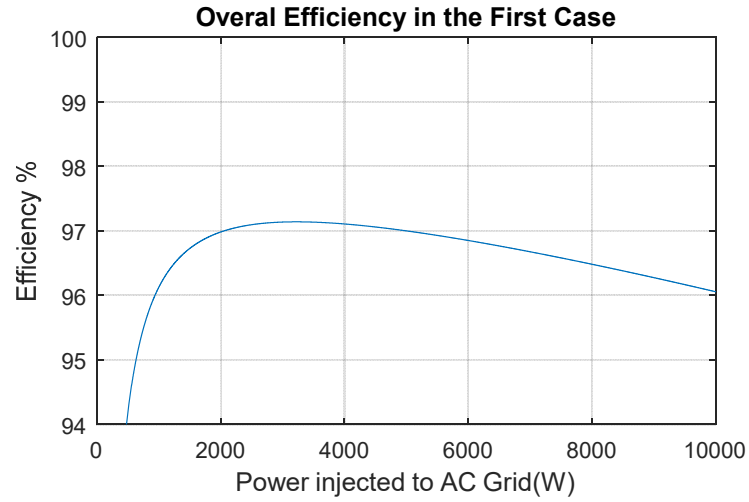

(a)

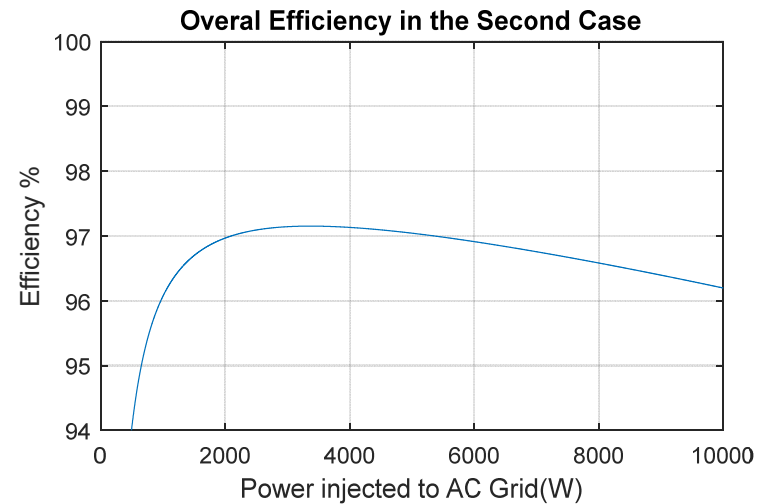

(b)

Fig. 1.11. (a) Efficiency curve in the first test case. (b) Efficiency curve in the second test case.

Subtask 1.6 Simulate systems with multiple DC-sections and monitor all the network nodes (steady-state voltages)

In a hybrid AC/DC grid with one DC subgrid, the simulation results showed that by keeping the original IEEE 34 node test feeder without change and adding huge DC load and high PV penetration level, and the ANSI C.84.1 voltage limit will be violated in some loading conditions. The voltage limit violation happens due to the extra voltage drop on the line in full load condition and regulating transformers in the light load condition. In order to have a fair comparison with the original IEEE 34 node test feeder model, in a distribution grid with multiple DC subgrids three sections of the AC test feeder are converted to the DC subgrid with a similar load type and distribution line parameters. The first, second, and third DC subgrids are added at nodes 816-822, 834-848, and 860-840, respectively, and regulating transformers between nodes $814-850$, and $852-832$ are removed from the model. Also, the shunt capacitors at nodes 844 and 848 are removed. This system is connected to the grid at node 800 as depicted in Fig. 1.12 and its parameters are provided in Table 1.3.

Table 1.3. Hybrid ACDC grid parameters

\begin{tabular}{|c|c|}
\hline Parameter & Value \\
\hline AC gird voltage & $24.9 \mathrm{kV}$ \\
\hline DC grid voltage & $40 \mathrm{kV}$ \\
\hline AC Load & $880 \mathrm{~kW}, 450 \mathrm{kVar}$ \\
\hline First DC subgrid load & $450 \mathrm{~kW}$ \\
\hline Second DC subgrid Load & $600 \mathrm{~kW}$ \\
\hline Third DC subgrid Load & $200 \mathrm{~kW}$ \\
\hline Maximum solar panel capacity & $1.2 \mathrm{MW}$ \\
\hline
\end{tabular}

Here, the reactive power reference is set by the $A C$ voltage magnitude and droop coefficients are determined according to the maximum power of the interlinking converter and the location of the DC subgrid to meet the ANSI requirements for all nodes. So if the 
interlinking converter is closer to the $A C$ grid it should provide less reactive power while if it is located at the end of the feeder it will provide more reactive power.

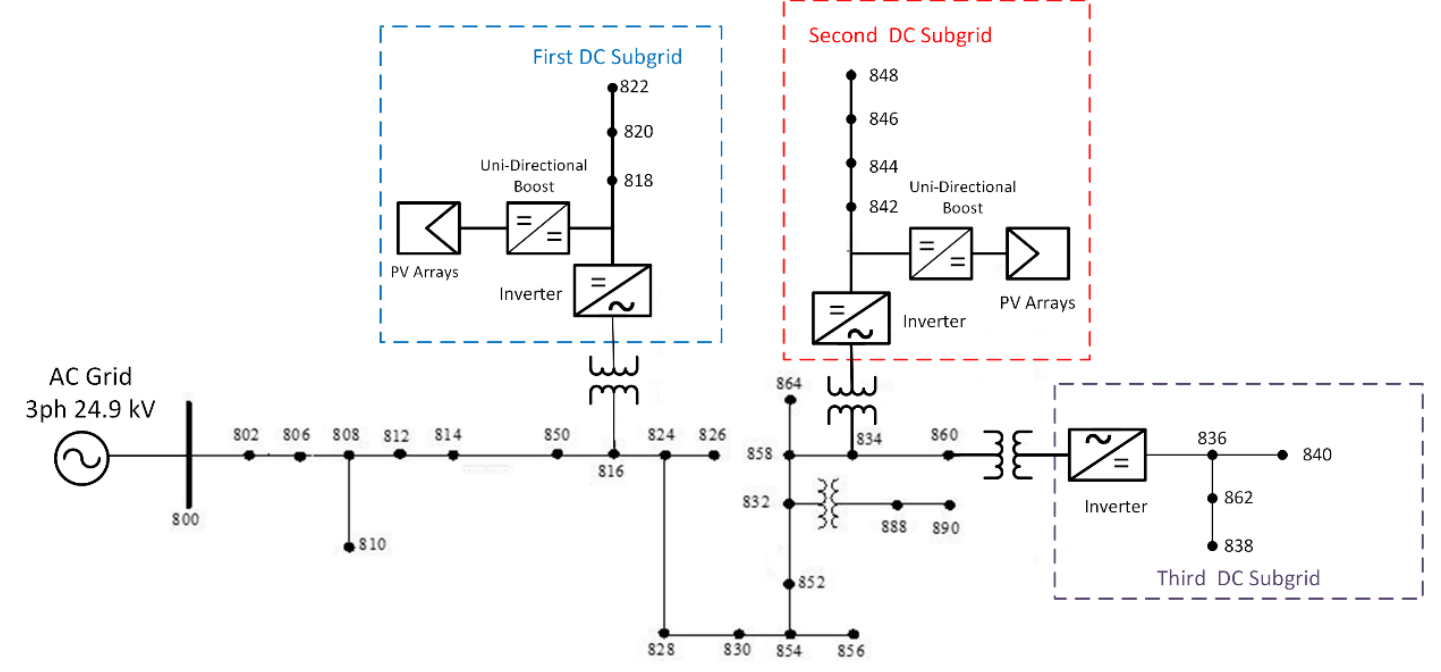

Fig. 1.12. Hybrid AC/DC grid with multiple DC subgrids.

For testing the validity of the control method and monitoring the steady-state voltage in different scenarios, four test cases are simulated. In the first two cases, the PV penetration is zero and heavy and light loads are tested, and the PV provides more than half of the system power in the third and fourth cases.

Table 1.4. Simulation Results under Four Scenarios

\begin{tabular}{|c|c|c|c|c|c|c|}
\hline $\begin{array}{c}\text { Case } \\
\text { No. }\end{array}$ & Description & $\begin{array}{c}\text { Max } \\
\text { Voltage }\end{array}$ & $\begin{array}{c}\text { Min } \\
\text { Voltage }\end{array}$ & $\begin{array}{c}\text { PQ 1 } \\
(\mathrm{kW}, \mathrm{kVar})\end{array}$ & $\begin{array}{c}\mathrm{PQ} 2 \\
(\mathrm{~kW}, \mathrm{kVar})\end{array}$ & $\begin{array}{c}\text { PQ 3 } \\
\text { (kW, kVar) }\end{array}$ \\
\hline 1 & 100\% load, 0 MW PV & 1.05 & 0.92 & $\begin{array}{l}P: 450 \\
Q:-100\end{array}$ & $\begin{array}{l}P: 600 \\
Q:-500\end{array}$ & $\begin{array}{l}P: 200 \\
Q:-220\end{array}$ \\
\hline 2 & $20 \%$ load, 0 MW PV & 1.04 & 0.99 & $\begin{array}{l}P: 900 \\
Q: 400\end{array}$ & $\begin{array}{l}P: 120 \\
\text { Q: } 60\end{array}$ & $\begin{array}{l}P: 40 \\
Q: 18\end{array}$ \\
\hline 3 & $100 \%$ load, $1.2 \mathrm{MW}$ PV & 1.048 & 0.97 & $\begin{array}{l}P: 58 \\
Q: 250\end{array}$ & $\begin{array}{l}P:-200 \\
Q:-130\end{array}$ & $\begin{array}{l}P: 200 \\
Q:-70\end{array}$ \\
\hline 4 & $20 \%$ load, 1.2 MW PV & 1.048 & 0.98 & $\begin{array}{l}P:-300 \\
Q: 600\end{array}$ & $\begin{array}{l}P:-600 \\
\text { Q: } 400\end{array}$ & $\begin{array}{l}P: 40 \\
Q: 150\end{array}$ \\
\hline
\end{tabular}

We have validated the developed hybrid AC/DC grid with multiple DC sections under four scenarios: the first scenario is that no output of PV arrays and loads are in the full value, the second scenario is under $20 \%$ of full load value and zero PV penetration, the third scenario is under $100 \%$ of full load value and $1.2 \mathrm{MW}$ of PV penetration, and the last scenario is under $20 \%$ of full load value and $1.2 \mathrm{MW}$ of PV penetration. The observation is concluded in Table 1.4 .

From Table 1.4 it can be noticed that all the AC nodes voltage are following ANSI limits for Case 1. The voltages at nodes closer to the main grid are near to ANSI upper voltage limit, i.e. 1.05 p.u., because of a step-up transformer at node 800 with 1:1.05 turn ratio. The DC voltage in all DC subgrids is equal to 1 p.u., and this is because of the small voltage drop on the distribution line. All reactive powers of three subsystems are negative, so all converters are injecting reactive power to keep the $\mathrm{AC}$ voltage in the standard range and nominal active power is transferred to the DC load. For Case 2, the ANSI limit 
standard is followed by $A C$ and DC subgrids. As mentioned for Case 1, the voltage drop on the distribution line in DC subgrids is small, and DC voltage is almost constant through the DC microgrid. Since the load has decreased, the voltage drop on the distribution line is small and there is no necessity to inject or absorb a large amount of reactive power through interlinking converters. Also, in contrast to Case 1, in this case the reactive power is injected from the AC grid to DC subgrids to keep the voltage regulated. As can be seen in cases 3 and 4 , the full load and light load conditions with higher than $50 \%$ PV penetration level, the voltage is near boundary limit and a large value of reactive power is absorbed from AC gird to keep the voltage regulated. Finally, it can be concluded that the droop control for reactive power control, works accurately and in all cases, it keeps the steady-state voltage in an acceptable range.

On the basis of discussing the impact of the hybrid AC/DC system with different load and PV output conditions, the power qualities of the hybrid AC/DC system are further analyzed. Next, we focused on the impact of the hybrid AC/DC system using the testing system shown in Fig. 1.12. We compared the hybrid AC/DC system with two different systems. The first one is a pure AC system and the second one is the AC system with solar PV units. In this test, ten scenarios were run, which is shown in Table 1.5.

Table 1.5. Detailed information of ten scenarios

\begin{tabular}{cccc}
\hline \hline Scenarios & Type of System & Load & Solar PV Output (MW) \\
\hline a & Pure AC system & minimum & None \\
b & Pure AC system & maximum & None \\
c & Hybrid AC/DC system & minimum & 0.5 \\
d & Hybrid AC/DC system & maximum & 0.5 \\
e & Hybrid AC/DC system & minimum & 0.85 \\
f & Hybrid AC/DC system & maximum & 0.85 \\
g & AC system with solar PV & minimum & 0.5 \\
h & AC system with solar PV & maximum & 0.5 \\
i & AC system with solar PV & minimum & 0.85 \\
j & AC system with solar PV & maximum & 0.85 \\
\hline \hline
\end{tabular}

The impact was studied from four aspects: voltage profile, active power balance, power loss, and Total Harmonic Distortion (THD) of voltage. Test results demonstrate that the hybrid AC/DC distribution system can improve the system performance compared to the pure AC distribution system.

First, we will show the results of the pure AC system and hybrid AC/DC system under different load conditions. And three aspects are compared: the voltage of each bus, THD of the voltage of each bus, and the power loss of each line.

Subfigures (a) and (b) in Figs. 1.13 and 1.14 are the power loss of each line. The blue bar is the power loss of Phase A, the red bar is the power loss of Phase B, and the yellow bar is the power loss of Phase C. Fig. (c) and (d) are THD of each bus. The blue line is the THD of Phase A, the yellow line is the THD of Phase $B$, and the green line is the THD of Phase C. Fig. (e) and Fig. (f) are the voltage of each line. Here we only focused on the red line in voltage figures, representing the minimum voltage of three phases. Fig. 1.13 shows the results when the hybrid AC/DC system with $0.85 \mathrm{MW}$ output power of each solar PV unit and the pure AC system are under minimum load conditions. Fig. 1.14 shows the results under maximum load conditions. From Fig. 1.13(a) and (b) and Fig 1.14(a) and (b), we can see that the maximum power loss of the pure AC system is larger 
than that of the hybrid AC/DC system. For maximum THD, the hybrid AC/DC system has a smaller THD of voltage than the pure AC system shown in Fig. 1.13(c) and (d) and Fig $1.14(\mathrm{c})$ and (d). When the minimum voltage of two systems is compared, the minimum voltage of the hybrid AC/DC distribution system increases $17.72 \%$ shown in Fig. 1. 13(e) and (f) and increases $26.47 \%$ in maximum load conditions in Fig. 1.14(e) and (f).

Since the pure AC system only has one conventional generator to provide power while the hybrid AC/DC system has solar PV units to provide power, the conventional generator in the hybrid AC/DC system provides less power than that in the pure AC system. For a certain voltage level, the more active power, the more current. Therefore, the power loss of the pure AC system is larger than the hybrid AC/DC system and as well as the voltage of each bus. Because the DC subsystem can help reduce the voltage fluctuation, the THD of the voltage of the hybrid AC/DC system is smaller than that of the pure AC system.

Next, we compared the performance of the AC system with solar PV units with the hybrid AC/DC system. The difference between the AC system with solar PV units and the hybrid AC/DC system is shown in Fig. 1.15. Here we only show Bus 816, Bus 818, Bus 820 , and Bus 822 . The other two subsystems are similar to this one. For the hybrid AC/DC system in Fig. 1.15(a), the PV and subsystems from Bus 818 to Bus 822 are formed a DC subsystem and they are connected to the AC system through a converter while for AC system with solar PV units in Fig. 1.15(b), there is no DC system. The subsystem from Bus 818 to Bus 822 is directly connected to the AC system and PV is connected to the $A C$ system by an AC/DC converter.

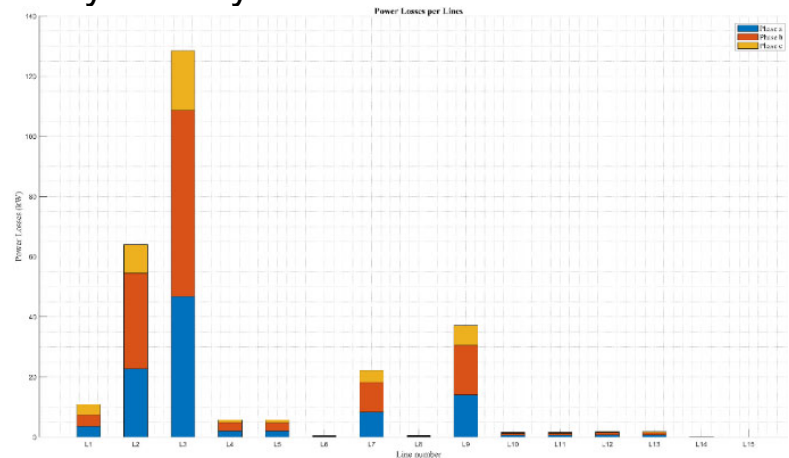

(a) Power loss of each line of pure AC system

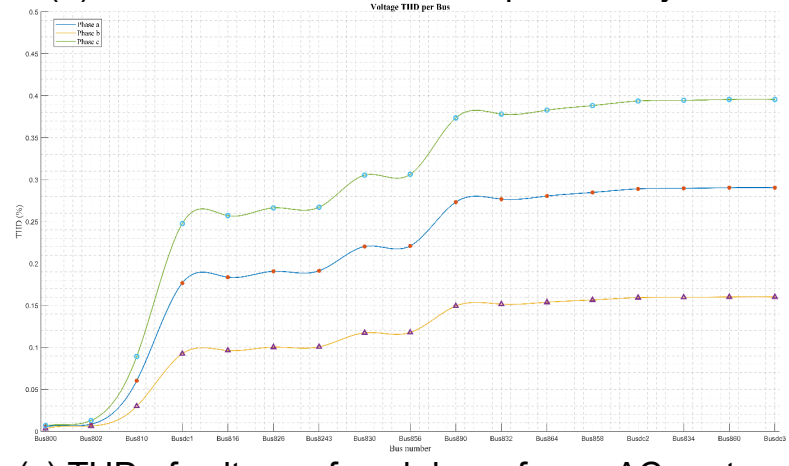

(c) THD of voltage of each bus of pure AC system

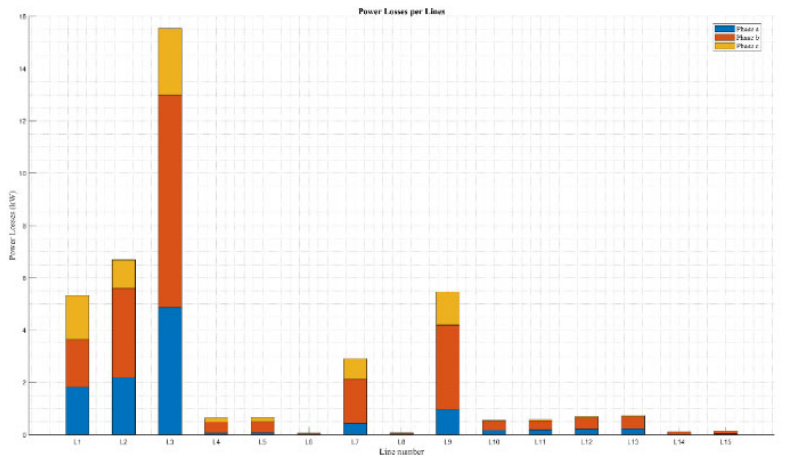

(b) Power line losses of hybrid AC/DC system

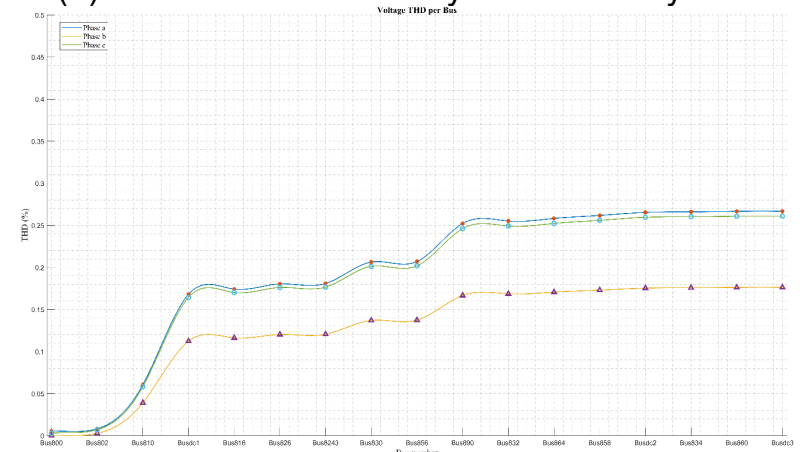

(d) Voltage THD of hybrid AC/DC system 


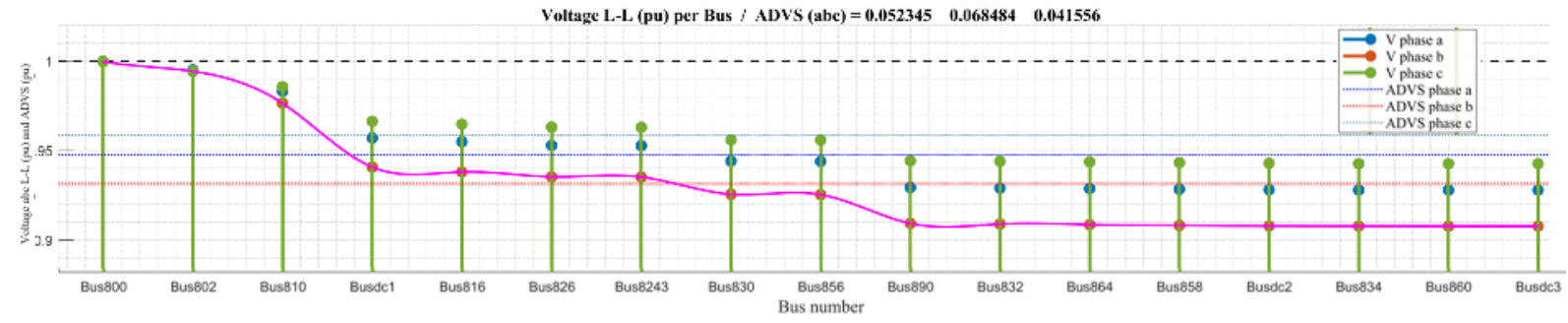

(e) Voltage of each bus of pure AC system

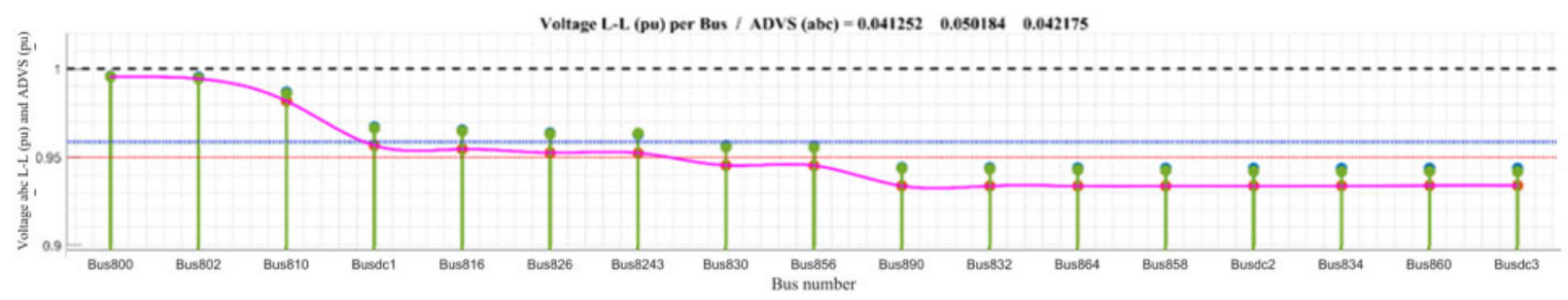

(f) Voltage of each bus of hybrid AC/DC system

Fig. 1.13. The results under minimum load condition, 0.85 MW PV

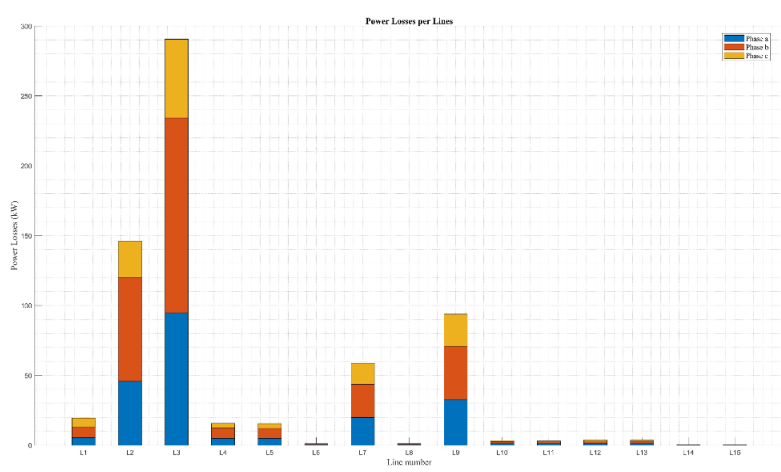

(a) Power loss of each line of pure AC system

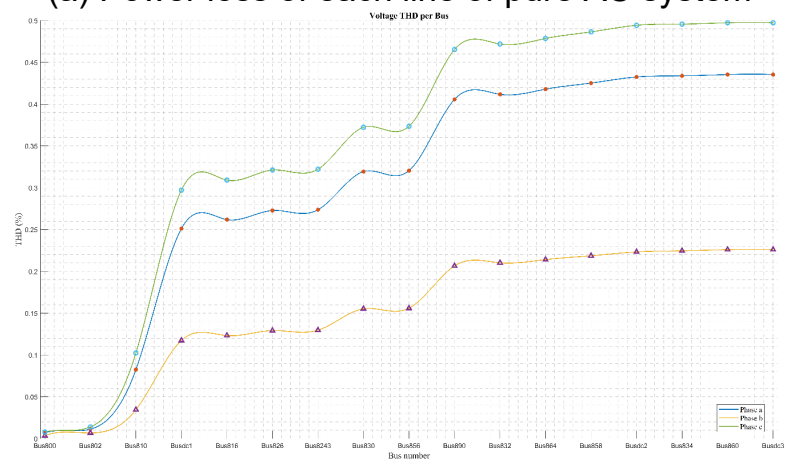

(c) THD of voltage of each bus of pure AC system

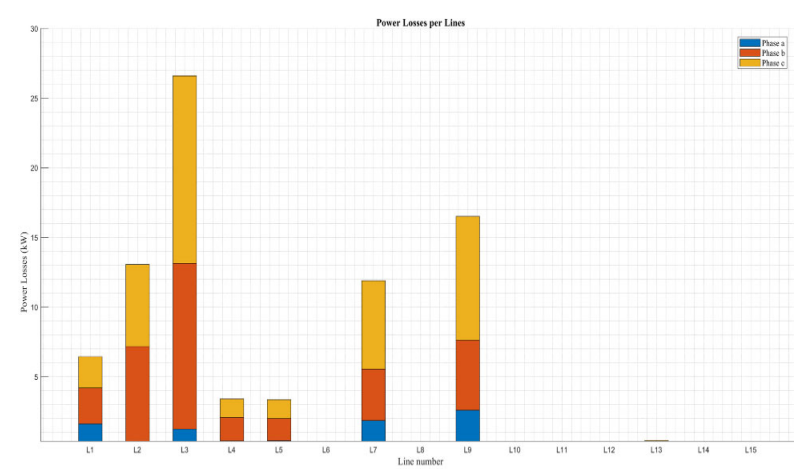

(b) Power line losses of hybrid AC/DC system

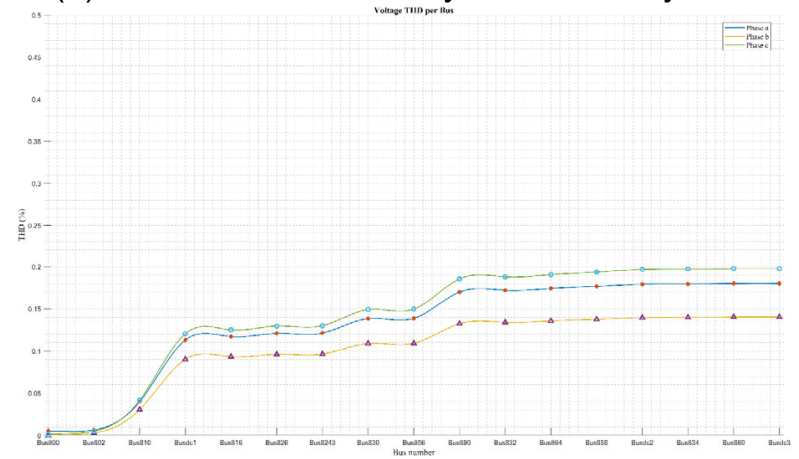

(d) Voltage THD of hybrid AC/DC system 


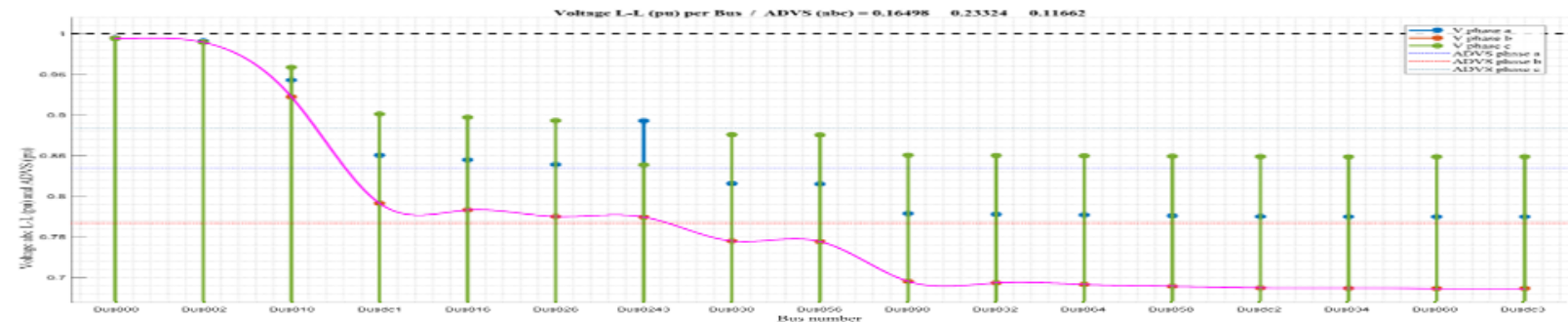

(e) Voltage of each bus of pure AC system

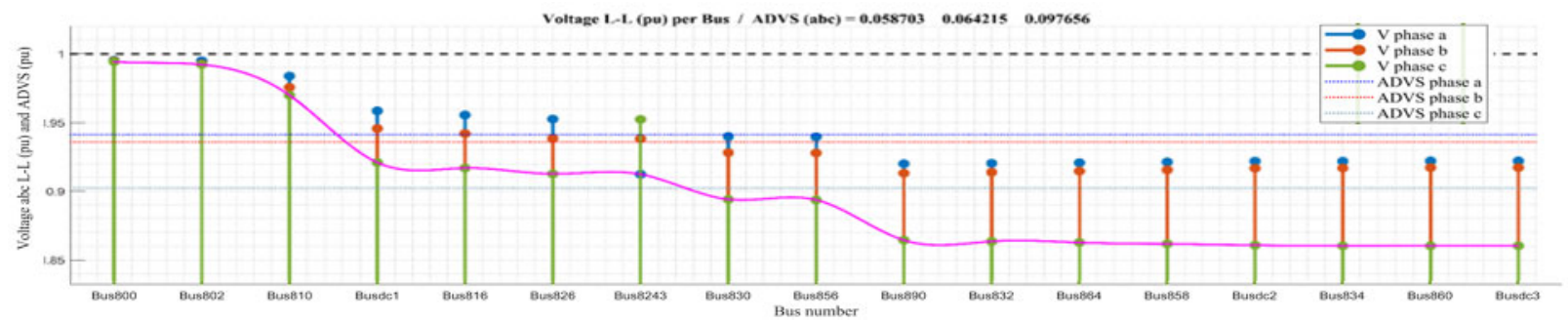

(f) Voltage of each bus of hybrid AC/DC system

Fig. 1.14. The results under maximum load condition, $0.85 \mathrm{MW}$ PV

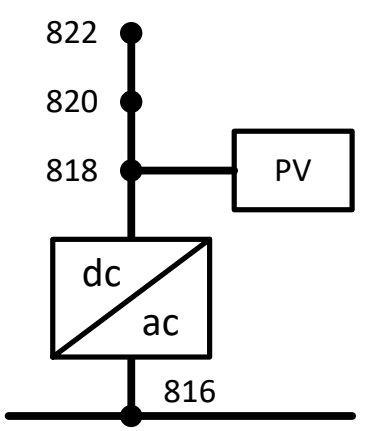

(a) hybrid AC/DC system

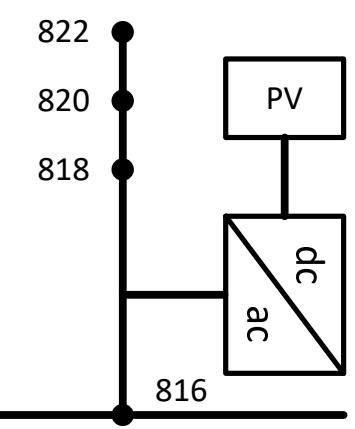

(b) AC system with solar system

Fig. 1.15. The structure of one subsystem for two systems.

In Fig. 1.16, the results of scenarios (c)-(j) in Table 1.5 are shown. The results shown in Fig. 1.16 are the comparison between the hybrid AC/DC system and the AC system with solar PV units. For voltage, the AC system with solar PV units has a little larger value than the hybrid AC/DC system because the reactive power of the AC system obtained from the utility grid is larger than that of the hybrid AC/DC system, which is shown in Table 1.6. When the load is in its minimum value, the maximum power loss of the AC system with solar PV units is larger than that of the hybrid AC/DC system. Due to DC subsystem, $P V$ units in hybrid AC/DC system provide active power to the load in DC subsystem first, then if there is extra power, it flows back to AC system while the whole power of solar PV units flows directly to $A C$ system for $A C$ system with solar PV units. When the load in the AC system is small, PV units in the AC system with solar PV units have a larger influence than that in the hybrid AC/DC system, so the power loss of the AC system with solar PV units is larger than that of the hybrid AC/DC system. When the load is in its maximum value, the conditions are somehow different. When the output power of each solar PV unit is $0.5 \mathrm{MW}$ in maximum load condition, the power loss of hybrid AC/DC is larger than that of the AC system with solar PV units. This is because when the output power of one solar PV unit is $0.5 \mathrm{MW}$ and load is in its maximum value, there is a small part of the power of $P V$ units in the hybrid AC/DC system feedback to the AC system, so the utility 
grid has to provide more power which increases the current in hybrid AC/DC system. And when the output power of solar PV units increases, the power loss reduces due to the reduction of the active power from the utility grid. As for THD of voltage, no matter what conditions the systems are in, the hybrid AC/DC system has less THD of voltage than the $A C$ system with solar PV units. That is because the PV units are directly connected to the $A C$ system in the AC system with solar PV units while they are connected to the DC subsystem in the hybrid AC/DC system. For the AC system with solar PV units, the fluctuation of PV units directly influences the voltage in the AC system which introduces some harmonic to increase THD of voltage. For the hybrid AC/DC system, the DC subsystem can help reduce the fluctuation caused by PV units, so the THD of voltage is small.

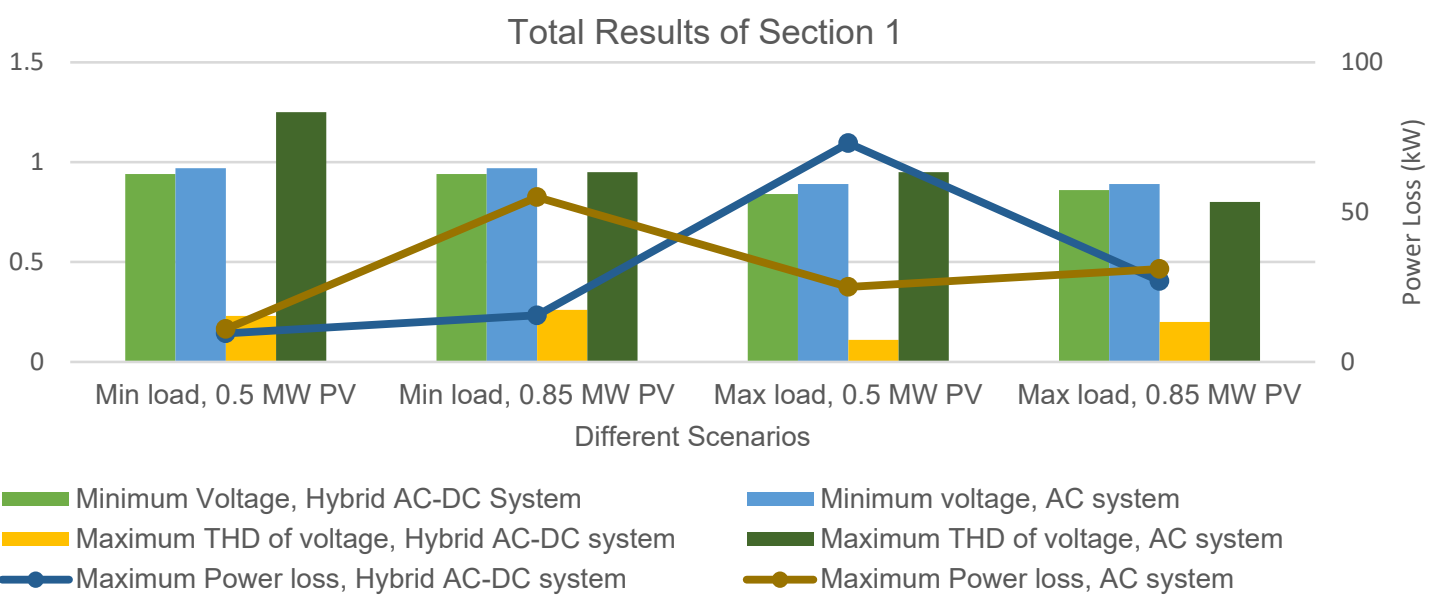

Fig. 1.16. Total results for Section 1

Table 1.6. Reactive power obtained from utility grid

\begin{tabular}{ccccc}
\hline \hline & $\begin{array}{c}\text { Minimum load 0.5 } \\
\text { MW PV }\end{array}$ & $\begin{array}{c}\text { Minimum load } \\
0.85 \mathrm{MW} \text { PV }\end{array}$ & $\begin{array}{c}\text { Maximum load 0.5 } \\
\text { MW PV }\end{array}$ & $\begin{array}{c}\text { Maximum load 0.5 } \\
\text { MW PV }\end{array}$ \\
\hline $\begin{array}{c}\text { Hybrid AC/DC } \\
\text { system }\end{array}$ & $180 \mathrm{VA}$ & $480 \mathrm{VA}$ & $520 \mathrm{VA}$ & $720 \mathrm{VA}$ \\
$\begin{array}{c}\text { AC system with } \\
\text { solar PV units }\end{array}$ & $420 \mathrm{VA}$ & $760 \mathrm{VA}$ & $680 \mathrm{VA}$ & $970 \mathrm{VA}$ \\
\hline \hline
\end{tabular}

Subtask 1.7: Simulate systems with hybrid AC/DC sections connected to the main AC distribution grid.

In this part, the hybrid AC/DC distribution system is connected to a 34-bus main AC grid through a transformer. The overall structure is shown in Fig. 1.17. The green rectangle in Fig. 1.17 represents the transformer. The right-hand side of the transformer is the $25 \mathrm{kV}$ hybrid AC/DC system and the left-hand side of the transformer is the $69 \mathrm{kV}$ main AC grid. The detailed structure of the main AC grid is shown in Fig. 1.18. The hybrid $\mathrm{AC} / \mathrm{DC}$ distribution system or other testing model is connected to the main AC grid at Bus 816 (which is shown as Bus dc1 circled in red in Fig. 1.30) or Bus 890.

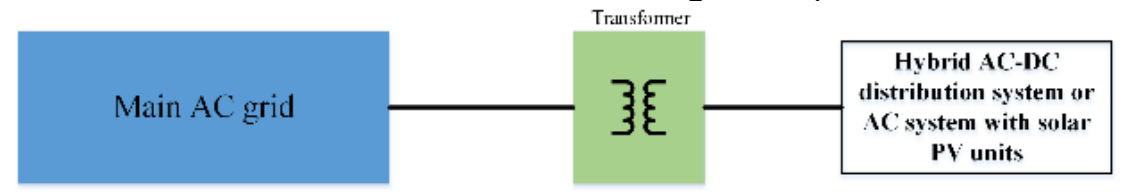


Fig. 1.17. The overall structure of the $25 \mathrm{kV}$ hybrid $A C / D C$ system (right) connected to the $69 \mathrm{kV}$ main $\mathrm{AC}$ grid (left) through a transformer (middle)

In this section, we analyzed the impact of the hybrid AC/DC distribution system on the main AC grid. First, we compared the performance of the main AC grid when it connected the hybrid AC/DC distribution system with that when it did not connect any distribution. Eight scenarios were run shown in Table 1.7. The load of the main AC grid is the same and the two test systems are connected to Bus 890 and Bus dc1, respectively.

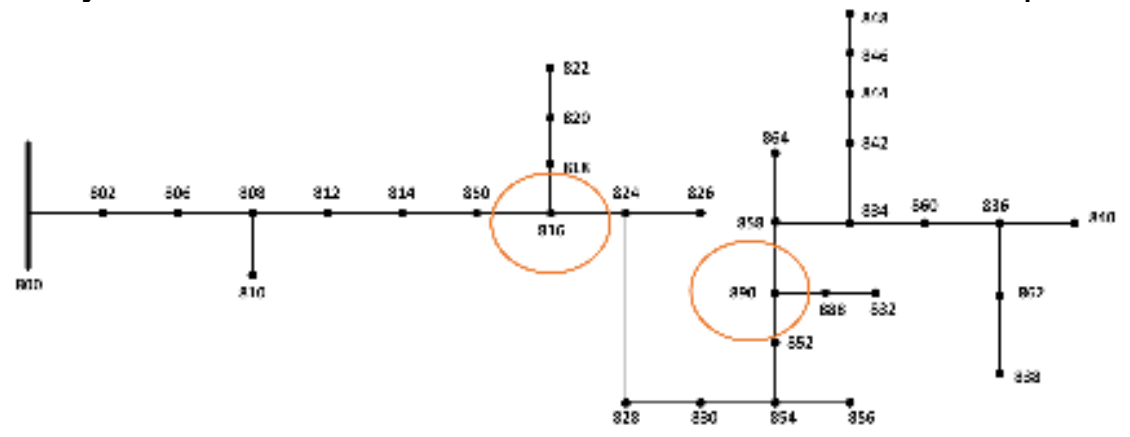

Fig. 1.18. Detailed structure of the main AC grid

Table 1.7. Detailed information of eight scenarios

\begin{tabular}{cccc}
\hline \hline Scenarios & Type of System & Bus connected & Output of Each Solar PV (MW) \\
\hline a & AC system with solar PV & Bus dc1 & 0 \\
b & AC system with solar PV & Bus dc1 & 1 \\
c & Hybrid AC/DC system & Bus dc1 & 0 \\
d & Hybrid AC/DC system & Bus dc1 & 1 \\
e & AC system with solar PV & Bus 890 & 0 \\
f & AC system with solar PV & Bus 890 & 1 \\
g & Hybrid AC/DC system & Bus 890 & 0 \\
h & Hybrid AC/DC system & Bus 890 & 1 \\
\hline \hline
\end{tabular}

The impact was studied from four aspects: voltage profile, active power balance, power loss, and Total Harmonic Distortion (THD) of voltage. Test results demonstrate that the hybrid AC/DC distribution system can improve the main AC grid system performance compared to the pure $A C$ distribution system and $A C$ system with solar PV units.

Fig. 1.19 shows the performance of the main AC grid when Bus 890 of the main AC grid connected solar PV system and hybrid AC/DC distribution system, respectively. Fig. 1.20 shows the performance of the main AC grid when Bus dc1 of main AC grid connected solar PV system and hybrid AC/DC distribution system, respectively. In both Fig. 1.19 and Fig. 1.20, the power loss of each line of the main $A C$ grid and the voltage of each bus of the main $A C$ grid are shown. For subfigures $(a)$ and $(b)$ in Fig. 1.19 and Fig. 1.20, the blue bar is the power loss of Phase A, the red bar is the power loss of Phase B, and the yellow bar is the power loss of Phase C. Subfigures (c) and (d) are the voltage of each bus of main AC grid. For voltage, we focused on analyzing the minimum voltage of three phases, which shows as the red line. In Fig. 1.19, the results are under $1 \mathrm{MW}$ output power of each solar PV unit, and the hybrid AC/DC system is connected to Bus 890. In Fig. 1.20, the results are under $1 \mathrm{MW}$ output power of each solar PV unit and the hybrid AC/DC system is connected to Bus dc1. For power loss, when the hybrid AC/DC distribution 
system is connected to Bus 890 , the maximum power loss of the main AC system reduces 72.5 MW shown in Fig. 1.19(a) and (b) and reduces $69 \mathrm{MW}$ when it is connected to Bus dc1 shown in Fig. 1.20(a) and (b). For voltage performance of main AC grid, the minimum voltage of main AC grid increases $7.69 \%$ shown in Fig. 1.19(c) and (d) when hybrid AC/DC system is connected to Bus 890 and $5.37 \%$ when it is connected to Bus dc 1 shown in Fig. 1.20(c) and (d).

From the analysis in the above section, we know that when there is enough solar PV power, the hybrid AC/DC system can output active power and reactive power to the utility grid. Therefore, when the hybrid AC/DC system is connected to the main AC grid, the power loss is reduced and the voltage level is increased.

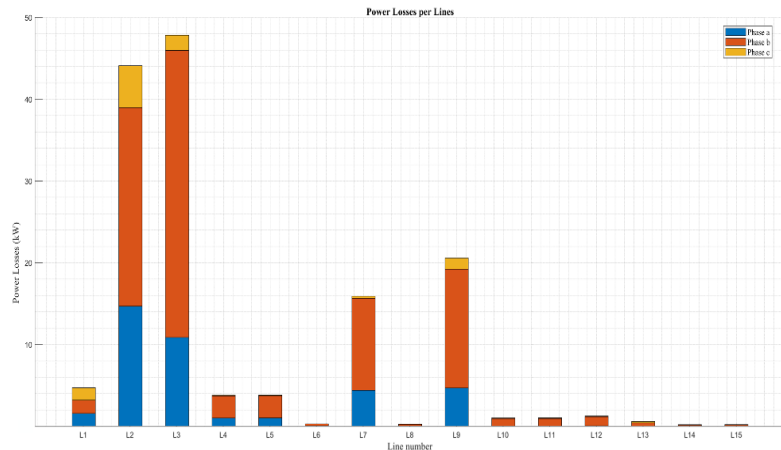

(a) Power loss of each line of main AC grid without connecting any distribution system

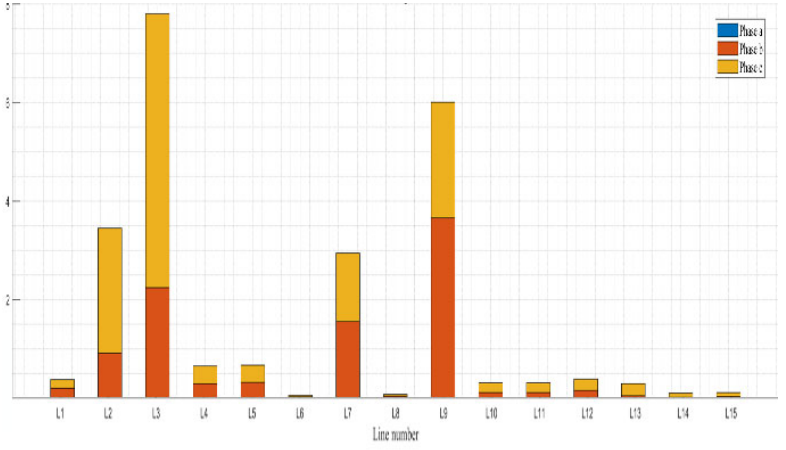

(b) Power loss of each line of main AC grid with hybrid AC/DC distribution system connected

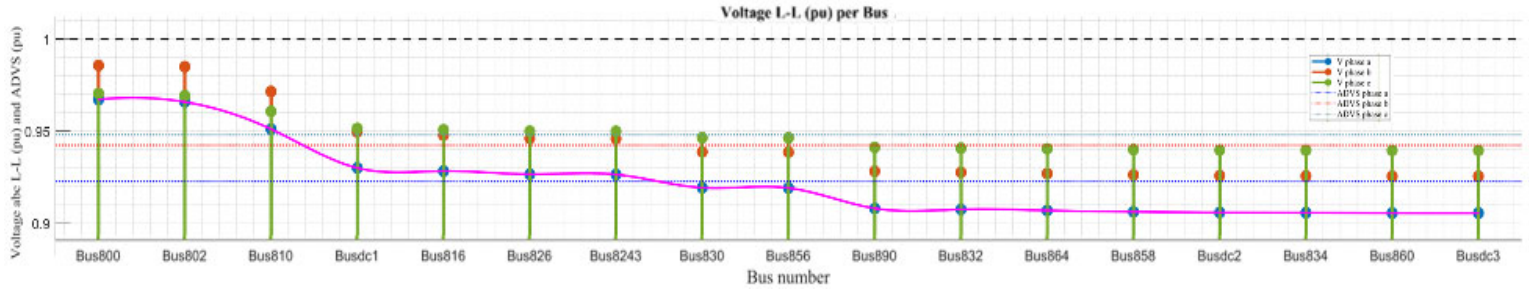

(c) Voltage of each bus of main AC grid without connecting any distribution system

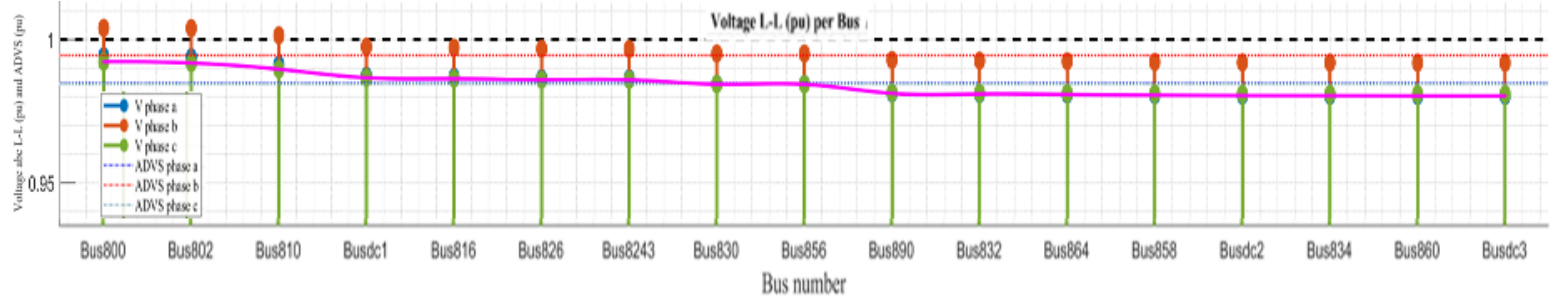

(d) Voltage of each bus of main AC grid with hybrid AC/DC distribution system connected

Fig. 1. 19. Performance of main $A C$ grid itself and that with hybrid $A C / D C$ system connected to Bus 890,1 MW PV 


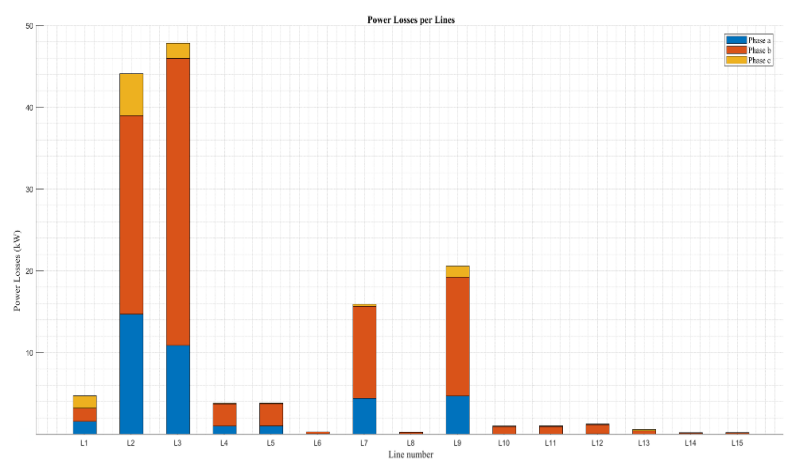

(a) Power loss of each line of main AC grid without connecting any distribution system

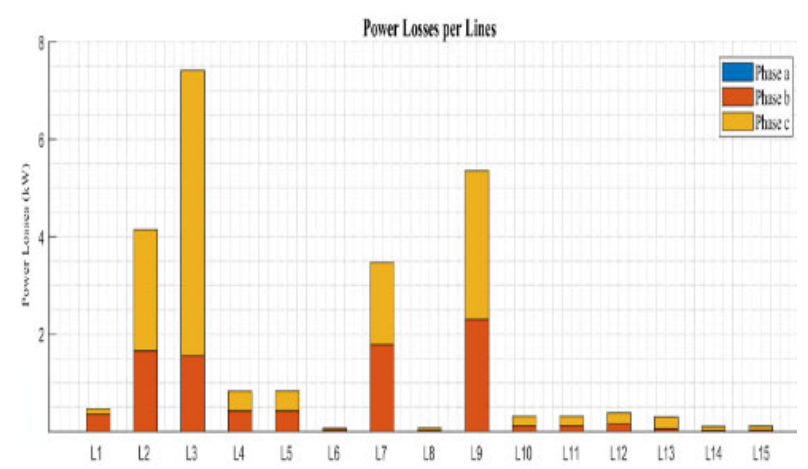

(b) Power loss of each line of main AC grid with hybrid AC/DC distribution system connected

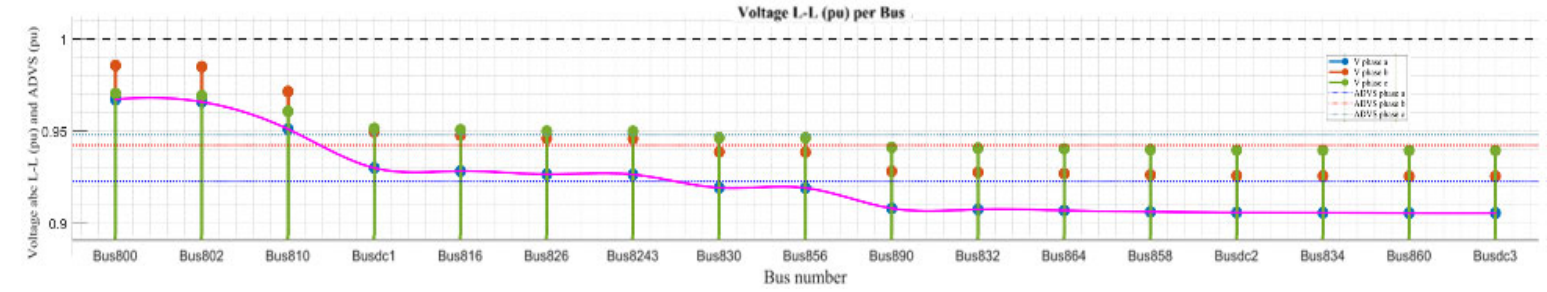

(c) Voltage of each bus of main AC grid without connecting any distribution system

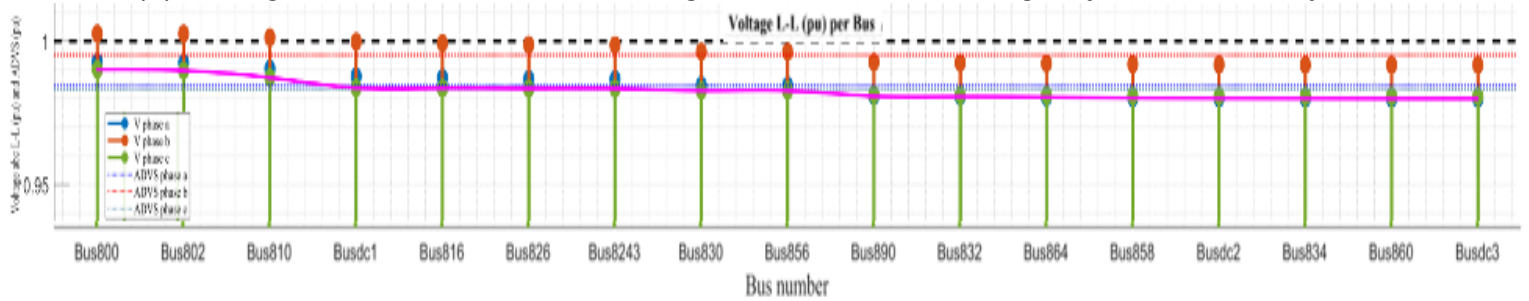

(d) Voltage of each bus of main AC grid with hybrid AC/DC distribution system connected

Fig. 1.20. Performance of main AC grid itself and that with hybrid AC/DC system connected to Bus dc1, 1 MW PV

Fig. 1.21 is the result when the main $A C$ grid connects the hybrid AC/DC system and $A C$ system with solar PV units, respectively. For the voltage of the main AC grid, its value is similar for connecting the hybrid AC/DC system or AC system with solar PV units because the reactive power is similar to the two conditions. The reactive power of the main AC grid connecting two different systems is shown in Fig. 1.22. From that we can see that the reactive powers for the two conditions are similar. When the output power of solar PV units is $0 \mathrm{MW}$, the power loss of the main AC system connecting the AC system with solar PV units is less than that of the hybrid AC/DC system. That is because the hybrid AC/DC system needs more active power than the AC system so the main AC grid should provide more active power when it connects the hybrid AC/DC system and the output power of solar PV units is zero. We show the active power of the main AC grid when two systems are connected to Bus dc1 respectively in Fig. 1.23. In Fig. 1.23, the total active power in Bus dc1 is about $2110 \mathrm{~kW}$ when the hybrid AC/DC system is connected while it is about $1650 \mathrm{~kW}$ when the AC system with solar PV units is connected. When the output power of each solar PV unit is $1 \mathrm{MW}$, the two distribution systems can output active power to the main AC grid so the power loss of the main AC grid is reduced. The situation is the same when they are connected to Bus 890. THD of the voltage of the main $A C$ grid connecting the hybrid AC/DC system is less than that connecting the $A C$ 
system with solar PV units. From the above section, we know the THD of the voltage of the hybrid AC/DC system is less than that of the AC system with solar PV units. When the hybrid AC/DC system is connected to the main AC grid, it has less influence on the THD of the voltage of the main AC grid.
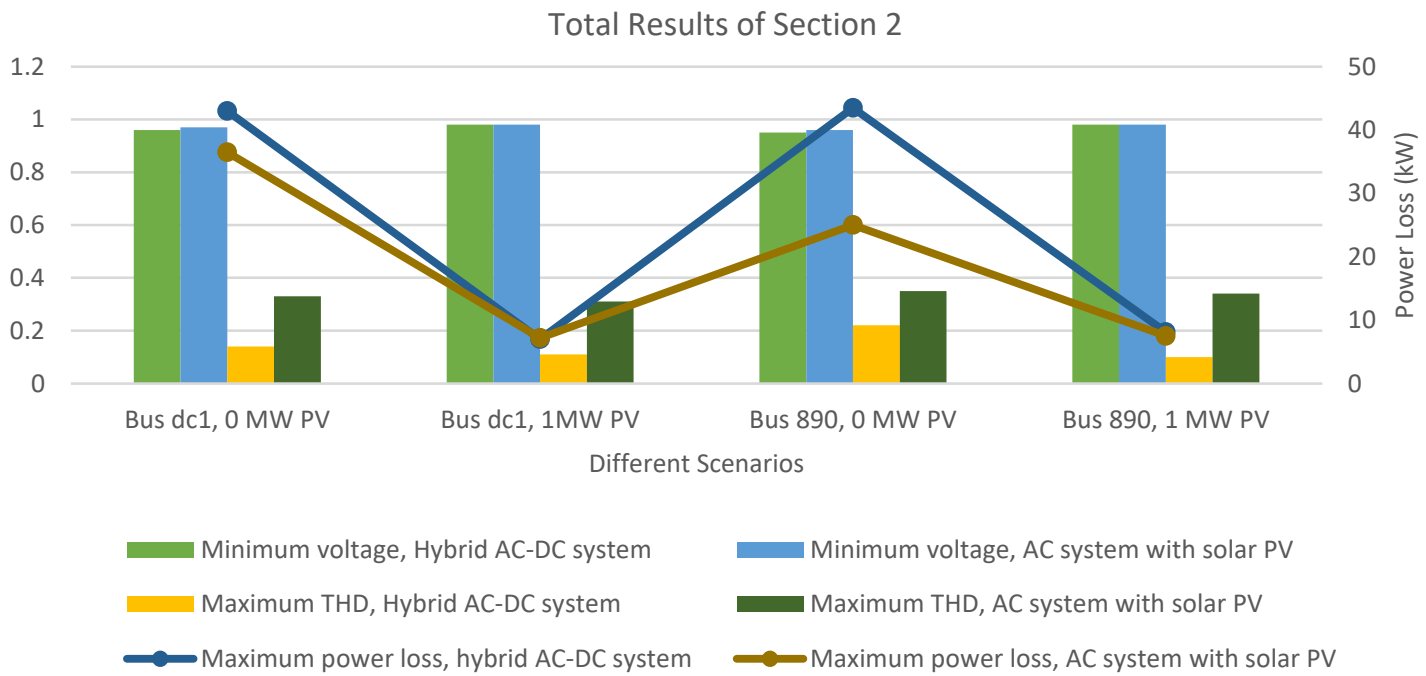

Fig. 1.21. Total Results of Section 2

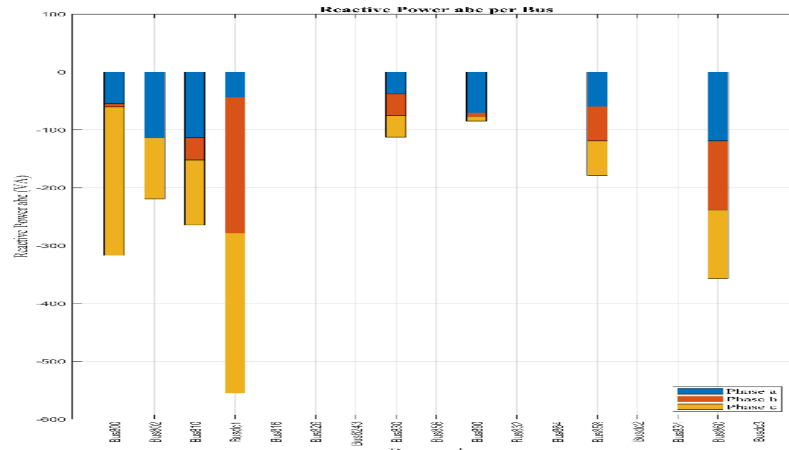

(a) Reactive power of main AC grid connecting AC system with solar PV unit in Bus dc1

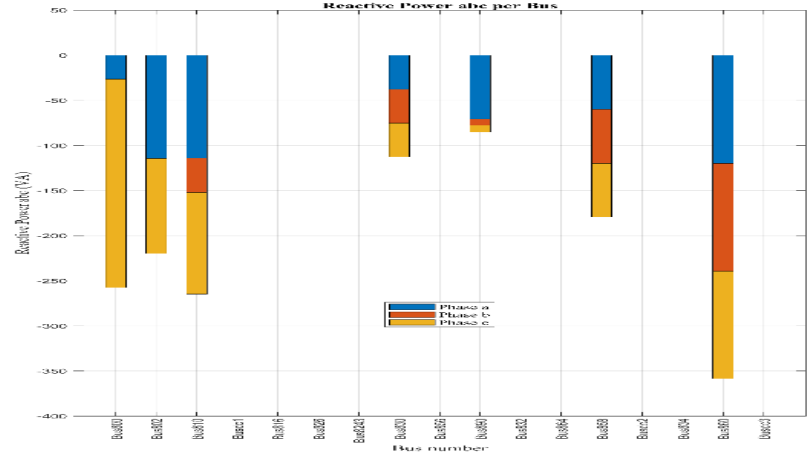

(c) Reactive power of main AC grid connecting AC system with solar PV unit in Bus 890

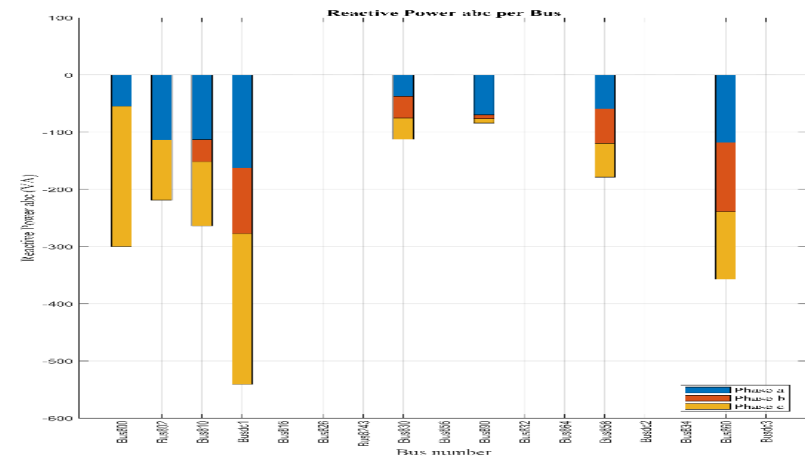

(b) Reactive power of main AC grid connecting hybrid AC/DC system in Bus dc1

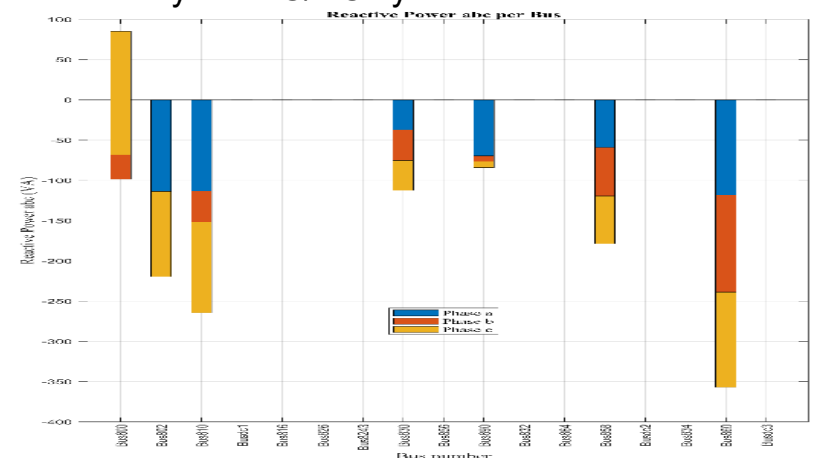

(d) Reactive power of main AC grid connecting hybrid AC/DC system in Bus 890

Fig. 1.22. The reactive power of each bus of main $A C$ grid connecting two different systems 


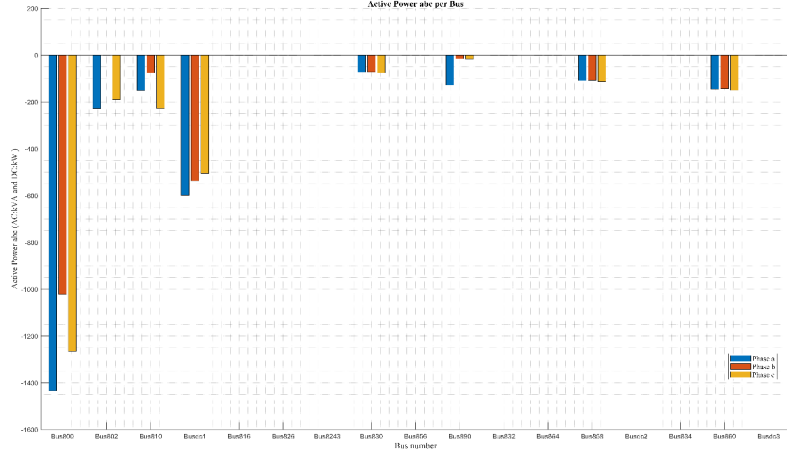

(a) AC system with solar PV units is connected

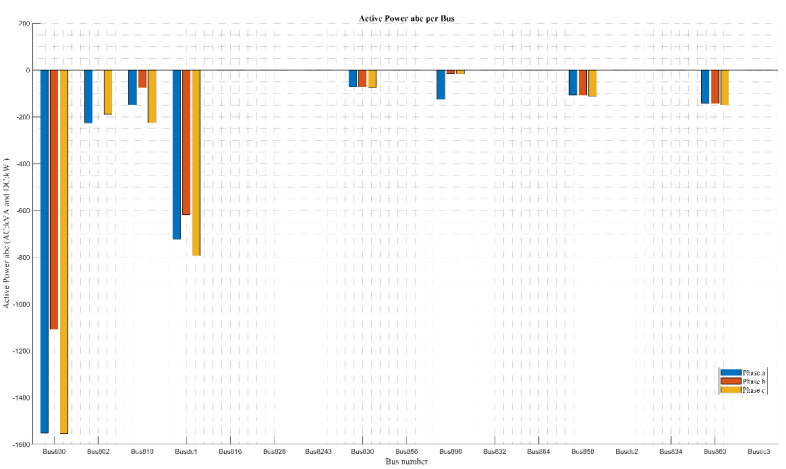

(b) Hybrid AC/DC system is connected

Fig. 1.23. Active power of main AC grid when two systems are connected to Bus dc1, 0 MW PV

To finish subtask 1.7, we used two different parts to check the performance of the hybrid AC/DC distribution system. First, we focused on the performance of the hybrid $A C / D C$ distribution system itself and compared it with the pure $A C$ system and $A C$ system with solar PV units.

- For voltage profile per bus, the hybrid AC/DC distribution system has less voltage drop and more stable voltage than the pure AC system.

- As for active power, hybrid AC/DC distribution system can provide active power support to the main AC grid.

- As the power loss aspect, the hybrid AC/DC distribution system has less power loss because less active power is needed from the main AC grid.

- For THD of voltage, the hybrid AC/DC distribution system has a very small value of THD of voltage due to its DC subsystem.

Then we connected the hybrid AC/DC distribution system to the main AC system and focused on the impact of the hybrid AC/DC distribution system on the main AC grid. We compared the performance of the main $A C$ grid itself with its performance connecting the hybrid AC/DC distribution system. Also, we compared the performance of the main AC grid connecting the AC system with solar PV units with its performance connecting the hybrid AC/DC system.

- The voltage level, power loss of the main AC grid is improved connecting the hybrid AC/DC system.

- The voltage THD of the main AC grid connecting the hybrid AC/DC system is smaller than that connecting the AC system with solar PV units.

In conclusion, due to the DC subsystem, the output power of solar PV units of the hybrid AC/DC system has less influence on the AC system. In some conditions, it can reduce the power loss of the $A C$ system to improve system efficiency. One of the biggest advantages for the hybrid AC/DC system is that the THD of voltage is much smaller thus we can use the hybrid AC/DC system in the condition that the THD of voltage needs to be a smaller value.

\section{Subtask 1.8: Identify the protection of hybrid AC/DC distribution systems}

Since solar PV is required to stay connected according to LVRT, solar PV may inject high currents for a few cycles because of MPPT (Maximum Power Point Tracking) control and/or required amount of grid support [23]-[25]. At a fault, the fault contributions from a 
solar PV system include the contribution from both the solar PV cells and the energy storage elements in the interfacing converters [26]. Once the initial fault transients disappear, solar PV can inject high currents for a few cycles to support grid voltage during LVRT. Solar PV converters can be overdesigned, and the cost is sacrificed in order to allow enough fault currents to interrupt faults in time while avoiding high current damages to the converters.

A real hybrid AC\&DC distribution system is a combination of multiple interconnected $A C$ and DC subsystems. The protection coordination is a combination of all coordination schemes in different subsystems. Once the system protection coordination is decomposed into the coordination in each AC subsystem, DC subsystem, and between $A C$ and DC subsystems, complex and complicated protection coordination issues in hybrid AC and DC distribution can be analyzed in a systematic way.

\subsubsection{Protection Coordination in DC}

Different from $A C$, rapidly increasing $D C$ fault currents flow through power electronics converters and destroy these converters. Thus, DC distribution protection requires a much faster protection speed than AC to protect power electronics from overcurrent and overheat [27]-[28]. Solid-state or hybrid breakers were developed as DCCBs (DC Circuit Breakers) and have a protection speed of 1 2 ms in order to prevent damages to semiconductors on the fault path [27]-[28]. Fuses are still applicable to protect conventional power equipment and devices because of their high fault withstands. The "fuse saving" is also applicable to DC distribution protection, as shown in Fig. 1.24.

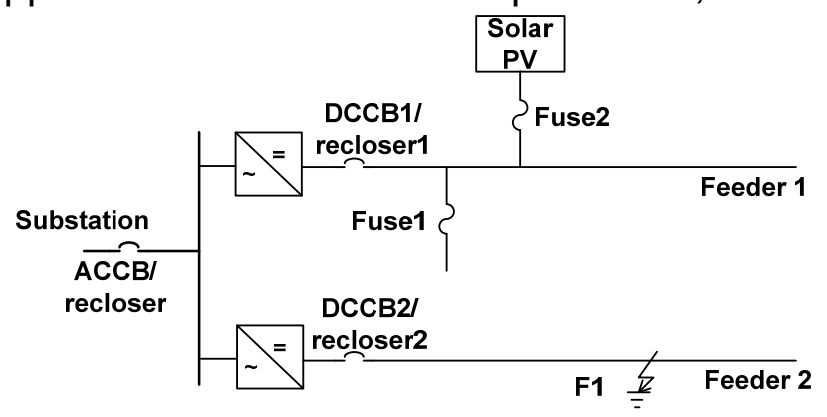

Fig. 1.24. 'Fuse saving' in a DC subsystem

Without solar PV integration, the tripping characteristics of the DC protection devices in the "fuse saving" is illustrated in Fig. 1.25. In the absence of solar PV integration, DCCBs always trips faster than fuses and there is no mis-tripping. However, in the presence of solar PV integration in Fig. 1.26, even though DCCBSD is always below fuse 1 , mis-tripping can still occur to the DCCB since the high solar PV leads to increased ifuse1 and reduced iрcсB. The currents after solar PV integration can be calculated by (1.3)-(1.5). The solar PV penetration level needs to be high enough so that the sufficiently low fault current through the DCCB causes the delayed opening of the DCCB.

$$
\begin{gathered}
i_{\text {fuse } 1}=i_{\text {fuse } 2,}+i_{D C C B} \\
\frac{i_{D C C B}}{i_{D C C B} \prime}=1+\frac{Z_{D C C B} Z_{\text {fuse } 1}}{\left(Z_{D C C B}+Z_{\text {fuse } 1}\right) Z_{\text {fuse } 2}} \\
\frac{i_{\text {fuse } 1}}{i_{\text {fuse } 1},}=\frac{Z_{D C C B} Z_{\text {fuse } 1}+Z_{\text {fuse } 2} Z_{\text {fuse } 1}+Z_{D C C B} Z_{\text {fuse } 2}}{\left(Z_{D C C B}+Z_{\text {fuse } 1}\right)\left(Z_{D C C B}+Z_{\text {fuse } 2}\right)}
\end{gathered}
$$


Very high PV solar capacity together with the TCC of fuse 2 being below fuse 1 leads to the sympathetic tripping or the fastest blowing of fuse 2 than fuse 1 and the DCCB as shown in Fig. 1.27.

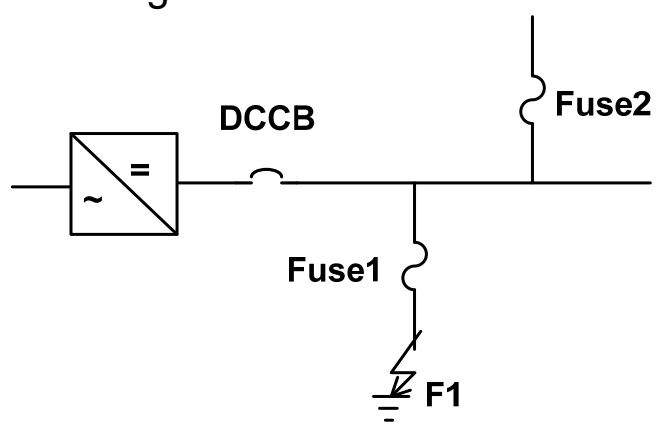

(a)

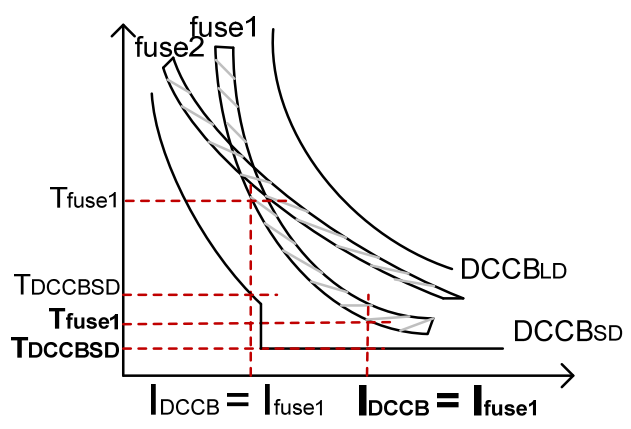

(b)

Fig. 1.25. No mis-tripping in "fuse saving" in DC distribution.

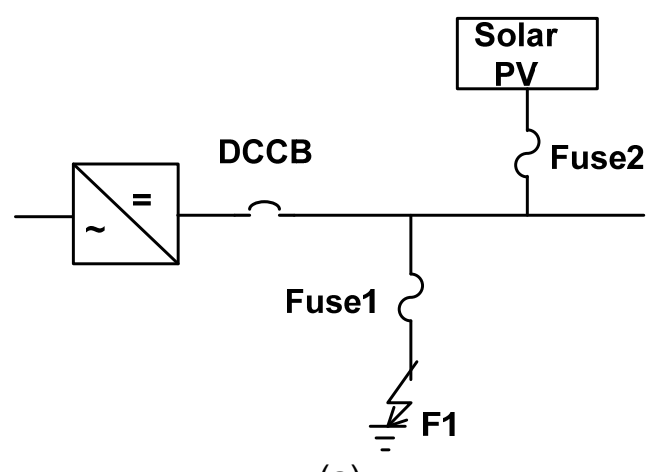

(a)

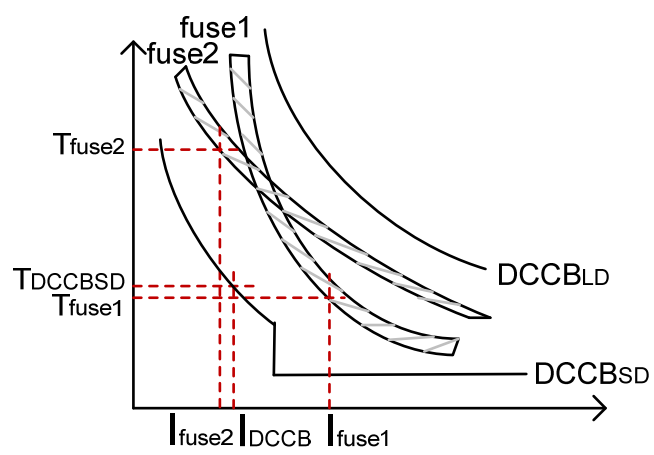

(b)

Fig. 1.26. Mis-tripping of DCCB due to high DER penetration.

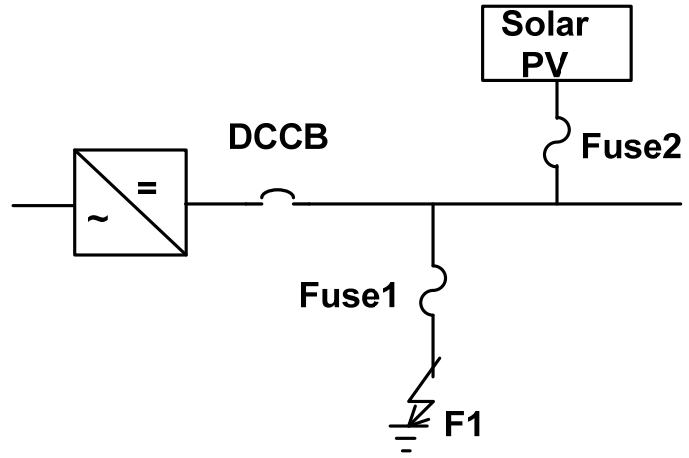

(a)

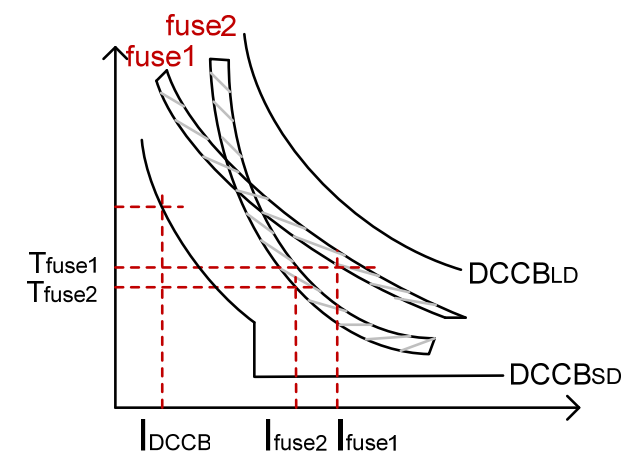

(b)

Fig. 1.27. Sympathetic tripping of fuse 2 with high DER penetration.

Mis-tripping can happen at low solar PV penetration with adaptive protection in DC. The upward shifting of the TCCs slows down the tripping of DCCBs and induces the mistripping of DCCBs as in Fig. 1.28(b) even if the issue does not happen in the forward direction in Fig. 1.28(a). 


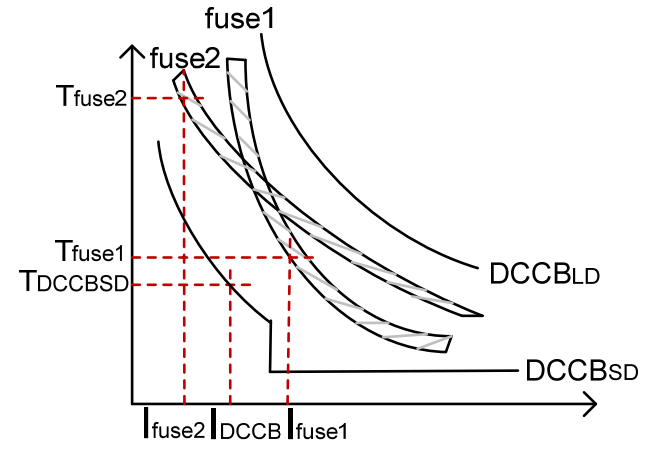

(a)

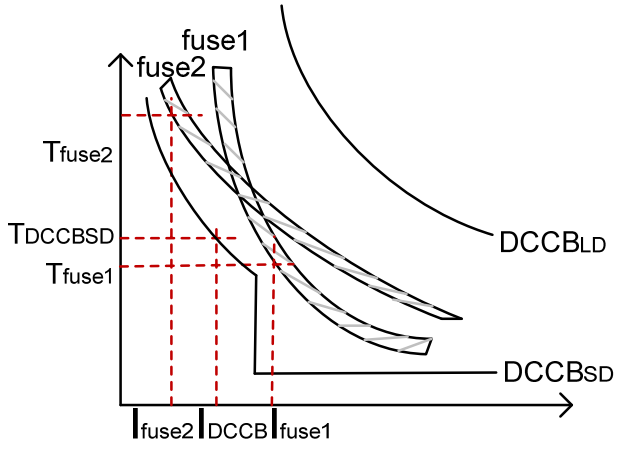

(b)

Fig. 1.28. Mis-tripping of DCCB at low solar PV penetration w/ adaptive coordination. (a) no mis-tripping in forward direction; (b) mis-tripping in reverse direction.

\subsection{Protection Coordination in AC\&DC}

Combining the "fuse saving" for both AC and DC subsystems, the "fuse saving" protection of hybrid AC and DC distributions can be achieved as Fig. 1.29.

Without solar PV integration, an adaptive protection coordination in Fig. 1.29 can be set for the hybrid AC\&DC system in Fig. 1.29(a). If the power flow is from $D C$ to $A C$, ACCB2sD/ACCB2LD is set below DCCB1sD/DCCB1 LD as Fig. 1.30(a) so that ACCB2 trips faster than DCCB1; if the power flow is from $A C$ to $D C$, the coordination is set as in Fig. 1.30(b) for DCCB1 to trip faster than ACCB1. In Fig. 1.30(a), an intersection still exists between $A C C B S D$ and $D C C B S D$ at high fault currents for semiconductor protection in DC. At the AC fault F1, mis-tripping can still happen to ACCB2 as shown in Fig. 1.30(a) after the intersection. At the DC fault F2, no mis-tripping occurs because DCCB1 always trips faster than ACCB2 in Fig. 1.30(b).

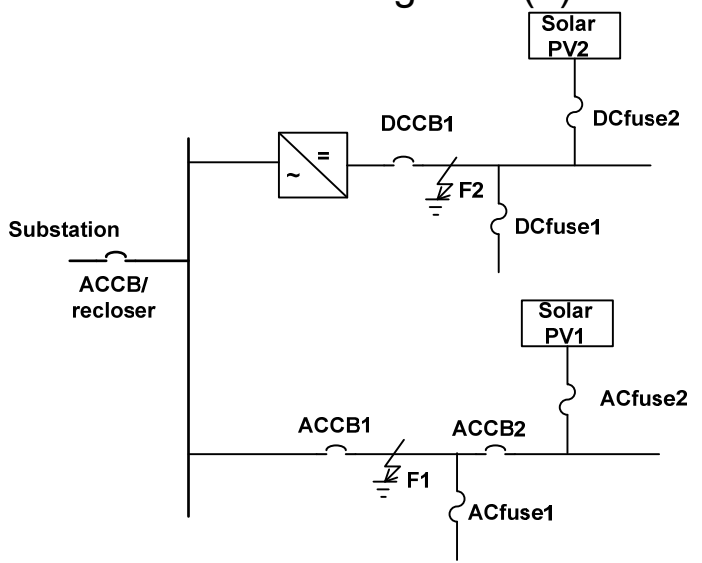

(a)

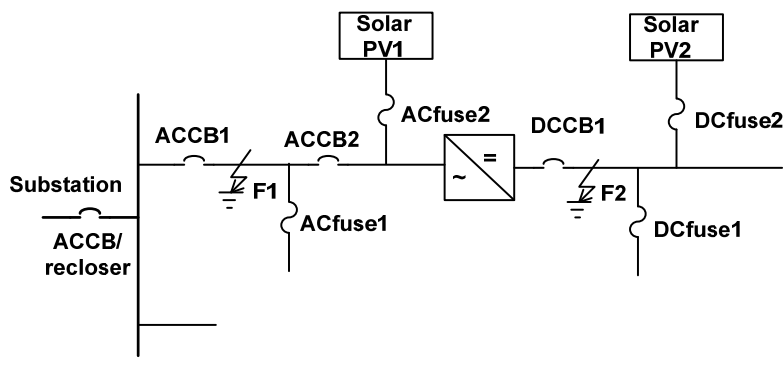

(b)

Fig. 1.29. "Fuse saving" for hybrid AC\&DC distributions with solar PV integration. (a) A hybrid distribution with AC\&DC feeders; (b) A hybrid distribution with a hybrid AC\&DC feeder. 


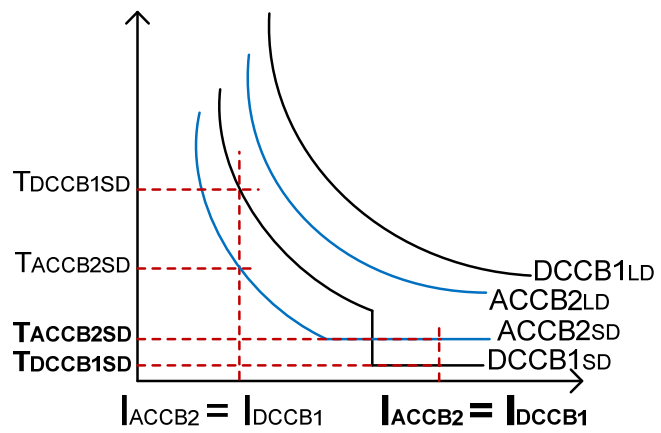

(a)

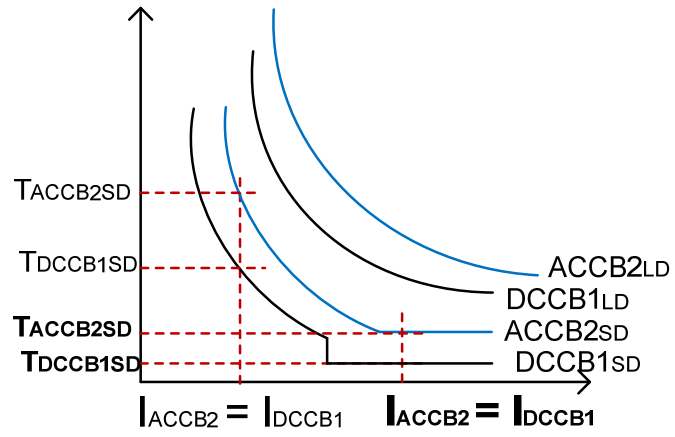

(b)

Fig. 1.30. Adaptive protection coordination between ACCB2 and DCCB1 in hybrid AC\&DC distribution. (a) Coordination and mis-tripping of ACCB2 at F1; (b) Coordination and no mis-tripping at F2.

Solar PV can be integrated in both AC and DC subsystems as shown in Fig. 1.29. Sympathetic tripping occurs in Fig. 1.29(a). In Fig. 1.29(b), the solar PV integration leads to different fault currents through ACCB2 and DCCB1. At F1, the currents flowing through the breakers can be calculated as (1.6) and (1.7). Without solar PV, no currents flow through these breakers.

$$
\begin{gathered}
i_{D C C B 1}=i_{D C f u s e 2 \prime} \\
i_{A C C B 22^{\prime}}=i_{D C C B 1}+i_{A C f u s e 2}
\end{gathered}
$$

At low penetration, ACCB2 trips faster than DCCB1 as shown in Fig. 1.31(a). However, as solar PV penetration in DC becomes high, very high fault currents flow through DCCB1. The high fault currents result in the mis-tripping of ACCB2 as shown in Fig. 1.31(b). This mis-tripping happens because of (1) high solar PV integration in DC and (2) ultra-fast protection speed of DCCBs at high fault currents.

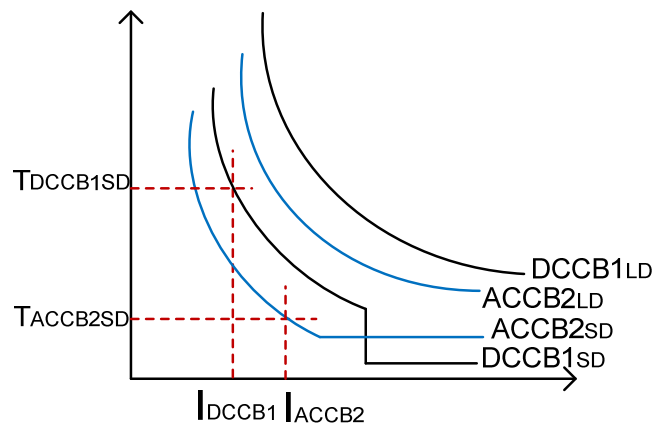

(a)

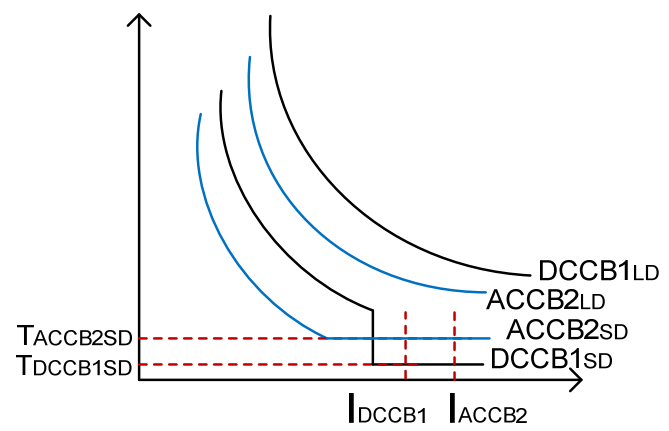

(b)

Fig. 1.31. Mis-tripping of ACCB2 at F1 with high solar PV 2 in DC. (a) Low penetration from solar PV2; (b) High penetration from solar PV 2.

In summary, if the "fuse saving" is applied to hybrid AC and DC distribution systems, the protection coordination issues identified include

- mis-tripping of ACCBs at high fault current levels in AC subsystems even without solar PV integration;

- mis-tripping of ACCBs/DCCBs at high solar PV penetration levels in AC/DC subsystems;

- mis-tripping of ACCBs at high solar PV penetration levels if the power flow is from $\mathrm{DC}$ to $\mathrm{AC}$; 
- sympathetic tripping at very high solar PV penetration levels in either AC or DC subsystems;

- mis-tripping or sympathetic tripping after the intersections of TCCs;

- mis-tripping even at low solar PV penetration if TCCs shifted upwards due to adaptive protection.

The major reason of mis-tripping and sympathetic tripping in hybrid AC and DC distribution systems is

- increased or reduced fault currents through protection devices than originally designed values. The integration of solar PV changes the fault current distribution, including current levels and directions.

The following two existing features in the protection coordination of hybrid $A C$ and $D C$ systems exacerbates the mis-tripping and sympathetic tripping. They are

- intersections of tripping characteristics of protection devices.

- the possible upward shifting of TCCs in adaptive protection.

To prevent mis-tripping and sympathetic tripping, the following mitigation measures may be applied. The final solution could be a combination of all mitigations targeting on one specific issue.

- The intersections of the tripping characteristics should be avoided as much as possible at the design stage.

- Solar PV inverters/converters can limit their fault contributions. The design of the solar PV inverter/converters should satisfy both control and protection requirements. The grid support currents from solar PV should be not too high to cause any protection coordination issues.

- Fault current limiters could also be used to artificially reduce the impacts on fault currents by solar PV integration. Fault current limiters are more flexible in placement than solar PV converters. The coordination of the converter control and fault current limiters in design and operation is challenging but can make it more realistic to implement fault current limiters in distribution systems.

Instead of "fuse saving", "fuse blowing" can blow fuses on faulted laterals in cases of mis-tripping. It is noted more utilities are adopting "fuse blowing" in recent years, which most probably is closely related to the integration of more DERs. Together with fault current limiting, longer delays are allowed in "fuse blowing" design. An example of a controlled circuit breaker opening or "fuse blowing" by upstream solid stat fault current limiters was implemented at residential and commercial buildings [29]. 
Task 2 Develop the universal and extended impedance-base active stabilization approach

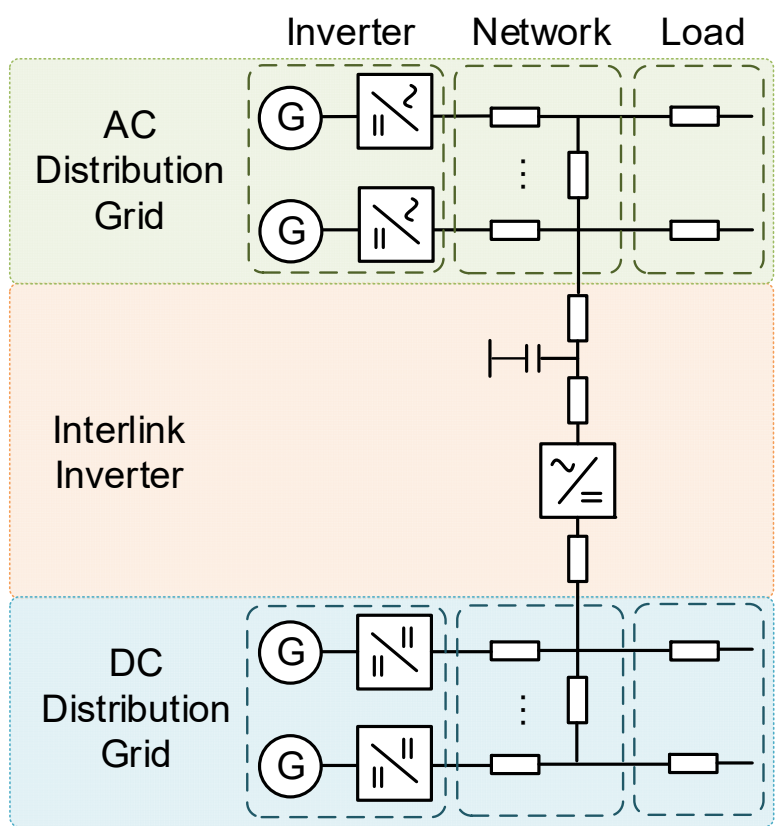

(a)

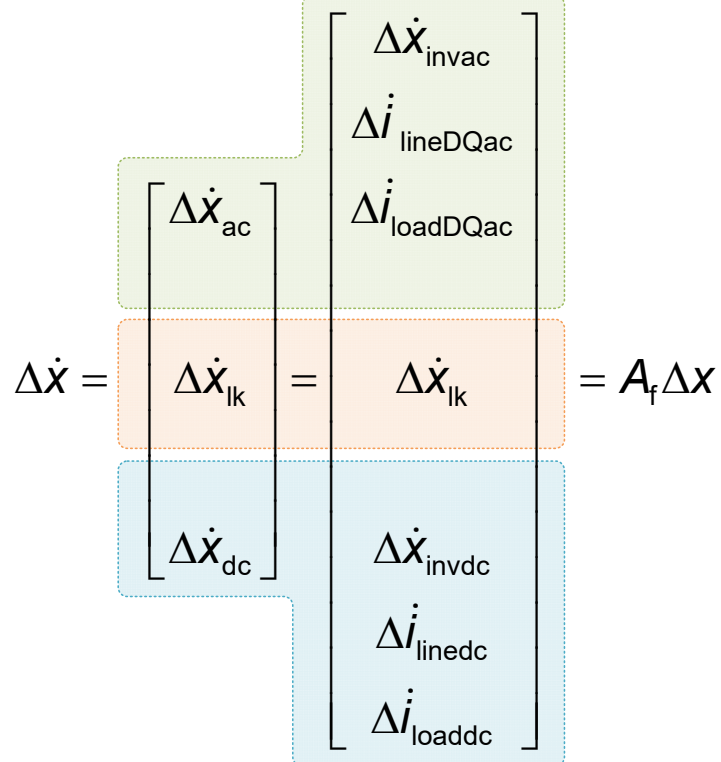

(b)

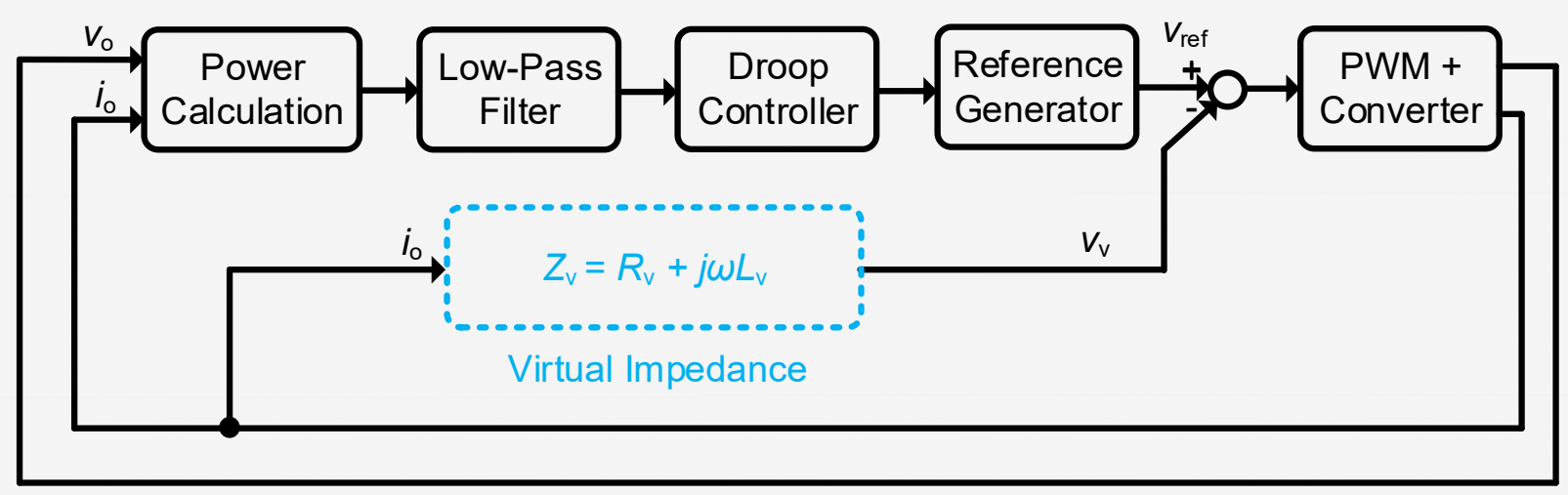

(c)

Fig. 2.1. Configuration and interface converter control diagram of the typical autonomous $A C$ and DC hybrid distribution grids. (a) System architecture. (b) Small-signal modeling of each section. (c) Interface converter control diagram.

In this report, we focus on hybrid $A C$ and $D C$ distribution grids, including $A C$ distribution feeders, DC distribution feeders and interlink inverters between common AC and DC buses, as depicted in Fig. 2.1 (a). Meanwhile, for both AC and DC subsections, they were separated into three segments, i.e., distributed energy resource (DER) interface converters, networks, and loads. The individual small-signal model of each section was detailed, and the complete model of a hybrid AC and DC distribution grids was thereby derived by combining these individual models in Fig. 2.1 (b). Further, the virtual impedance loops were added to the derived models of both AC and DC subsections to identify their impacts on system stability, as shown in Fig. 2.1 (c). 
Subtask 2.1 Based on the baseline case in Subtask 1.1, develop the impedance-based model and stability criteria in DC sub-section.

The entire DC distribution feeders are derived into three parts, i.e., interface converters, coupling lines connecting to the local point of interconnection (POI), and loads. The small-signal model of each part is derived, considering both control dynamics and main power circuits. Further, it is assumed that the DC distribution feeders are comprised of $s$ converters, $n$ lines, $m$ buses, and $p$ loads.

\subsubsection{Modeling of Interface Converters in DC Subsections}

For the models of interface converters, the instantaneous active power $p_{\mathrm{dc}}$ in DC distribution system is calculated by the measured output voltage and current, which is shown as:

$$
p_{\mathrm{dc}}=v_{\mathrm{odc}} i_{\mathrm{odc}}
$$

where $v_{\text {odc }}$ and $i_{\text {odc }}$ are the converter output voltage and current.

Meanwhile, the corresponding average active power $P_{\mathrm{dc}}$ is obtained using a low-pass filter (LPF), as detailed below:

$$
P_{\mathrm{dc}}=\frac{\omega_{\mathrm{c}}}{s+\omega_{\mathrm{c}}} p_{\mathrm{dc}}
$$

where $\omega_{c}$ represents the cut-off frequency of the low-pass filter.

Therefore, the small-signal representation of power control is derived:

$$
\Delta \dot{P}_{\mathrm{dc}}=-\omega_{\mathrm{c}} \Delta P+\omega_{\mathrm{c}} I_{\text {odc }} \Delta v_{\text {odc }}+\omega_{\mathrm{c}} V_{\text {odc }} \Delta i_{\text {odc }}
$$

The droop control at the $\mathrm{DC}$ side is realized as:

$$
v_{\text {odc }}=V_{\text {ndc }}-m_{\text {pdc }} P_{\text {dc }}
$$

where $V_{\text {ndc }}$ is the reference of output voltage in DC subsection; $m_{\text {pdc }}$ is the droop coefficient.

Thus, the small-signal model of the output voltage is:

$$
\Delta \dot{v}_{\text {odc }}=-m_{\text {pdc }} \Delta \dot{P}_{\mathrm{dc}}
$$

Furthermore, the interface converters in the $\mathrm{DC}$ subsection connect to the local buses through the coupling inductance $L_{c d c}$, and virtual impedance (i.e., $R_{v d c}+j \omega L_{v d c}$ ) is added to the corresponding converter control diagram. Hence, it yields:

$$
\dot{i}_{\mathrm{odc}}=-\frac{R_{\mathrm{cdc}}+R_{\mathrm{vdc}}}{L_{\mathrm{cdc}}+L_{\mathrm{vdc}}} i_{\mathrm{odc}}+\frac{1}{L_{\mathrm{cdc}}+L_{\mathrm{vdc}}}\left(v_{\mathrm{odc}}-v_{\mathrm{bdc}}\right)
$$

Then the small-signal model of the output current is:

$$
\Delta \dot{i}_{\mathrm{odc}}=-\frac{R_{\mathrm{cdc}}+R_{\mathrm{vdc}}}{L_{\mathrm{cdc}}+L_{\mathrm{vdc}}} \Delta i_{\mathrm{odc}}+\frac{1}{L_{\mathrm{cdc}}+L_{\mathrm{vdc}}}\left(\Delta v_{\mathrm{odc}}-\Delta v_{\mathrm{bdc}}\right)
$$

where $\Delta v_{\text {bdc }}$ is the small-signal representation of bus voltage. 
For the $i^{\text {th }}$ DC-DC converter, combining (2.3), (2.5) and (2.7), for each interface converter, there are totally three state variables (i.e., $\Delta P_{\mathrm{dc}}, \Delta v_{\text {odci, }}$, and $\Delta i_{\text {odci }}$ ) in the vector of state variables $\left(\Delta x_{\text {invdci }}\right.$ ) with small-signal representation, defined as:

$$
\begin{aligned}
& {\left[\Delta \dot{X}_{\text {invdci }}\right]=A_{\text {invdc } i}\left[\Delta x_{\text {invdci }}\right]+B_{\text {invdci } i}\left[\Delta v_{\text {bdci }}\right]} \\
& {\left[\Delta \dot{i}_{\text {odci }}\right]=C_{\text {invdci }}\left[\Delta x_{\text {invdci }}\right]}
\end{aligned}
$$

where

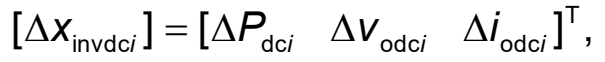

$$
\begin{aligned}
& A_{\text {invdci }}=\left[\begin{array}{ccc}
-\omega_{\mathrm{c}} & \omega_{\mathrm{c}} I_{\text {odci }} & \omega_{\mathrm{c}} V_{\mathrm{odci}} \\
m_{\mathrm{pdci}} \omega_{\mathrm{c}} & -m_{\mathrm{pdci}} \omega_{\mathrm{c}} I_{\mathrm{odci} i} & -m_{\mathrm{pdci}} \omega_{\mathrm{c}} V_{\mathrm{odci}} \\
0 & \frac{1}{L_{\mathrm{cdci} i}+L_{\mathrm{vdci} i}} & \frac{-\left(R_{\mathrm{cdci}}+R_{\mathrm{vdci}}\right)}{L_{\mathrm{cdci}}+L_{\mathrm{vdci}}}
\end{array}\right], \quad B_{\text {invdci }}=\left[\begin{array}{c}
0 \\
0 \\
\frac{-1}{L_{\mathrm{cdci} i}+L_{\mathrm{vdci}}}
\end{array}\right], C_{\text {invdci }}=\left[\begin{array}{lll}
0 & 0 & 1
\end{array}\right] \text {. }
\end{aligned}
$$

Hence, based on (2.8), a combined small-signal model of all the DC-DC converters ( $s$ converters in total) is represented as:

$$
\begin{aligned}
& {\left[\Delta \dot{x}_{\text {invdc }}\right]=A_{\text {invdc }}\left[\Delta x_{\text {invdc }}\right]+B_{\text {invdc }}\left[\Delta v_{\text {bdc }}\right]} \\
& {\left[\Delta i_{\text {odc }}\right]=C_{\text {invdc }}\left[\Delta x_{\text {invdc }}\right]}
\end{aligned}
$$

where

$$
\begin{aligned}
& {\left[\Delta x_{\text {invdc }}\right]=\left[\begin{array}{llll}
\Delta x_{\text {invdc1 }} & \Delta x_{\text {invdc2 }} & \cdots & \Delta x_{\text {invdcs }}
\end{array}\right]^{\top} \text {, }} \\
& A_{\text {invdc }}=\left[\begin{array}{ccc}
A_{\text {invdc1 }} & & \\
& \ddots & \\
& & A_{\text {invdcs }}
\end{array}\right], \quad B_{\text {invdc }}=\left[\begin{array}{lll}
B_{\text {invdc1 }} & & \\
& \ddots & \\
& & B_{\text {invdcs }}
\end{array}\right], \quad C_{\text {invdc }}=\left[\begin{array}{lll}
C_{\text {invdc1 }} & \\
& \ddots & \\
& & C_{\text {invdcs }}
\end{array}\right] \text {. }
\end{aligned}
$$

\subsubsection{Modeling of Networks in DC Subsections}

The power lines ( $n$ lines and $m$ buses) in the DC subsection are modeled as the combination of series resistance $R$ linedc and inductance $L$ linedc. The state equations of line current of $i^{\text {th }}$ line connected between nodes $j$ and $h$ are:

$$
\dot{i}_{\text {linedci }}=-\frac{R_{\text {linedci }}}{L_{\text {linedci }}} i_{\text {linedci }}+\frac{1}{L_{\text {linedci }}}\left(v_{\text {bdcj }}-v_{\text {bdch }}\right)
$$

Then the small-signal model of the line current is:

$$
\left[\Delta \dot{i}_{\text {linedci }}\right]=A_{\text {netdci }}\left[\Delta i_{\text {linedci }}\right]+B_{\text {netdci }}\left[\begin{array}{c}
\Delta v_{\text {bdcj }} \\
\Delta v_{\text {bdck }}
\end{array}\right]
$$

where

$$
A_{\text {netdci }}=\left[-\frac{R_{\text {linedci }}}{L_{\text {linedci }}}\right], \quad B_{\text {netdci }}=\left[\frac{1}{L_{\text {linedci }}} \frac{-1}{L_{\text {linedci }}}\right] .
$$


Thus, based on (2.11), a combined small-signal model of networks ( $n$ lines and $m$ buses) is represented as:

$$
\left[\Delta \dot{i}_{\text {linedc }}\right]=A_{\text {netdc }}\left[\Delta i_{\text {linedc }}\right]+B_{\text {netdc }}\left[\Delta v_{\text {bdc }}\right]
$$

where

$$
A_{\text {netdc }}=\left[\begin{array}{ccc}
A_{\text {netdc1 }} & & \\
& \ddots & \\
& & A_{\text {netdcn }}
\end{array}\right]_{n \times n} \quad, B_{\text {netdc }}=\left[\begin{array}{lll}
B_{\text {netdc1 }} & \\
& \ddots & \\
& & B_{\text {netdcn }}
\end{array}\right]_{n \times m} .
$$

\subsubsection{Modeling of Loads in DC Subsections}

For the load current in the DC side, its state equation is similar to that of line current, which is shown as:

$$
\dot{i}_{\text {loaddci }}=-\frac{R_{\text {loaddci }}}{L_{\text {loaddci }}} I_{\text {loaddci }}+\frac{1}{L_{\text {loaddci }}} v_{\text {bdci }}
$$

Therefore, the small-signal model of the load is derived:

$$
\left[\Delta \dot{i}_{\text {loaddci }}\right]=A_{\text {loaddci }}\left[\Delta i_{\text {loaddci }}\right]+B_{\text {loaddci }}\left[\Delta v_{\text {bdci }}\right]
$$

where

$$
A_{\text {loaddci }}=\left[\frac{-R_{\text {loaddci }}}{L_{\text {loaddci }}}\right], \quad B_{\text {loaddci }}=\left[\frac{1}{L_{\text {loaddci }}}\right] .
$$

Therefore, based on (2.14), a combined small-signal model of loads ( $p$ loads) is represented as:

$$
\left[\Delta \dot{i}_{\text {loaddc }}\right]=A_{\text {loaddc }}\left[\Delta i_{\text {loaddc }}\right]+B_{\text {loaddc }}\left[\Delta v_{\text {bdc }}\right]
$$

where

$$
A_{\text {loaddc }}=\left[\begin{array}{ccc}
A_{\text {loaddc1 }} & & \\
& \ddots & \\
& & A_{\text {loaddcp }}
\end{array}\right]_{p \times p}, \quad B_{\text {loaddc }}=\left[\begin{array}{ccc}
\frac{1}{L_{\text {loaddc1 }}} & & \\
& \ddots & \\
& & \frac{1}{L_{\text {loaddcp }}}
\end{array}\right]_{p \times m} .
$$

\subsubsection{Complete Model of DC Subsections}

It is defined that $M_{\text {invdc, }} M_{\text {netdc, }}$ and $M_{\text {loaddc }}$ are the mapping matrices among inverters, lines, and loads. For example, Minvdc maps the inverter POls onto the corresponding network buses. Hence, the DC bus voltage can be expressed below:

$$
\left[v_{\text {bdc }}\right]=R_{\text {Ndc }}\left(M_{\text {invdc }}\left[i_{\text {odc }}\right]+M_{\text {netdc }}\left[i_{\text {linedc }}\right]+M_{\text {loaddc }}\left[i_{\text {loaddc }}\right]\right)
$$

Then the corresponding small-signal models of the bus voltage is derived: 


$$
\left[\Delta v_{\text {bdc }}\right]=R_{\text {Ndc }}\left(M_{\text {invdc }}\left[\Delta i_{\text {odc }}\right]+M_{\text {netdc }}\left[\Delta i_{\text {linedc }}\right]+M_{\text {loaddc }}\left[\Delta i_{\text {loaddc }}\right]\right)
$$

where

$$
R_{\mathrm{Ndc}}=\left[\begin{array}{lll}
r_{N} & & \\
& \ddots & \\
& & r_{N}
\end{array}\right]_{m \times m}, M_{\mathrm{invdc}}=\left[\begin{array}{lll}
1 & & \\
& \ddots & \\
& & 1
\end{array}\right]_{\mathrm{m} \times s}, M_{\mathrm{netdc}}=\left[\begin{array}{ccc}
-1 & & \\
1 & \ddots & \\
& \ddots & -1 \\
& & 1
\end{array}\right]_{m \times n}, M_{\text {loaddc }}=\left[\begin{array}{ccc}
-1 & & \\
& \ddots & \\
& & -1
\end{array}\right]_{m \times p} .
$$

Note that $r_{\mathrm{N}}$ is a large virtual resistance connecting the bus and ground, involved to satisfy the required number of equations.

Combining (2.9), (2.12), (2.15) and (2.17), the complete small-signal model of DC subsection is derived:

$$
\left[\begin{array}{ll}
\Delta \dot{x}_{\mathrm{dc}}
\end{array}\right]=\left[\begin{array}{lll}
\Delta \dot{x}_{\text {invdc }} & \Delta \dot{\dot{l}}_{\text {linedc }} & \Delta \dot{i}_{\text {loaddc }}
\end{array}\right]^{\top}=A_{\mathrm{dc}}\left[\Delta x_{\mathrm{dc}}\right]
$$

where the state matrix $A_{\mathrm{dc}}$ of the $\mathrm{DC}$ subsection is given below

$$
A_{\text {dc }}=\left[\begin{array}{ccc}
A_{\text {invdc }}+B_{\text {invdc }} R_{\text {Ndc }} M_{\text {invdc }} C_{\text {invdc }} & B_{\text {invdc }} R_{\text {Ndc }} M_{\text {netdc }} & B_{\text {invdc }} R_{\text {Ndc }} M_{\text {loaddc }} \\
B_{\text {netdc }} R_{\text {Ndc }} M_{\text {invdc }} C_{\text {invdc }} & A_{\text {netdc }}+B_{\text {netdc }} R_{\text {Ndc }} M_{\text {netdc }} & B_{\text {netdc }} R_{\text {Ndc }} M_{\text {loaddc }} \\
B_{\text {loaddc }} R_{\text {Ndc }} M_{\text {invdc }} C_{\text {invdc }} & B_{\text {loaddc }} R_{\text {Ndc }} M_{\text {netdc }} & A_{\text {loaddc }}+B_{\text {loaddc }} R_{\text {Ndc }} M_{\text {loaddc }}
\end{array}\right]
$$

Subtask 2.2 Based on the baseline case in Subtask 1.1, develop the impedance-based model and stability criteria in AC subsection.

In this task, similar to the DC subsection, the main components in the AC subsection include three parts (i.e., interface inverters, lines, and loads). The small-signal modeling of each part is presented as follows separately. Meanwhile, it is also assumed that the AC subsection consists of $s$ inverters, $n$ lines, $m$ buses, and $p$ loads [12].

\subsubsection{Models of Interface Inverters in AC Subsections}

As shown in (2.19), the instantaneous active power $p$ and reactive power $q$ can be calculated using output voltage $\left(v_{o d}, v_{o q}\right)$ and current $\left(i_{o d}, i_{o q}\right)$ in dq reference frame, which are shown as:

$$
\left\{\begin{array}{l}
p_{\text {ac }}=v_{\text {odac }} i_{\text {odac }}+v_{\text {oqac }} i_{\text {oqac }} \\
q_{\text {ac }}=v_{\text {oqac }} i_{\text {odac }}-v_{\text {odac }} i_{\text {oqac }}
\end{array}\right.
$$

For the model of inverters, the average active power $P_{\mathrm{ac}}$ and reactive power $Q_{\mathrm{ac}}$ are derived as:

$$
\left\{\begin{array}{l}
P_{\mathrm{ac}}=\frac{\omega_{\mathrm{c}}}{S+\omega_{\mathrm{c}}} p_{\mathrm{ac}} \\
Q_{\mathrm{ac}}=\frac{\omega_{\mathrm{c}}}{S+\omega_{\mathrm{c}}} q_{\mathrm{ac}}
\end{array}\right.
$$


Then the small-signal representation of power control is derived:

$$
\left\{\begin{aligned}
\Delta \dot{P}_{\text {ac }}=-\omega_{\text {cac }} \Delta P_{\text {ac }}+ & \omega_{\text {cac }}\left(I_{\text {odac }} \Delta v_{\text {odac }}+I_{\text {oqac }} \Delta v_{\text {oqac }}\right. \\
& \left.+V_{\text {odac }} \Delta i_{\text {odac }}+V_{\text {oqac }} \Delta i_{\text {ogac }}\right) \\
\Delta \dot{Q}_{\mathrm{ac}}=-\omega_{\text {cac }} \Delta Q_{\text {ac }}+ & \omega_{\text {cac }}\left(-I_{\text {ogac }} \Delta v_{\text {odac }}+I_{\text {odac }} \Delta v_{\text {oqac }}\right. \\
+ & \left.V_{\text {oqac }} \Delta i_{\text {odac }}-V_{\text {odac }} \Delta i_{\text {ogac }}\right)
\end{aligned}\right.
$$

Furthermore, each inverter follows the conventional $P-f$ and $Q-V$ droop characteristics to achieve power-sharing among multiple inverters, as shown in (2.22):

$$
\left\{\begin{array}{l}
\omega=\omega_{\mathrm{n}}-m_{\text {pac }} P_{\text {ac }} \\
V_{\text {odac }}=V_{\text {nac }}-n_{\text {qac }} Q_{\text {ac }} \\
V_{\text {ogac }}=0
\end{array}\right.
$$

where $\omega_{\mathrm{n}}$ is the nominal frequency; $V_{\text {nac }}$ is the reference of output voltage in the AC side; $m_{\text {pac }}$ and $n_{\text {qac }}$ are droop gains.

Thus, the small-signal models of the frequency and output voltage in dq frame are:

$$
\left\{\begin{array}{l}
\Delta \omega=-m_{\mathrm{pac}} \Delta P_{\mathrm{ac}} \\
\Delta \dot{v}_{\text {odac }}=-n_{\mathrm{qac}} \Delta \dot{Q}_{\mathrm{ac}} \\
\Delta \dot{v}_{\text {oqac }}=0
\end{array}\right.
$$

Since an individual dq frame is used for each inverter, multiple dq frames can be synchronized and converted into a common frame. In general, the dq frame of the first interface inverter is selected as the common DQ frame. The phase angle difference between an inverter and the common DQ frame is represented as:

$$
\delta_{\mathrm{ac}}=\int\left(\omega-\omega_{\mathrm{com}}\right) \mathrm{dt}
$$

where $\omega_{\text {com }}$ is the angular frequency of the common $D Q$ frame.

Therefore, the small-signal representation is:

$$
\Delta \dot{\delta}_{\mathrm{ac}}=-m_{\mathrm{pac}} \Delta P_{\mathrm{ac}}-\Delta \omega_{\mathrm{com}}
$$

Similar to the DC subsection, the state equation of inverter output current iodqac is derived since each inverter connects to a local bus through a coupling inductance $L_{\text {cac }}$. Additionally, the virtual impedance (i.e., $R_{\mathrm{vac}}+j \omega L_{\mathrm{vac}}$ ) is added to the model.

$$
\left\{\begin{array}{l}
i_{\text {odac }}=-\frac{R_{\text {cac }}+R_{\text {vac }}}{L_{\text {cac }}+L_{\text {vac }}} i_{\text {odac }}+\frac{\left(v_{\text {odac }}-v_{\text {bdac }}\right)}{L_{\text {cac }}+L_{\text {vac }}}+\omega i_{\text {oqac }} \\
i_{\text {oqac }}=-\frac{R_{\text {cac }}+R_{\text {vac }}}{L_{\text {cac }}+L_{\text {vac }}} i_{\text {oqac }}+\frac{\left(v_{\text {ogac }}-v_{\text {bqac }}\right)}{L_{\text {cac }}+L_{\text {vac }}}-\omega i_{\text {odac }}
\end{array}\right.
$$

Therefore, the small-signal model of output current in dq frame are derived: 


$$
\left\{\begin{array}{l}
\Delta i_{\text {odac }}=-\frac{R_{\mathrm{cac}}+R_{\mathrm{vac}}}{L_{\mathrm{cac}}+L_{\mathrm{vac}}} \Delta i_{\text {odac }}+\frac{\left(\Delta v_{\text {odac }}-\Delta v_{\mathrm{bdac}}\right)}{L_{\mathrm{cac}}+L_{\mathrm{vac}}}+\omega_{0} \Delta i_{\text {oqac }}+I_{\text {oqac }} \Delta \omega \\
\Delta \dot{i}_{\mathrm{oqac}}=-\frac{R_{\mathrm{cac}}+R_{\mathrm{vac}}}{L_{\mathrm{cac}}+L_{\mathrm{vac}}} \Delta i_{\text {oqac }}+\frac{\left(\Delta v_{\text {oqac }}-\Delta v_{\mathrm{bqac}}\right)}{L_{\mathrm{cac}}+L_{\mathrm{vac}}}-\omega_{0} \Delta i_{\text {odac }}-I_{\text {odac }} \Delta \omega
\end{array}\right.
$$

Meanwhile, with the synchronized frames and the derived phase angle difference in (2.24), the inverter output current $i_{\text {odqac }}$ and bus voltage $v_{\text {bdqac }}$ can be transferred to the corresponding $i_{\mathrm{oDQ}}$ ac and $V_{\mathrm{bDQ}}$ in the common DQ frame, respectively.

$$
\begin{gathered}
{\left[i_{\text {oDQac }}\right]=T\left[i_{\text {odqac }}\right]} \\
{\left[v_{\text {bdqac }}\right]=T^{-1}\left[v_{\text {bDQac }}\right]}
\end{gathered}
$$

where

$$
T=\left[\begin{array}{cc}
\cos \delta_{0} & -\sin \delta_{0} \\
\sin \delta_{0} & \cos \delta_{0}
\end{array}\right]
$$

Hence, their corresponding small-signal models are:

$$
\begin{gathered}
{\left[\Delta i_{\text {oDQac }}\right]=T\left[\Delta i_{\text {odqac }}\right]+\left[\begin{array}{c}
-I_{\text {odac }} \sin \delta_{0}+I_{\text {oqac }} \cos \delta_{0} \\
l_{\text {odac }} \cos \delta_{0}-I_{\text {oqac }} \sin \delta_{0}
\end{array}\right][\Delta \delta]} \\
{\left[\Delta v_{\text {bdqac }}\right]=T^{-1}\left[\Delta v_{\text {bDQac }}\right]+\left[\begin{array}{l}
-V_{\text {bDac }} \sin \delta_{0}+V_{\text {bQac }} \cos \delta_{0} \\
-V_{\text {bDac }} \cos \delta_{0}-V_{\text {bQac }} \sin \delta_{0}
\end{array}\right][\Delta \delta]}
\end{gathered}
$$

For the $i^{\text {th }}$ inverter, similar to the small-signal modeling of DC section, by linearizing (2.21), (2.23), (2.25) and (2.27), there are seven state variables (i.e., $\Delta \delta_{\mathrm{aci}}, \Delta P_{\mathrm{aci}}, \Delta Q_{\mathrm{aci}}$, $\Delta v_{\text {odqaci }}$, and $\left.\Delta i_{\text {odqaci }}\right)$ in the state vector $x_{\text {invac } i}$ for one interface inverter in AC MGs.

$$
\begin{aligned}
& {\left[\Delta \dot{x}_{\text {invaci }}\right]=A_{\text {invaci }}\left[\Delta x_{\text {invaci }}\right]+B_{\text {invaci }}\left[\Delta v_{\text {bDQaci }}\right]+B_{\text {wcomi }}\left[\Delta \omega_{\text {com }}\right]} \\
& {\left[\begin{array}{c}
\Delta \omega_{i} \\
\Delta i_{\text {oDQaci }}
\end{array}\right]=\left[\begin{array}{c}
C_{\text {invwaci }} \\
C_{\text {invcaci }}
\end{array}\right]\left[\Delta x_{\text {invaci }}\right]}
\end{aligned}
$$

where $A_{\text {invaci, }} B_{\text {invaci, }} B_{w c o m i}, C_{\text {invwaci, }}$ and $C_{\text {invcaci }}$ are given below

$$
\left[\begin{array}{llll}
\Delta x_{\text {invi }}
\end{array}\right]=\left[\begin{array}{llll}
\Delta \delta_{\text {aci }} & \Delta P_{\text {aci }} & \Delta Q_{\text {aci }} \quad \Delta v_{\text {odqaci }} \Delta i_{\text {odqaci }}
\end{array}\right]^{\top}
$$




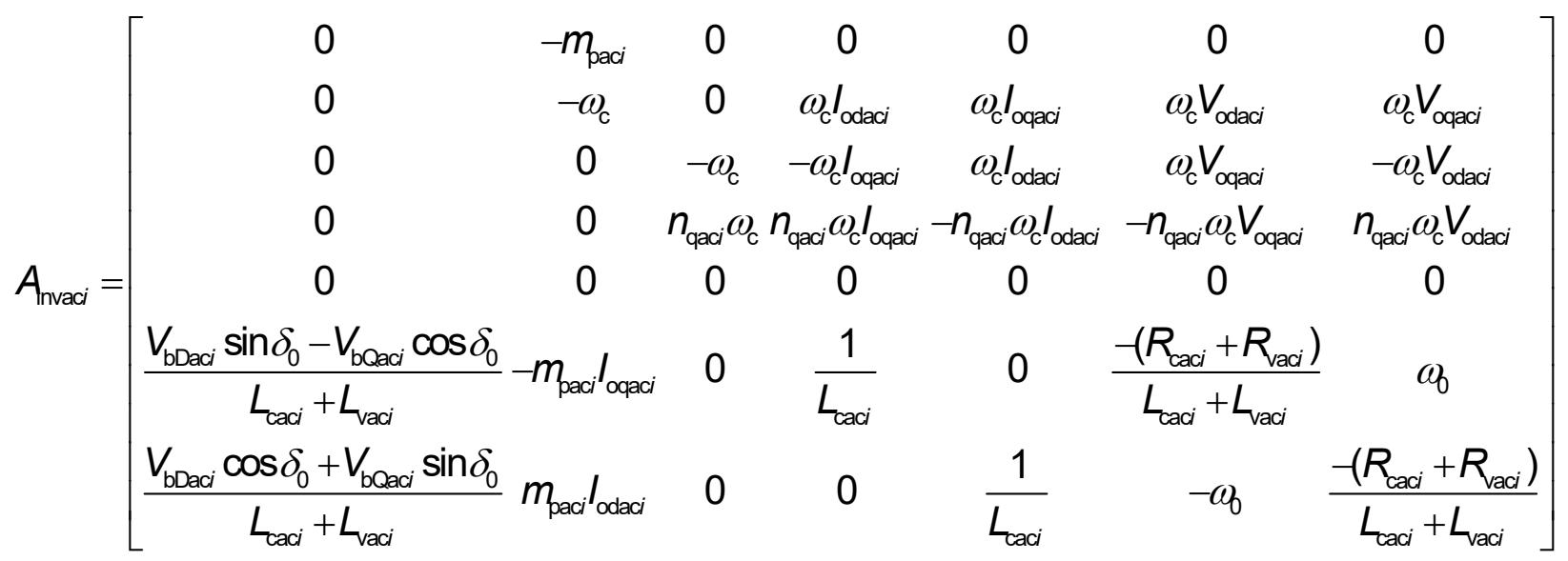

$$
\begin{aligned}
& B_{\text {invaci }}=\left[\begin{array}{ccccc}
0 & \cdots & 0 & \frac{-\cos \delta_{0}}{L_{\mathrm{cac} i}+L_{\mathrm{vac} i}} & \frac{\sin \delta_{0}}{L_{\mathrm{cac} i}+L_{\mathrm{vaci}}} \\
0 & \cdots & 0 & \frac{-\sin \delta_{0}}{L_{\mathrm{cac} i}+L_{\mathrm{vac} i}} & \frac{-\cos \delta_{0}}{L_{\mathrm{cac} i}+L_{\mathrm{vac} i}}
\end{array}\right]^{\top}, \quad B_{\omega \mathrm{com} i}=\left[\begin{array}{llll}
-1 & 0 & \cdots & 0
\end{array}\right]^{\top},
\end{aligned}
$$

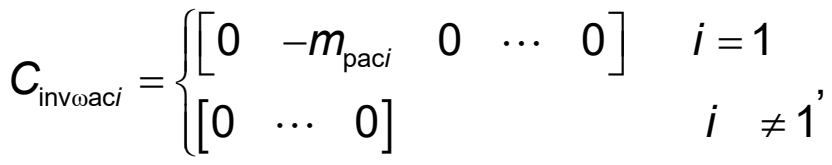

$$
\begin{aligned}
& C_{\text {invcaci }}=\left[\begin{array}{cccccc}
-I_{\text {odaci }} \sin \delta_{0}-I_{\text {oqaci }} \cos \delta_{0} & 0 & \cdots & 0 & \cos \delta_{0} & -\sin \delta_{0} \\
I_{\text {odaci }} \cos \delta_{0}-I_{\text {oqaci }} \sin \delta_{0} & 0 & \cdots & 0 & \sin \delta_{0} & \cos \delta_{0}
\end{array}\right] .
\end{aligned}
$$

Therefore, a comprehensive small-signal model of all the $s$ interface inverters derived as:

$$
\begin{aligned}
{\left[\Delta \dot{x}_{\text {invac }}\right] } & =A_{\text {invac }}\left[\Delta x_{\text {invac }}\right]+B_{\text {invac }}\left[\Delta v_{\text {bDQac }}\right] \\
{\left[\Delta i_{\text {oDQac }}\right] } & =C_{\text {invcac }}\left[\Delta x_{\text {invac }}\right]
\end{aligned}
$$

where

$$
\begin{aligned}
& {\left[\Delta X_{\text {invac }}\right]=\left[\begin{array}{llll}
\Delta x_{\text {invac1 }} & \Delta X_{\text {invac2 }} & \cdots & \Delta X_{\text {invacs }}
\end{array}\right]^{\top} \text {, }} \\
& A_{\text {invac }}=\left[\begin{array}{cccc}
A_{\text {invac1 } 1}+B_{\omega c o m 1} C_{\text {invwac1 }} & & & \\
B_{\omega c o m 2} C_{\text {invwac1 }} & A_{\text {invac2 }} & & \\
\vdots & & \ddots & \\
B_{\omega c 0 m s} C_{\text {invwac1 } 1} & & & A_{\text {invacs }}
\end{array}\right] \text {, } \\
& B_{\text {invac }}=\left[\begin{array}{ccc}
B_{\text {invac1 }} & & \\
& \ddots & \\
& & B_{\text {invacs }}
\end{array}\right], \quad C_{\text {invcac }}=\left[\begin{array}{lll}
C_{\text {invcac1 }} & & \\
& \ddots & \\
& & C_{\text {invcacs }}
\end{array}\right] \text {. }
\end{aligned}
$$




\subsubsection{Modeling of Networks in AC Subsections}

For the line currents, their state equations are similar to those in the DC subsection, while the state variables in the dq frame need to be transferred to the common DQ frame, as derived below:

$$
\left\{\begin{array}{l}
\dot{i}_{\text {lineDaci }}=-\frac{R_{\text {lineaci }}}{L_{\text {lineaci }}} i_{\text {lineDaci }}+\frac{1}{L_{\text {lineaci }}}\left(v_{\text {bDacj }}-v_{\text {bDach }}\right)+\omega i_{\text {lineQaci }} \\
\dot{i}_{\text {lineQaci }}=-\frac{R_{\text {lineaci }}}{L_{\text {lineaci }}} i_{\text {lineQaci }}+\frac{1}{L_{\text {lineaci }}}\left(v_{\text {bQacj }}-v_{\text {bQach }}\right)-\omega i_{\text {lineDaci }}
\end{array}\right.
$$

Then the small-signal model of line current is:

$$
\left[\Delta i_{\text {lineDQaci }}\right]=A_{\text {netaci }}\left[\Delta i_{\text {lineDQaci }}\right]+B_{\text {1netaci }}\left[\Delta v_{\text {bDQacj }, h}\right]+B_{2 \text { netaci }}[\Delta \omega]
$$

where

$$
\begin{aligned}
& A_{\text {netaci }}=\left[\begin{array}{cc}
\frac{-R_{\text {lineaci }}}{L_{\text {lineaci }}} & \omega_{0} \\
-\omega_{0} & \frac{-R_{\text {lineaci }}}{L_{\text {lineaci }}}
\end{array}\right], \quad B_{\text {1netaci }}=\left[\begin{array}{ccc}
\frac{1}{L_{\text {lineaci }}} & -\frac{1}{L_{\text {lineaci }}} & \\
\frac{1}{L_{\text {lineaci }}} & -\frac{1}{L_{\text {lineaci }}}
\end{array}\right], \\
& B_{\text {2netaci }}=\left[\begin{array}{c}
I_{\text {lineQaci }} \\
-I_{\text {lineDaci }}
\end{array}\right] .
\end{aligned}
$$

Therefore, based on (2.35), a combined small-signal model of networks ( $n$ lines and $m$ buses) is represented as:

$$
\left[\Delta \dot{i}_{\text {lineDQac }}\right]=A_{\text {netac }}\left[\Delta i_{\text {lineDQac }}\right]+B_{1 \text { netac }}\left[\Delta v_{\text {bDQac }}\right]+B_{\text {2netac }}[\Delta \omega]
$$

where

$$
A_{\text {netac }}=\left[\begin{array}{ccc}
A_{\text {net1 }} & & \\
& \ddots & \\
& & A_{\text {net } n}
\end{array}\right]_{2 n \times 2 n}, \quad B_{2 \text { netac }}=\left[\begin{array}{llll}
B_{2 \text { netac1 }} & B_{2 \text { netac2 }} & \cdots & B_{2 \text { netac } n}
\end{array}\right]_{1 \times 2 n}^{\top},
$$



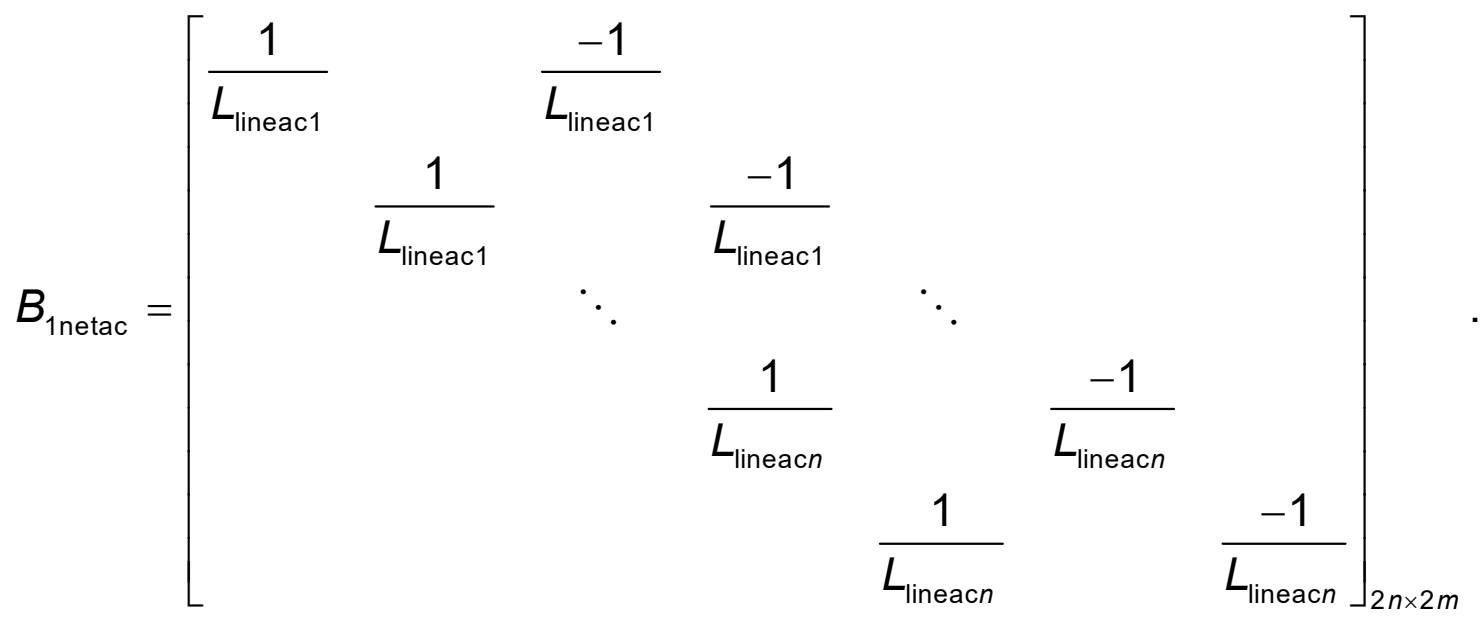

\subsubsection{Modeling of Loads in AC Subsections}

For the load current in the AC side, its state equations are similar to those of the line current in the DQ frame, which are shown as:

$$
\left\{\begin{array}{l}
\dot{i}_{\text {loadDaci }}=-\frac{R_{\text {loadaci }}}{L_{\text {loadaci }}} i_{\text {loadDaci }}+\frac{1}{L_{\text {loadaci }}} v_{\text {bDaci }}+\omega i_{\text {loadQaci }} \\
\dot{i}_{\text {loadQaci }}=-\frac{R_{\text {loadaci }}}{L_{\text {loadaci }}} i_{\text {loadQaci }}+\frac{1}{L_{\text {loadaci }}} v_{\text {bQaci }}-\omega i_{\text {loadDaci }}
\end{array}\right.
$$

Hence, the corresponding small-signal models are:

$$
\left[\Delta i_{\text {loadDQaci }}\right]=A_{\text {loadaci }}\left[\Delta i_{\text {loadDQaci }}\right]+B_{\text {1loadaci }}\left[\Delta v_{\text {bDQaci }}\right]+B_{2 \text { loadaci }}[\Delta \omega]
$$

where

$$
A_{\text {loadaci }}=\left[\begin{array}{cc}
\frac{-R_{\text {loadaci }}}{L_{\text {loadaci }}} & \omega_{0} \\
-\omega_{0} & \frac{-R_{\text {loadaci }}}{L_{\text {loadaci }}}
\end{array}\right], \quad B_{\text {1loadaci }}=\left[\begin{array}{cc}
\frac{1}{L_{\text {loadaci }}} & \\
& \frac{1}{L_{\text {loadaci }}}
\end{array}\right], \quad B_{\text {2loadaci }}=\left[\begin{array}{c}
I_{\text {loadQaci }} \\
-l_{\text {loadDaci }}
\end{array}\right] .
$$

Based on (2.38), a combined small-signal model of loads ( $p$ loads) is represented as:

$$
\left[\Delta i_{\text {loadDQac }}\right]=A_{\text {loadac }}\left[\Delta i_{\text {loadDQac }}\right]+B_{1 \text { loadac }}\left[\Delta v_{\text {bDQac }}\right]+B_{\text {2loadac }}[\Delta \omega]
$$

where 
$A C$ and DC hybrid distribution grids with solar integration: architecture, stabilization and cost assessment

Dongbo Zhao

$$
\begin{aligned}
& A_{\text {loadac }}=\left[\begin{array}{lll}
A_{\text {load1ac }} & & \\
& \ddots & \\
& & A_{\text {loadacp }}
\end{array}\right]_{2 p \times 2 p}, B_{1 \text { loadac }}=\left[\begin{array}{lll}
B_{1 \text { loadac1 }} & \\
& \ddots & \\
& & B_{1 \text { loadac } p}
\end{array}\right]_{2 p \times 2 m}, \\
& B_{\text {2loadac }}=\left[\begin{array}{llll}
B_{\text {2loadac1 }} & B_{\text {2loadac2 }} & \cdots & B_{\text {2loadac } p}
\end{array}\right]_{1 \times 2 p}^{\top} .
\end{aligned}
$$

\subsubsection{Complete Model of AC Subsections}

Similar to the DC subsection, mapping matrices are defined to show the representation of $\mathrm{AC}$ bus voltage, as derived below. Meanwhile, the matrix $R_{\mathrm{Nac}}$ composed of a large virtual resistance $r_{\mathrm{N}}$ is involved in satisfying the equation set mathematically.

$$
\left[v_{\text {bDQac }}\right]=R_{\text {Nac }}\left(M_{\text {invac }}\left[i_{\text {oDQac }}\right]+M_{\text {loadac }}\left[i_{\text {loadDQac }}\right]+M_{\text {netac }}\left[i_{\text {lineDQac }}\right]\right)
$$

Therefore, the corresponding small-signal model is:

$$
\left[\Delta v_{\text {bDQac }}\right]=R_{\text {Nac }}\left(M_{\text {invac }}\left[\Delta i_{\text {oDQac }}\right]+M_{\text {loadac }}\left[\Delta i_{\text {loadDQac }}\right]+M_{\text {netac }}\left[\Delta i_{\text {lineDQac }}\right]\right)
$$

where

$$
\begin{aligned}
& R_{\mathrm{Nac}}=\left[\begin{array}{ccc}
r_{N} & & \\
& \ddots & \\
& & r_{N}
\end{array}\right]_{2 m \times 2 m}, \quad M_{\text {invac }}=\left[\begin{array}{lll}
1 & & \\
& \ddots & \\
& & 1
\end{array}\right]_{2 m \times 2 s}, \\
& M_{\text {netac }}=\left[\begin{array}{cccc}
-1 & & & \\
0 & -1 & & \\
1 & 0 & \ddots & \\
& 1 & \ddots & -1 \\
& & \ddots & 0 \\
& & & 1
\end{array}\right]_{2 m \times 2 n} \quad, M_{\text {loadac }}=\left[\begin{array}{ccc}
-1 & & \\
& \ddots & \\
& & -1
\end{array}\right]_{2 m \times 2 p} \text {. }
\end{aligned}
$$

Hence, combining (2.33), (2.36), (2.39), and (2.41), the complete small-signal statespace model of the AC subsection is summarized as:

$$
\left[\begin{array}{ll}
\Delta \dot{x}_{\mathrm{ac}}
\end{array}\right]=\left[\begin{array}{lll}
\Delta \dot{X}_{\text {invac }} & \Delta \dot{i}_{\text {lineDQac }} \Delta \dot{i}_{\text {loadDQac }}
\end{array}\right]^{\top}=A_{\mathrm{ac}}\left[\Delta x_{\mathrm{ac}}\right]
$$

where the state matrix $A_{\mathrm{ac}}$ of the $\mathrm{AC}$ subsection is given below

$$
A_{\mathrm{ac}}=\left[\begin{array}{ccc}
A_{\text {invac }}+B_{\text {invac }} R_{\text {Nac }} M_{\text {invac }} C_{\text {invcac }} & B_{\text {invac }} R_{\text {Nac }} M_{\text {netac }} & B_{\text {invac }} R_{\text {Nac }} M_{\text {loadac }} \\
B_{\text {1netac }} R_{\text {Nac }} M_{\text {invac }} C_{\text {invcac }}+B_{\text {2netac }} C_{\text {invwac }} & A_{\text {netac }}+B_{\text {1netac }} R_{\text {Nac }} M_{\text {netac }} & B_{\text {1netac }} R_{\text {Nac }} M_{\text {loadac }} \\
B_{\text {1loadac }} R_{\text {Nac }} M_{\text {invac }} C_{\text {invac }}+B_{\text {2loadac }} C_{\text {invwac }} & B_{\text {1loadac }} R_{\text {Nac }} M_{\text {netac }} & A_{\text {loadac }}+B_{\text {1loadac }} R_{\text {Nac }} M_{\text {loadac }}
\end{array}\right]
$$


Subtask 2.3 Interconnect the impedance-based models in both AC and DC subsections with appropriate impedance-based models of interface inverters between AC and DC buses developed and integrated.

\subsubsection{AC-side Modeling of Interlink Inverters}

To satisfy the operating conditions in both $A C$ and DC MGs, a $V-P$ droop control is used at the DC side for each interlink inverter, which is aligned with other sources at the DC subsection, as shown below:

$$
V_{\mathrm{lk} \_d c}^{*}=V_{\text {ndc }}-m_{\mathrm{lk}} P_{\mathrm{lk} \_\mathrm{dc}}
$$

where $m_{\mathrm{k}}$ is the droop coefficient; $P_{\mathrm{lk} \_\mathrm{dc}}$ is the active power in the DC side of the interlink converter.

Hence, the small-signal model is:

$$
\Delta v_{\mathrm{lk} \_\mathrm{dc}}^{*}=-m_{\mathrm{lk}} \Delta P_{\mathrm{lk} \_\mathrm{dc}}
$$

To smooth power exchange between $A C$ and DC subsections, at the DC side of the interlink inverter, DC-link voltage is controlled to balance the active power while reactive power is controlled at the AC side locally. Thus, the average active power at the DC side and the average reactive power at the $A C$ side are calculated as:

$$
\left\{\begin{array}{l}
P_{\mathrm{Ik} \_\mathrm{dc}}=\frac{\omega_{\mathrm{c}}}{s+\omega_{\mathrm{c}}} v_{\mathrm{Ik} \_\mathrm{dc}} i_{I_{\mathrm{Ik} \_\mathrm{dc}}} \\
Q_{\mathrm{Ik} \_\mathrm{ac}}=\frac{\omega_{\mathrm{c}}}{s+\omega_{\mathrm{c}}}\left(v_{\mathrm{qlk} \_\mathrm{ac}} i_{\text {odlk_ac }}-v_{\text {dlk_ac }} i_{\text {oqlk_ac }}\right)
\end{array}\right.
$$

Then the small-signal models of the power control are:

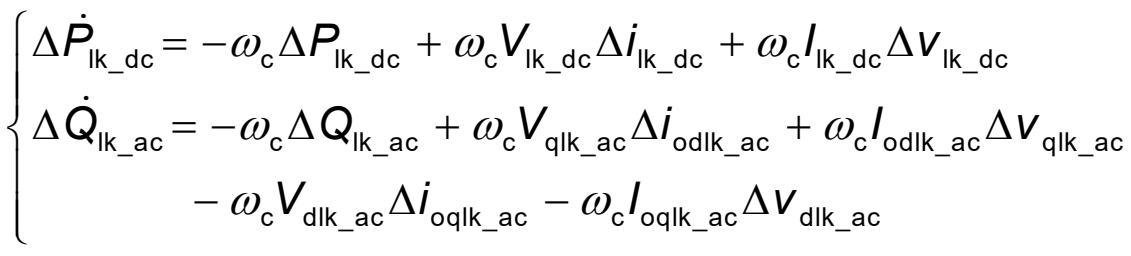

A multi-loop control diagram is utilized for interlink inverters. Particularly, the outer control diagram includes DC-link voltage and reactive power control loops, and the inner control diagram includes the proportional-integral $(\mathrm{PI})$ based current control loops. The outer control loops are separately shown in (2.47)-(2.48), which are used to calculate the interlink inverter output current $i_{\text {odqlk_ac at }}$ at the AC side:

$$
\begin{array}{r}
\left\{\begin{array}{l}
\dot{\phi}_{\mathrm{v}}=v_{\mathrm{lk} \_\mathrm{dc}}^{*}-v_{\mathrm{lk} \_\mathrm{dc}} \\
\dot{\tau}_{\mathrm{q}}=Q_{\mathrm{lk} \_\mathrm{ac}}^{*}-Q_{\mathrm{lk} \_\mathrm{ac}}
\end{array}\right. \\
\left\{\begin{array}{l}
i_{\mathrm{odlk} \_\mathrm{ac}}^{*}=k_{\mathrm{pv}}\left(v_{\mathrm{lk} \_\mathrm{dc}}^{*}-v_{\mathrm{lk} \_\mathrm{dc}}\right)+k_{\mathrm{iv}} \phi_{\mathrm{v}} \\
i_{\mathrm{oq} \mathrm{k}_{\mathrm{k}} \mathrm{ac}}^{*}=k_{\mathrm{pq}}\left(Q_{\mathrm{lk} \_\mathrm{ac}}^{*}-Q_{\mathrm{lk} \_\mathrm{ac}}\right)+k_{\mathrm{iq}} \tau_{\mathrm{q}}
\end{array}\right.
\end{array}
$$


Then their corresponding small-signal models are:

$$
\begin{gathered}
\left\{\begin{array}{l}
\Delta \dot{\phi}_{\mathrm{v}}=\Delta v_{\mathrm{lk} \_\mathrm{dc}}^{*}-\Delta v_{\mathrm{lk} \_\mathrm{dc}} \\
\Delta \dot{\tau}_{\mathrm{q}}=-\Delta Q_{\mathrm{lk} \_\mathrm{ac}}
\end{array}\right. \\
\left\{\begin{array}{l}
\Delta i_{\text {odlk_ac }}^{*}=k_{\mathrm{pv}}\left(\Delta v_{\mathrm{lk} \_\mathrm{dc}}^{*}-\Delta v_{\mathrm{lk} \_\mathrm{dc}}\right)+k_{\mathrm{iv}} \Delta \phi_{\mathrm{v}} \\
\Delta i_{\text {oqlk_ac }}^{*}=-k_{\mathrm{pq}} \Delta Q_{\mathrm{lk} \_\mathrm{ac}}+k_{\mathrm{iq}} \Delta \tau_{\mathrm{q}}
\end{array}\right.
\end{gathered}
$$

The inner control loops are separately shown in (2.51)-(2.52), which are used to calculate the interlink inverter output voltage Vodqk_ac at the AC side.

$$
\begin{gathered}
\left\{\begin{array}{l}
\dot{\gamma}_{\mathrm{d}}=i_{\text {odlk_ac }}^{*}-i_{\text {odlk_ac }} \\
\dot{\gamma}_{\mathrm{q}}=i_{\text {oqlk_ac }}^{*}-i_{\text {oqlk_ac }}
\end{array}\right. \\
\left\{\begin{array}{l}
v_{\text {odlk_ac }}=k_{\mathrm{pc}}\left(i_{\text {odlk_ac }}^{*}-i_{\text {odlk_ac }}\right)+k_{\text {ic }} \gamma_{\mathrm{d}}-\omega_{\mathrm{n}} L_{\mathrm{f}} i_{\text {oqlk_ac }}-k i_{\mathrm{cd}} \\
v_{\text {oqlk_ac }}=k_{\mathrm{pc}}\left(i_{\text {oqlk_ac }}^{*}-i_{\text {oqlk_ac }}\right)+k_{\mathrm{ic}} \gamma_{\mathrm{q}}+\omega_{\mathrm{n}} L_{\mathrm{f}} i_{\text {odlk_ac }}-k i_{\mathrm{cq}}
\end{array}\right.
\end{gathered}
$$

where $k$ is the gain of active damping; $i_{\text {cdq }}$ are currents of filter capacitor in DC side; $L_{f}$ is the per-phase filter inductance.

Then their corresponding small-signal models are derived:

$$
\begin{gathered}
\left\{\begin{array}{l}
\Delta \dot{\gamma}_{\mathrm{d}}=\Delta i_{\text {odlk_ac }}^{*}-\Delta i_{\text {odlk_ac }} \\
\Delta \dot{\gamma}_{\mathrm{q}}=\Delta i_{\text {oqlk_ac }}^{*}-\Delta i_{\text {oqlk_ac }}
\end{array}\right. \\
\left\{\begin{array}{l}
\Delta v_{\text {odlk_ac }}=k_{\text {pc }}\left(\Delta i_{\text {odlk_ac }}^{*}-\Delta i_{\text {odlk_ac }}\right)+k_{\text {ic }} \Delta \gamma_{\mathrm{d}}-\omega_{\mathrm{n}} L_{\mathrm{f}} \Delta i_{\text {oqlk_ac }}-L_{\mathrm{f}} I_{\text {oqlk_ac }} \Delta \omega-k \Delta i_{\text {cd }} \\
\Delta v_{\text {oqlk_ac }}=k_{\text {pc }}\left(\Delta i_{\text {oqlk_ac }}^{*}-\Delta i_{\text {oqlk_ac }}\right)+k_{\text {ic }} \Delta \gamma_{\mathrm{q}}+\omega_{\mathrm{n}} L_{\mathrm{f}} \Delta i_{\text {odlk_ac }}+L_{\mathrm{f}} I_{\text {odlk_ac }} \Delta \omega-k \Delta i_{\text {cq }}
\end{array}\right.
\end{gathered}
$$

On the other hand, considering the LC filter and the coupling impedance ( $\left.R_{\text {clk_ac, }} L_{c l k \_a c}\right)$ between the interlink inverter and local $A C$ bus, the following state equations with the state variables $i_{\text {odqlk_ac, }} V_{\text {dqlk_ac }}$ and $i_{\text {dqlk_ac }}$ are derived:

$$
\left\{\begin{array}{l}
\dot{i}_{\text {odlk_ac }}=-\frac{R_{f}}{L_{f}} i_{\text {odlk_ac }}+\frac{1}{L_{f}}\left(v_{\text {dlk_ac }}-v_{\text {odlk_ac }}\right)+\omega i_{\text {oqlk_ac }} \\
\dot{i}_{\text {oqlk_ac }}=-\frac{R_{f}}{L_{f}} i_{\text {oqlk_ac }}+\frac{1}{L_{f}}\left(v_{\text {qlk_ac }}-v_{\text {oqlk_ac }}\right)-\omega i_{\text {odlk_ac }} \\
\left\{\begin{array}{l}
\dot{v}_{\text {dlk_ac }}=\frac{1}{C_{f}}\left(i_{\text {dlk_ac }}-i_{\text {odlk_ac }}\right)+\omega v_{\text {qlk_ac }} \\
\dot{v}_{\text {qlk_ac }}=\frac{1}{C_{f}}\left(i_{\text {qlk_ac }}-i_{\text {oqlk_ac }}\right)-\omega V_{\text {dlk_ac }}
\end{array}\right.
\end{array}\right.
$$


$A C$ and DC hybrid distribution grids with solar integration: architecture, stabilization and cost assessment

$$
\left\{\begin{array}{l}
\dot{i}_{\mathrm{dlk} \_\mathrm{ac}}=-\frac{R_{\mathrm{clk} \_\mathrm{ac}}}{L_{\mathrm{clk} \_\mathrm{ac}}} i_{\text {dlk_ac }}+\frac{1}{L_{\mathrm{clk} \_\mathrm{ac}}}\left(v_{\mathrm{bdlk} \_\mathrm{ac}}-v_{\mathrm{dlk} \_\mathrm{ac}}\right)+\omega i_{\mathrm{qlk} \_\mathrm{ac}} \\
\dot{i}_{\mathrm{qlk} \_\mathrm{ac}}=-\frac{R_{\mathrm{clk} \_\mathrm{ac}}}{L_{\mathrm{clk} \_\mathrm{ac}}} i_{\mathrm{qlk} \_\mathrm{ac}}+\frac{1}{L_{\mathrm{clk} \_\mathrm{ac}}}\left(v_{\mathrm{bqlk} \_\mathrm{ac}}-v_{\mathrm{qlk} \_\mathrm{ac}}\right)-\omega i_{\mathrm{dlk} \_\mathrm{ac}}
\end{array}\right.
$$

where the Vdqlk_ac is the voltage of capacitor $C_{f}$ at the $A C$ side of the interlink inverter.

Hence, their corresponding small-signal models are shown as:

$$
\begin{aligned}
& \left\{\begin{array}{l}
\Delta \dot{i}_{\text {odlk_ac }}=-\frac{R_{\mathrm{f}}}{L_{\mathrm{f}}} \Delta i_{\text {odlk_ac }}+\frac{1}{L_{\mathrm{f}}}\left(\Delta v_{\text {dlk_ac }}-\Delta v_{\text {odlk_ac }}\right)+\omega_{0} \Delta i_{\text {oqlk_ac }}+I_{\text {oqlk_ac }} \Delta \omega \\
\Delta \dot{i}_{\text {oqlk_ac }}=-\frac{R_{\mathrm{f}}}{L_{\mathrm{f}}} \Delta i_{\text {oqlk_ac }}+\frac{1}{L_{\mathrm{f}}}\left(\Delta v_{\text {qlk_ac }}-\Delta v_{\text {oqlk_ac }}\right)-\omega_{0} \Delta i_{\text {odlk_ac }}-I_{\text {odlk_ac }} \Delta \omega
\end{array}\right. \\
& \left\{\begin{array}{l}
\Delta \dot{v}_{\text {dlk_ac }}=\frac{1}{C_{f}}\left(\Delta i_{\text {dlk_ac }}-\Delta i_{\text {odlk_ac }}\right)+\omega_{0} \Delta v_{\text {qlk_ac }}+V_{\text {qlk_ac }} \Delta \omega \\
\Delta \dot{V}_{\text {qlk_ac }}=\frac{1}{C_{f}}\left(\Delta i_{\text {qlk_ac }}-\Delta i_{\text {oqlk_ac }}\right)-\omega_{0} \Delta v_{\text {dlk_ac }}-V_{\text {dlk_ac }} \Delta \omega
\end{array}\right. \\
& \left\{\begin{array}{l}
\Delta \dot{i}_{\text {dlk_ac }}=-\frac{R_{\text {clk_ac }}}{L_{\text {clk_ac }}} \Delta i_{\text {dlk_ac }}+\frac{1}{L_{\text {clk_ac }}}\left(\Delta v_{\text {bdlk_ac }}-\Delta v_{\text {dlk_ac }}\right)+\omega_{0} \Delta i_{\text {qlk_ac }}+I_{\text {qlk_ac }} \Delta \omega \\
\Delta \dot{i}_{\text {qlk_ac }}=-\frac{R_{\text {clk_ac }}}{L_{\text {clk_ac }}} \Delta i_{\text {qlk_ac }}+\frac{1}{L_{\text {clk_ac }}}\left(\Delta v_{\text {bqlk_ac }}-\Delta v_{\text {qlk_ac }}\right)-\omega_{0} \Delta i_{\text {dlk_ac }}-I_{\text {dk_ac }} \Delta \omega
\end{array}\right.
\end{aligned}
$$

Moreover, noted that the variables of interlink converter also need to be transferred to a common $D Q$ frame, $\delta_{\mathrm{lk}}$ is defined as the angle difference between the interlinking inverter and the common DQ frame.

$$
\delta_{\mathrm{lk}}=\int\left(\omega-\omega_{\text {com }}\right) \mathrm{dt}
$$

Its small-signal model is thereby derived:

$$
\Delta \dot{\delta}_{\mathrm{lk}}=-\Delta \omega_{\text {com }}
$$

Finally, similar to the $\mathrm{AC}$ subsection, considering the angle difference $\delta_{\mathrm{lk}}$ between the interlink inverter and the common $\mathrm{DQ}$ frame, the local AC bus voltage Vbdqlk_ac connecting the $\mathrm{AC}$ side of the interlink inverter and the corresponding injected current $i_{\text {dqlk_ac }}$ can be transferred to the common $\mathrm{DQ}$ frame, respectively.

\subsubsection{DC-side Modeling of Interlink Inverters}

Furthermore, the power balance between the AC and DC sides of the interlink inverter is derived below based on the power balance across the interlink inverter.

$$
\begin{aligned}
& p_{\mathrm{lk} \_\mathrm{ac}}=-p_{\mathrm{lk} \_\mathrm{dc}} \cdot \eta \\
& v_{\text {odlk_ac }} i_{\text {odlk_ac }}+v_{\text {oqlk_ac }} i_{\text {oqlk_ac }}=-v_{\text {lk_dc }}\left(i_{\mathrm{lk} \_d c}+C_{\mathrm{lk} \_\mathrm{dc}} \dot{v}_{\mathrm{lk} \_\mathrm{dc}}\right) \cdot \eta
\end{aligned}
$$


Hence, the small-signal model is:

$$
\begin{aligned}
& \left(V_{\text {odlk_ac }} \Delta i_{\text {odlk_ac }}+I_{\text {odlk_ac }} \Delta V_{\text {odlk_ac }}+V_{\text {oqlk_ac }} \Delta i_{\text {oqlk_ac }}\right.
\end{aligned}
$$

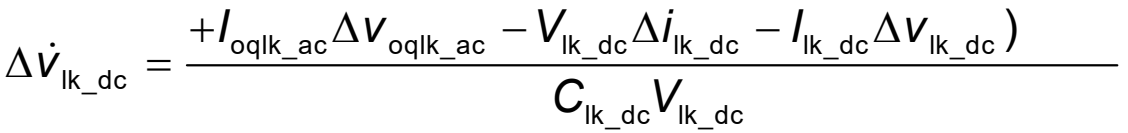

where $C_{1 k}$ dc is the filter capacitor at the DC side of the interlink converter; $\eta$ is the efficiency of the interlink inverter.

Meanwhile, the DC side of the interlink inverter connects to the DC bus using the coupling inductance $L_{\text {clk_dc: }}$

$$
\dot{i}_{\mathrm{lk} \_\mathrm{dc}}=-\frac{R_{\mathrm{clk} \_\mathrm{dc}}}{L_{\mathrm{clk} \_\mathrm{dc}}} i_{\mathrm{Ik}_{-} \mathrm{dc}}+\frac{1}{L_{\mathrm{clk} \_\mathrm{dc}}}\left(v_{\mathrm{lk} \_\mathrm{dc}}-v_{\mathrm{blk} \_\mathrm{dc}}\right)
$$

Then the small-signal model is:

$$
\Delta \dot{i}_{\mathrm{lk} \_\mathrm{dc}}=-\frac{R_{\mathrm{clk} \_\mathrm{dc}}}{L_{\mathrm{clk} \_\mathrm{dc}}} \Delta i_{\mathrm{Ik}_{2} \mathrm{dc}}+\frac{1}{L_{\mathrm{clk} \_\mathrm{dc}}}\left(\Delta v_{\mathrm{Ik} \_\mathrm{dc}}-\Delta v_{\mathrm{blk} \_\mathrm{dc}}\right)
$$

\subsubsection{Complete Model of Interlink Inverters}

Combining (2.43)-(2.66), there are fifteen state variables in total, including $\Delta \delta_{\mathrm{lk}}, \Delta P_{\mathrm{lk}} \mathrm{dc}$, $\Delta Q_{\text {lk_ac }}, \Delta \Phi_{v}, \Delta T_{q}, \Delta y_{d q}, \Delta i_{\text {odqlk_ac }}, \Delta V_{\text {dqlk_ac }}, \Delta i_{\text {dqlk_ac }}, \Delta V_{\text {lk_dc }}$, and $\Delta i_{\text {ik_dc }}$ for an interlink inverter. The corresponding small-signal representation is thereby obtained:

$$
\left[\Delta \dot{x}_{\mathrm{lk}}\right]=A_{\mathrm{lk}}\left[\Delta x_{\mathrm{lk}}\right]
$$

where the state matrix $A_{\mathrm{lk}}$ of the interlink inverter is given below

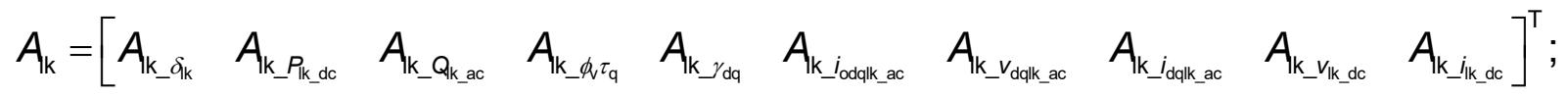

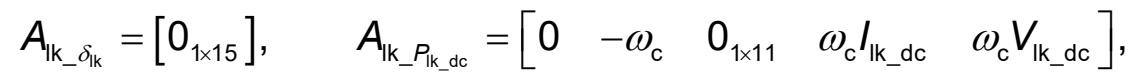

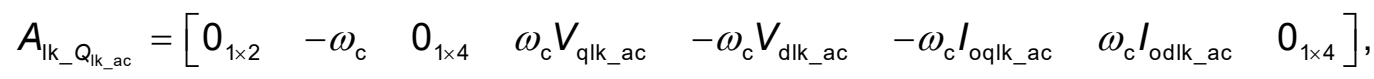

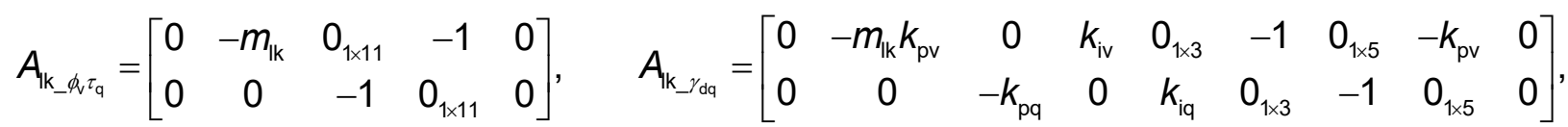

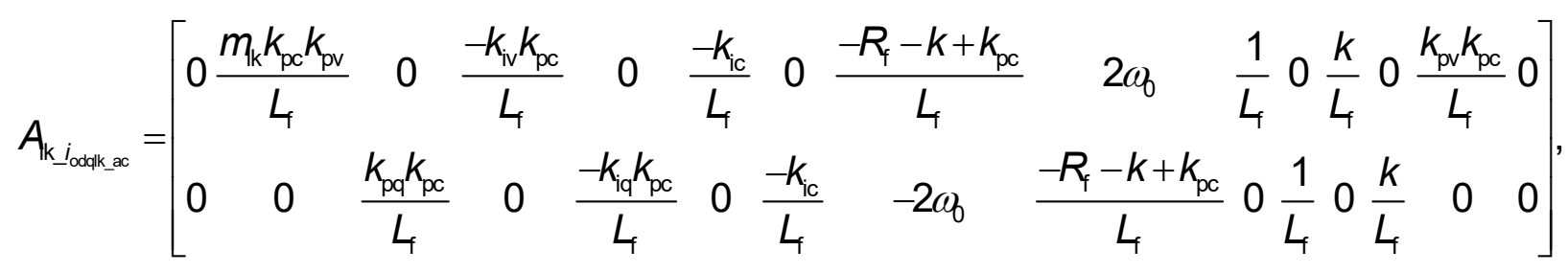




$$
\begin{aligned}
& A_{\mathrm{lk} \_v_{\text {dqlk_ac }}}=\left[\begin{array}{cccccccc}
0_{1 \times 7} & \frac{-1}{C_{f}} & 0 & 0 & \omega_{0} & \frac{1}{C_{f}} & 0 & 0_{1 \times 2} \\
0_{1 \times 7} & 0 & \frac{-1}{C_{f}} & -\omega_{0} & 0 & 0 & \frac{1}{C_{f}} & 0_{1 \times 2}
\end{array}\right],
\end{aligned}
$$

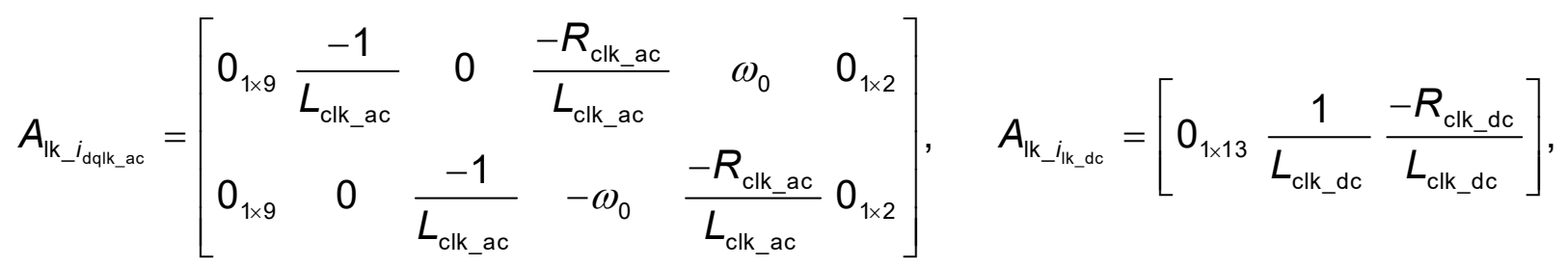

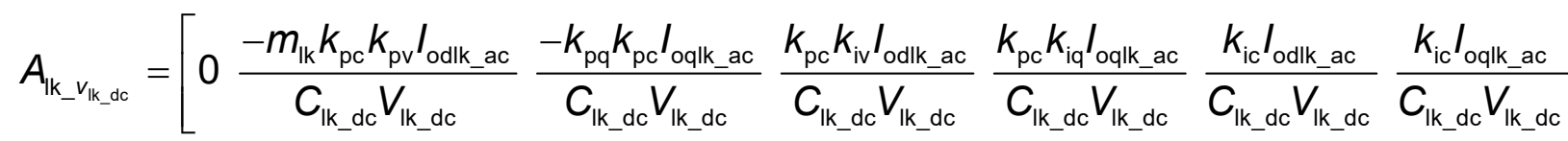

$$
\begin{aligned}
& \frac{\left(k-k_{\text {pc }}\right) l_{\text {odlk_ac }}+\omega_{0} L_{f} I_{\text {oqlk_ac }}+V_{\text {odlk_ac }}}{C_{\text {Ik_dc }} V_{\text {IK_dc }}} \frac{\left(k-k_{\text {pc }}\right) I_{\text {oqlk_ac }}-\omega_{0} L_{f} I_{\text {odlk_ac }}+V_{\text {oqlk_ac }}}{C_{\text {Ik__d }} V_{\text {Ik_dc }}} 00
\end{aligned}
$$

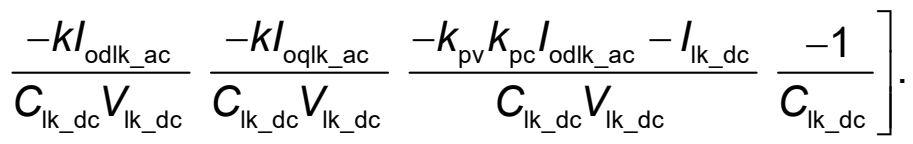

Subtask 2.4 Develop the impedance-based stability criteria in hybrid AC and DC distribution grids, considering: (1) AC subgrids, (2) DC subgrids, and (3) interface inverters between $\mathrm{AC}$ and $\mathrm{DC}$ buses.

Considering the coupling components among the interlink inverters, AC and DC subsections, the small-signal models in (2.18), (2.42) and (2.67) should be further derived. For example, assuming an autonomous and hybrid AC and DC distribution grid is comprised of two DGs, two loads and one line in the AC subsection, and two DGs, two loads and one line in the DC subsection, as well as one interface inverter between AC and DC buses, the small-signal model of DC subsection based on the coupling components between DC subsection and the interlink inverter is written as:

$$
\left[\Delta \dot{x}_{\mathrm{dc}}\right]=A_{\mathrm{dc}}\left[\Delta x_{\mathrm{dc}}\right]+B_{\mathrm{dc} \_\mathrm{lk}}\left[\Delta x_{\mathrm{lk}}\right]
$$

where

$$
B_{\mathrm{dc} \_l \mathrm{k}}=\left[\begin{array}{c}
B_{\text {invdc }} \\
B_{\text {netdc }} \\
B_{\text {loaddc }}
\end{array}\right] M_{\mathrm{dc} \_\_\mathrm{k}} T_{\mathrm{dc} \_l \mathrm{k}}, \quad M_{\mathrm{dc} \_l \mathrm{k}}=\left[\begin{array}{l}
1 \\
0
\end{array}\right], \quad T_{\mathrm{dc} \_l \mathrm{k}}=\left[\begin{array}{ll}
0_{1 \times 14} & 1
\end{array}\right] .
$$

Then, the small-signal model of $A C$ subsection is further derived:

$$
\left[\Delta \dot{x}_{\mathrm{ac}}\right]=A_{\mathrm{ac}}\left[\Delta \mathrm{x}_{\mathrm{ac}}\right]+B_{\mathrm{ac} \_\mathrm{kk}}\left[\Delta x_{\mathrm{lk}}\right]
$$

where 


$$
\begin{aligned}
& B_{\mathrm{ac} \_\mathrm{k}}=\left[\begin{array}{c}
B_{\text {invac }} \\
B_{\text {1netac }} \\
B_{\text {1loadac }}
\end{array}\right] M_{\mathrm{Ik} \_\mathrm{ac}} T_{\mathrm{ac} \_\mathrm{k}} \text {, }
\end{aligned}
$$

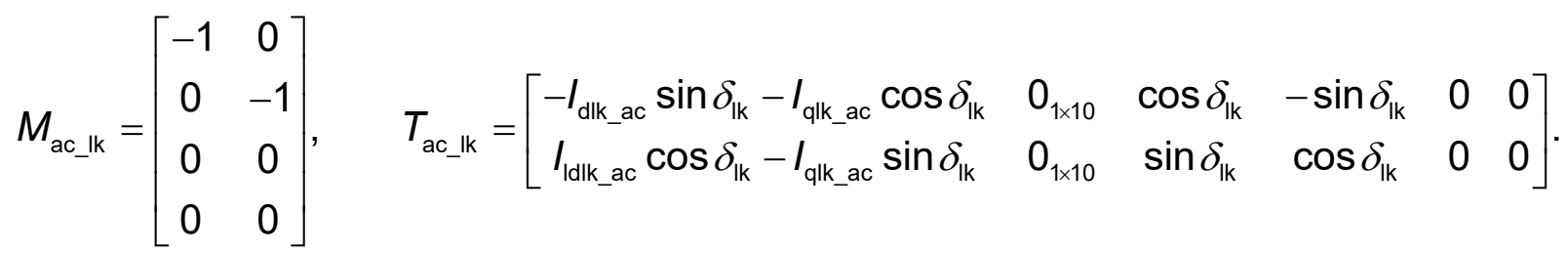

Finally, the small-signal model of the interlink inverter is shown as:

$$
\left[\Delta \dot{x}_{\mathrm{lk}}\right]=\left(A_{\mathrm{lk}}+B_{\mathrm{lk}_{-} \mathrm{dc} 2}+B_{\mathrm{lk}_{-} \mathrm{ac} 2}\right)\left[\Delta x_{\mathrm{lk}}\right]+B_{\mathrm{lk}_{-} \mathrm{ac} 1}\left[\Delta x_{\mathrm{ac}}\right]+B_{\mathrm{lk}_{-} \mathrm{dc} 1}\left[\Delta x_{\mathrm{dc}}\right]
$$

where

$$
\begin{aligned}
& B_{\mathrm{lk} \_\mathrm{dc} 1}=B_{\mathrm{lk} 3} r_{\mathrm{N}} T_{\mathrm{lk} \_\mathrm{dc} 1} ; \quad B_{\mathrm{lk} \_\mathrm{dc} 2}=B_{\mathrm{lk} 3} r_{\mathrm{N}} T_{1 \mathrm{k} \_\mathrm{dc} 2} ;
\end{aligned}
$$

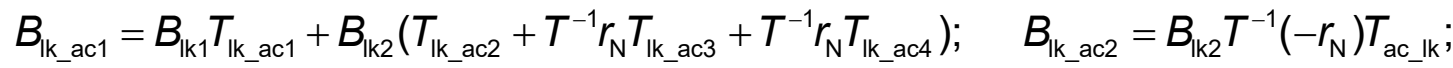$$
B_{\mathrm{lk} 1}=\left[\begin{array}{ll}
-1 & 0_{1 \times 14}
\end{array}\right]^{\top}, \quad B_{\mathrm{lk} 2}=\left[\begin{array}{cccc}
0_{1 \times 11} & \frac{1}{L_{\mathrm{clk} \_\mathrm{ac}}} & 0 & 0_{1 \times 2} \\
0_{1 \times 11} & 0 & \frac{1}{L_{\text {clk_ac }}} & 0_{1 \times 2}
\end{array}\right]^{\top}, \quad B_{\mathrm{kk} 3}=\left[\begin{array}{ll}
0_{1 \times 14} & \frac{-1}{L_{\mathrm{clk} \_\mathrm{dc}}}
\end{array}\right]^{\top},
$$

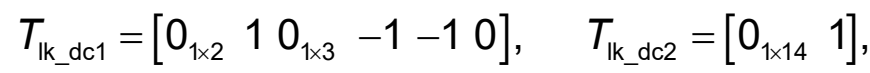$$
T_{\mathrm{lk} \_a c 1}=\left[\begin{array}{lll}
0 & -m_{\mathrm{pac}} & 0_{1 \times 18}
\end{array}\right], \quad T_{\mathrm{lk} \_\mathrm{ac} 2}=\left[\begin{array}{ll}
-V_{\mathrm{bDac}} \sin \delta_{0}+V_{\mathrm{bQac}} \cos \delta_{0} & 0_{1 \times 19} \\
-V_{\mathrm{bDac}} \cos \delta_{0}-V_{\mathrm{bQac}} \sin \delta_{0} & 0_{1 \times 19}
\end{array}\right] \text {, }
$$$$
T_{\mathrm{Ik} \_ \text {ac3 }}=\left[\begin{array}{cccccc}
0_{1 \times 14} & -1 & 0 & -1 & 0 & 0_{1 \times 2} \\
0_{1 \times 14} & 0 & -1 & 0 & -1 & 0_{1 \times 2}
\end{array}\right]
$$$$
T_{\mathrm{lk} \_ \text {ac } 4}=\left[\begin{array}{ccccc}
-i_{\text {odac }} \sin \delta_{0}-i_{\text {oqac }} \cos \delta_{0} & 0_{1 \times 4} & \cos \delta_{0} & -\sin \delta_{0} & 0_{1 \times 13} \\
i_{\text {odac }} \cos \delta_{0}-i_{\text {oqac }} \sin \delta_{0} & 0_{1 \times 4} & \sin \delta_{0} & \cos \delta_{0} & 0_{1 \times 13}
\end{array}\right] \text {. }
$$

Combining (2.68)-(2.70), a complete small-signal model of an autonomous AC and DC hybrid distribution feeder is obtained:

$$
[\Delta \dot{x}]=\left[\begin{array}{lll}
\Delta \dot{x}_{\mathrm{ac}} & \Delta \dot{x}_{\mathrm{lk}} & \Delta \dot{x}_{\mathrm{dc}}
\end{array}\right]^{\top}=A_{\mathrm{f}}[\Delta x]
$$

where $A_{\mathrm{f}}$ is the coefficient matrix of the entire hybrid $\mathrm{AC}$ and $\mathrm{DC}$ distribution grids

$$
A_{\mathrm{f}}=\left[\begin{array}{ccc}
A_{\mathrm{ac}} & B_{\mathrm{ac} \_\mathrm{lk}} & 0 \\
B_{\mathrm{lk} \_\mathrm{ac} 1} & A_{\mathrm{lk}}+B_{\mathrm{lk} \_\mathrm{ac} 2}+B_{\mathrm{lk} \_\mathrm{dc} 2} & B_{\mathrm{lk} \_\mathrm{dc} 1} \\
0 & B_{\mathrm{dc} \_\mathrm{k}} & A_{\mathrm{dc}}
\end{array}\right] .
$$


Subtask 2.5 Develop the additional virtual impedance control loops in local inverter controllers to adjust the stability margin and enhance the stability of hybrid AC and DC grids.

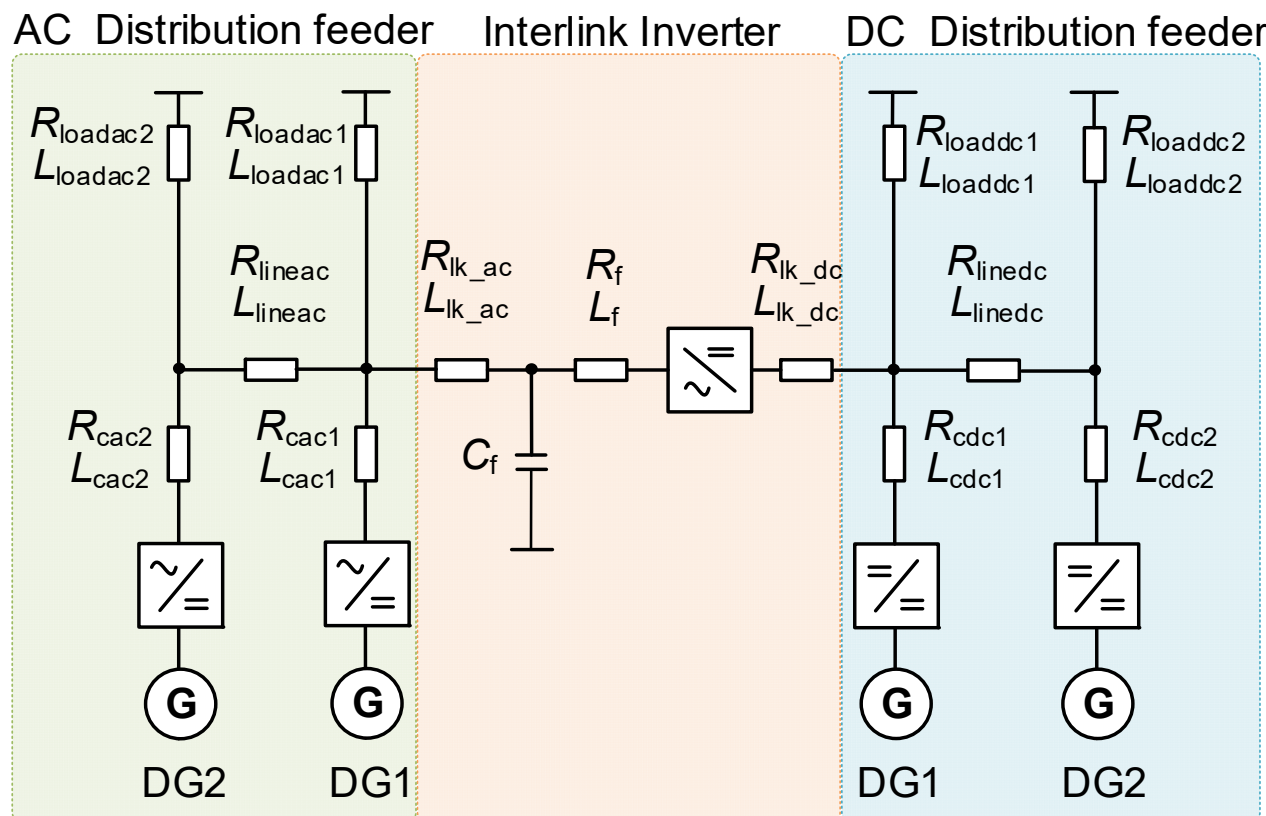

Fig. 2.2. A 10-bus test system.

Furthermore, based on the developed small-signal model in (2.71), a 10-bus test system of an autonomous and hybrid AC and DC distribution grids is shown in Fig. 2.2. In the meanwhile, Point A and B are selected as two examples, which indicate stable and unstable operation conditions, respectively. Their corresponding simulation test results in terms of operating conditions are shown in Fig. 2.3 and Fig. 2.4.

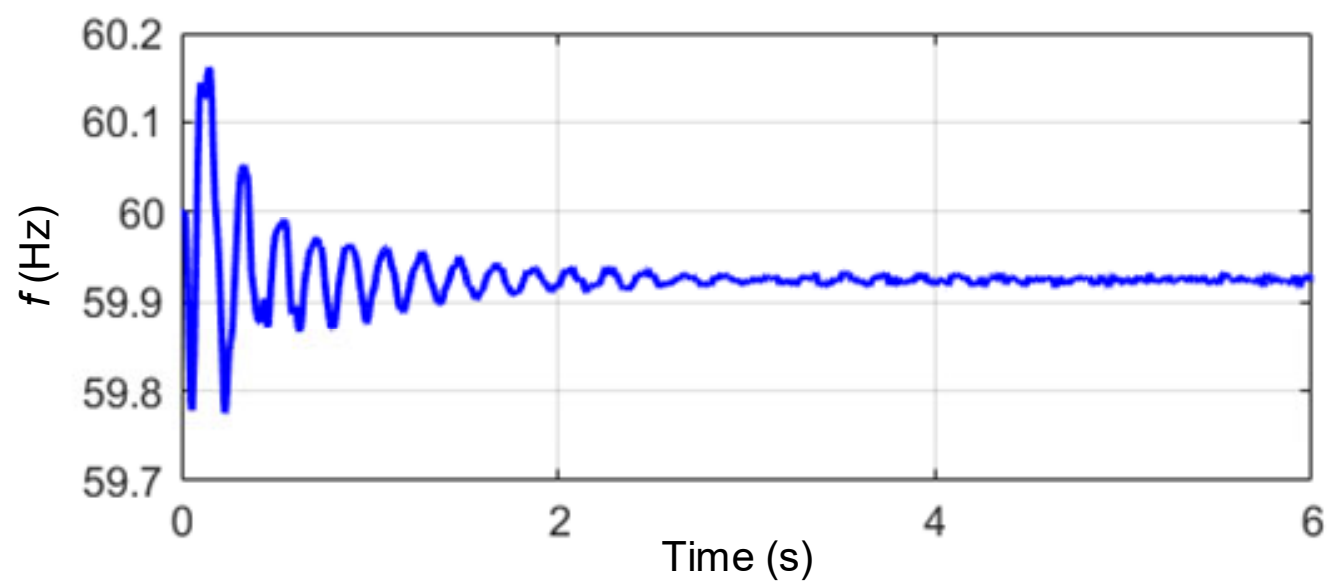

(a) 


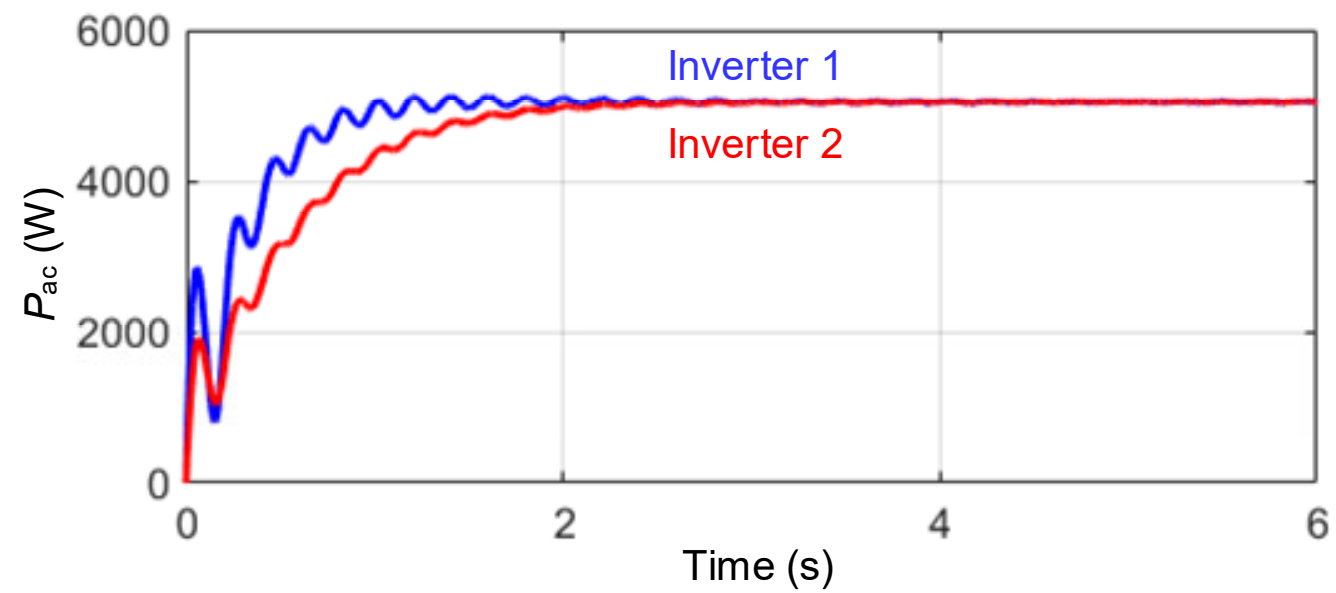

(b)

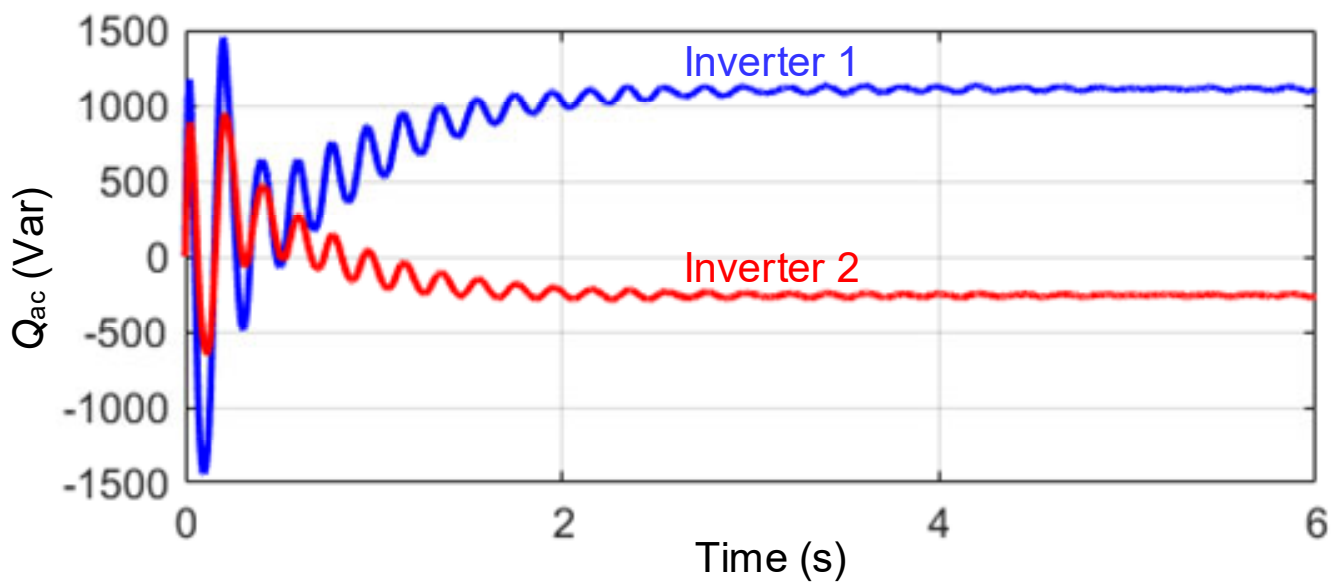

(c)

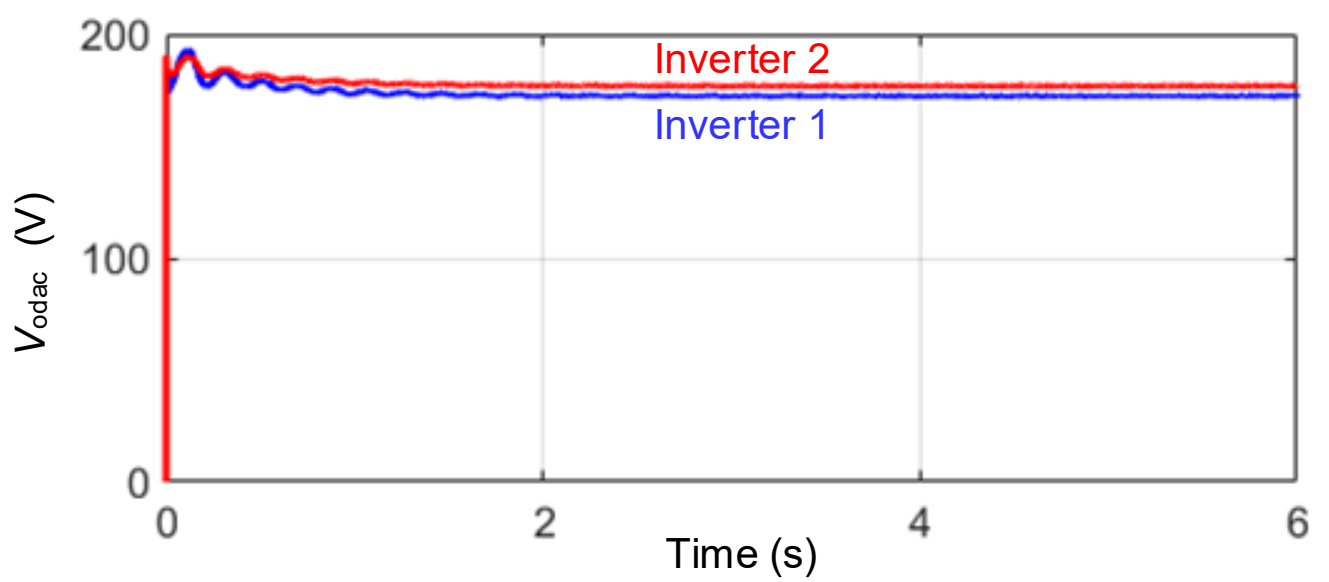

(d) 


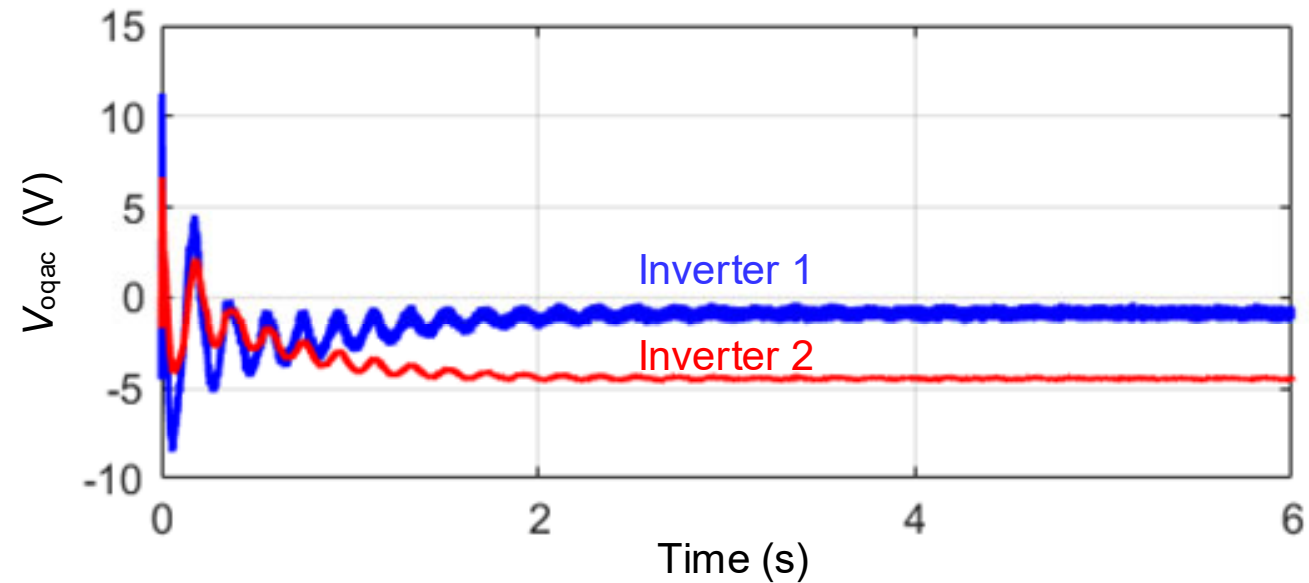

(e)

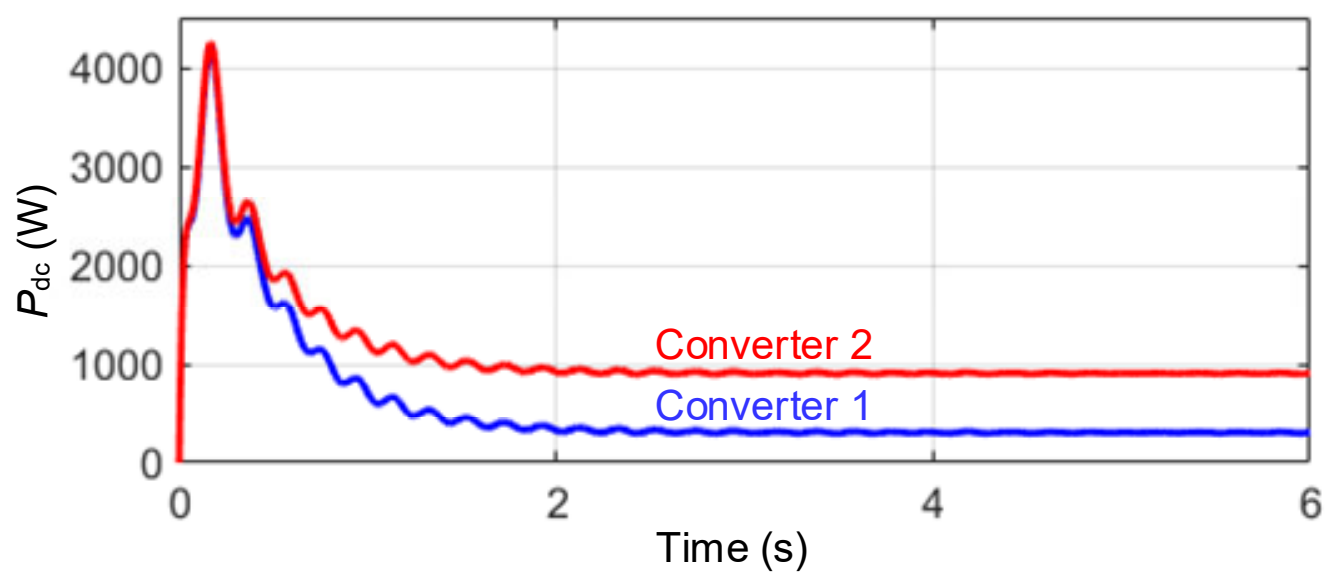

(f)

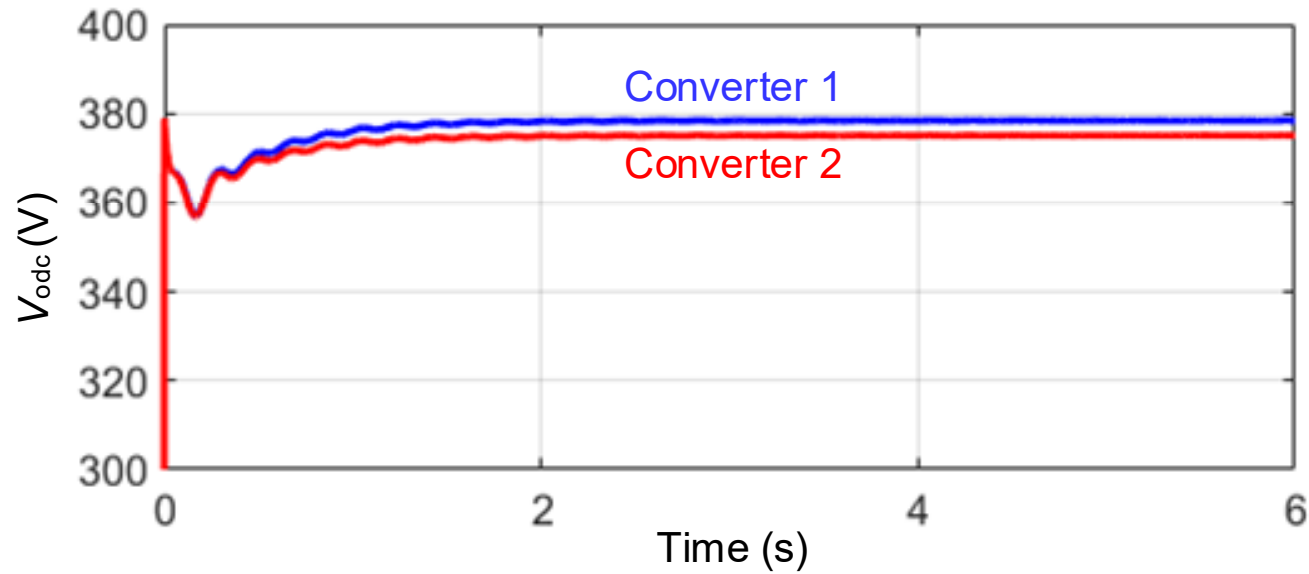

(g)

Fig. 2.3. Stable operation condition with system for operating Point A. 


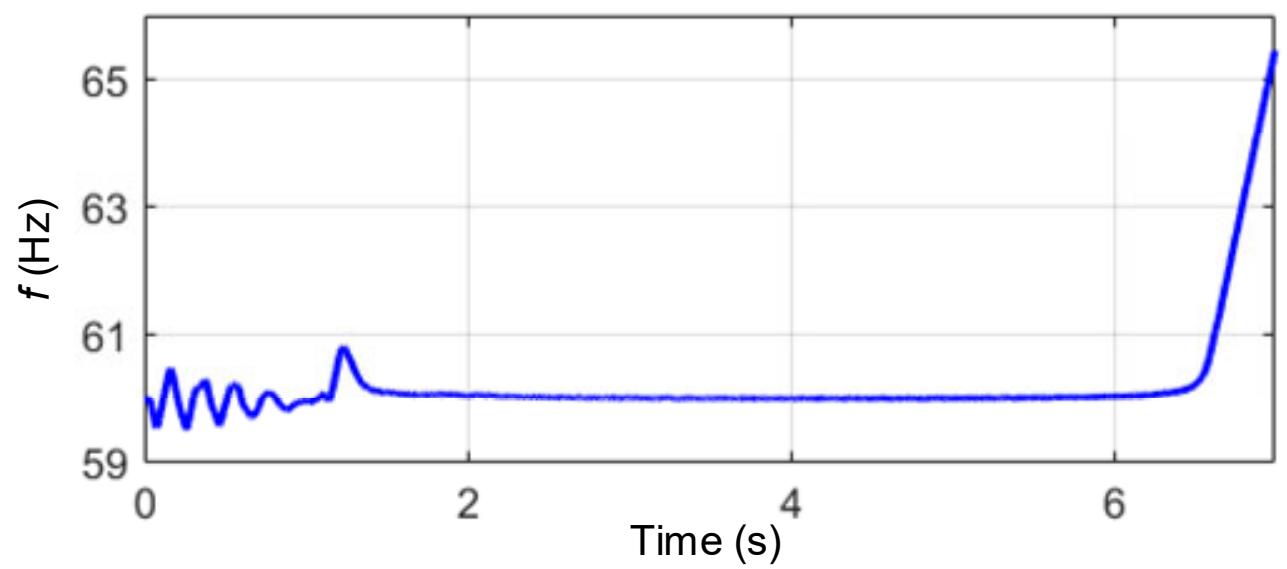

(a)

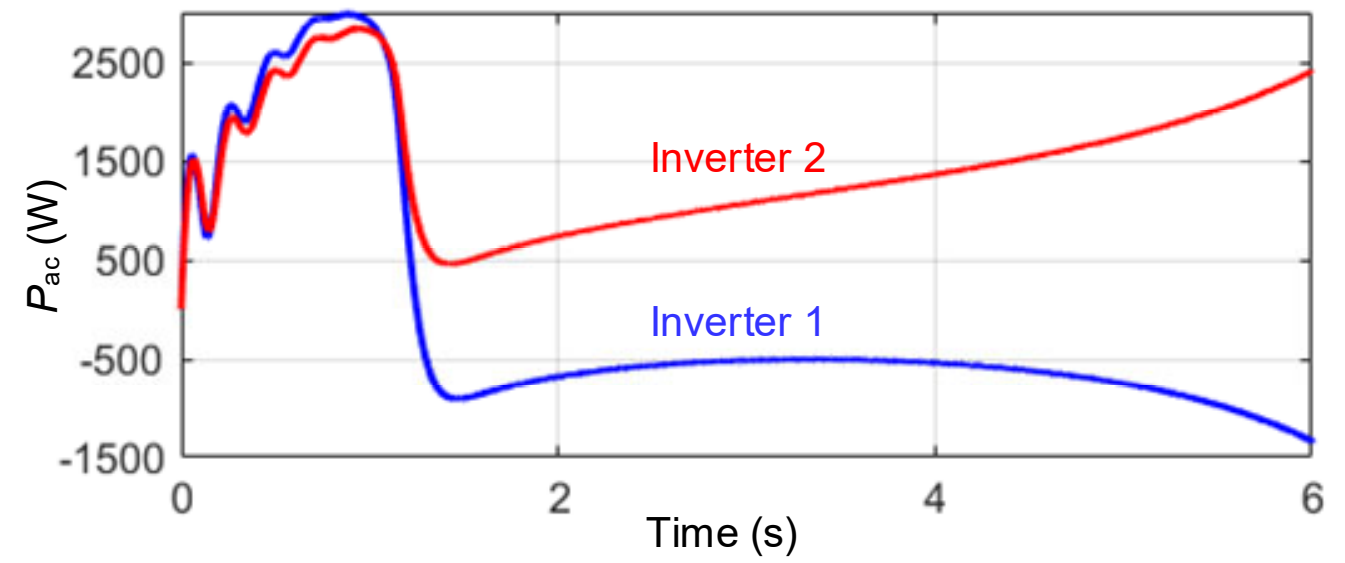

(b)

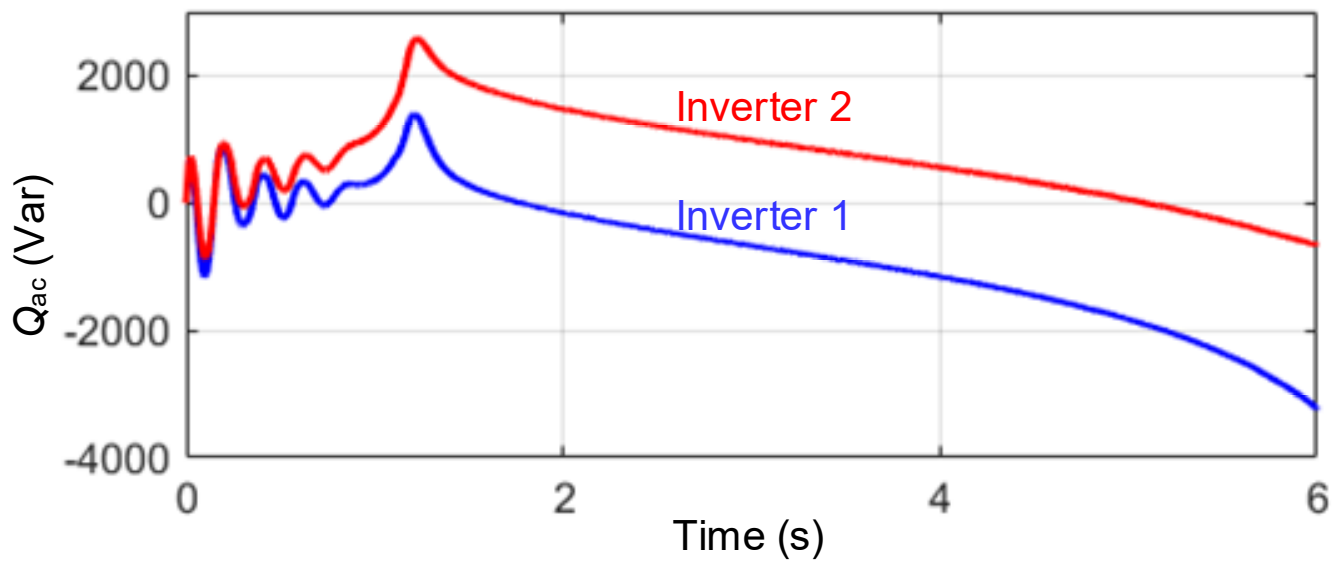

(c) 


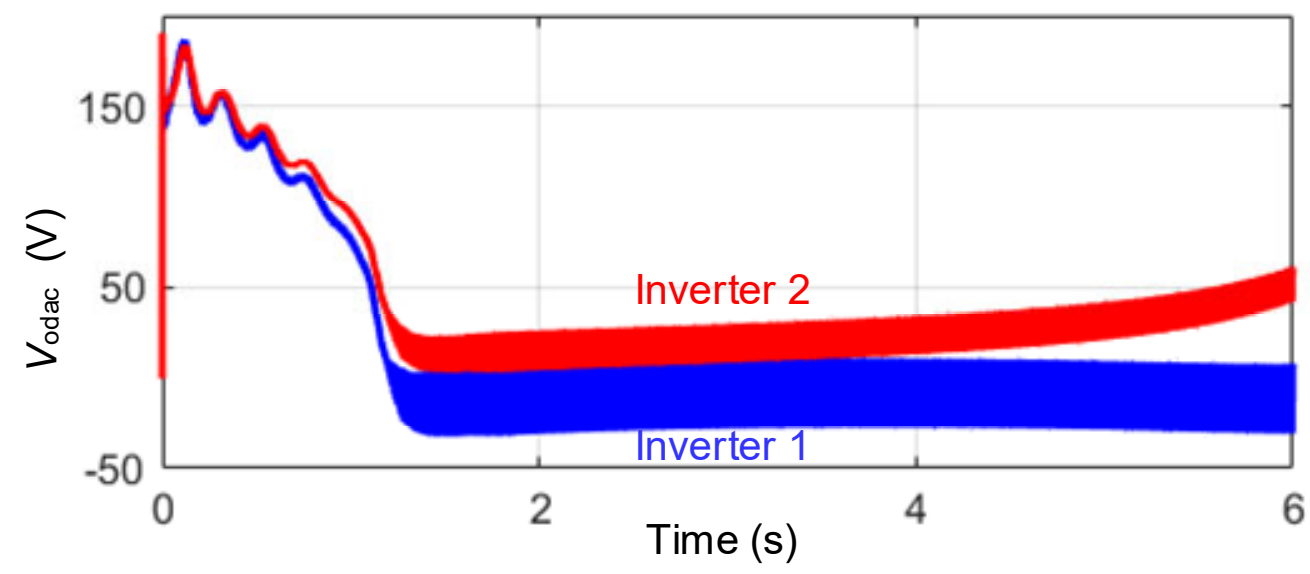

(d)

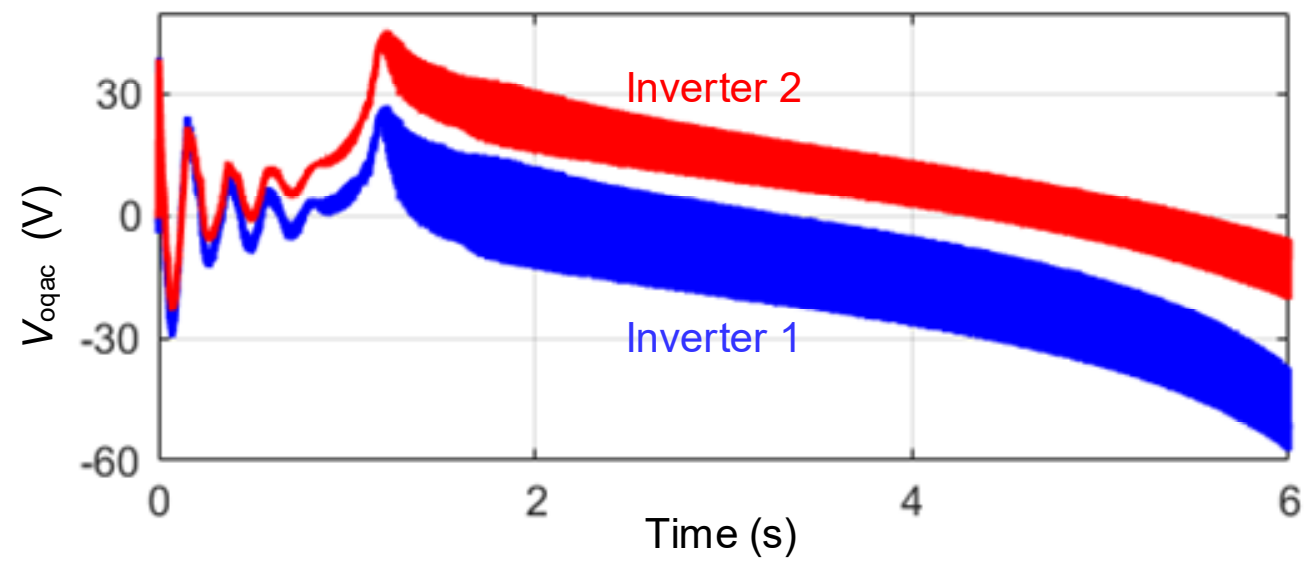

(e)

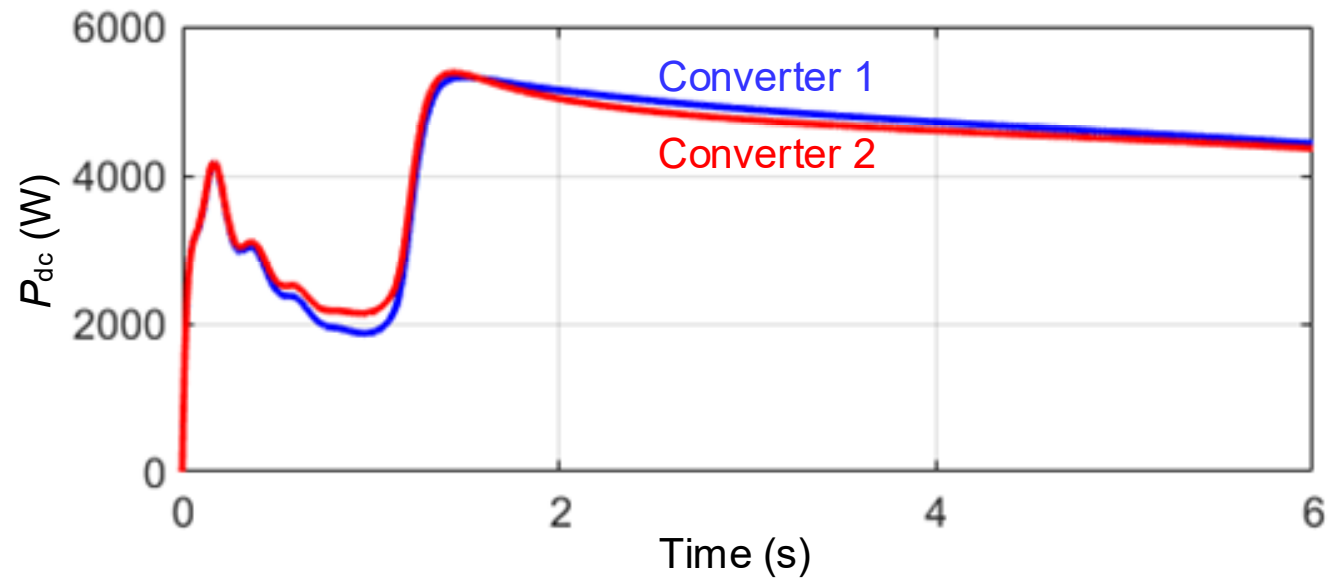

(f) 
$\mathrm{AC}$ and $\mathrm{DC}$ hybrid distribution grids with solar integration: architecture, stabilization and cost assessment

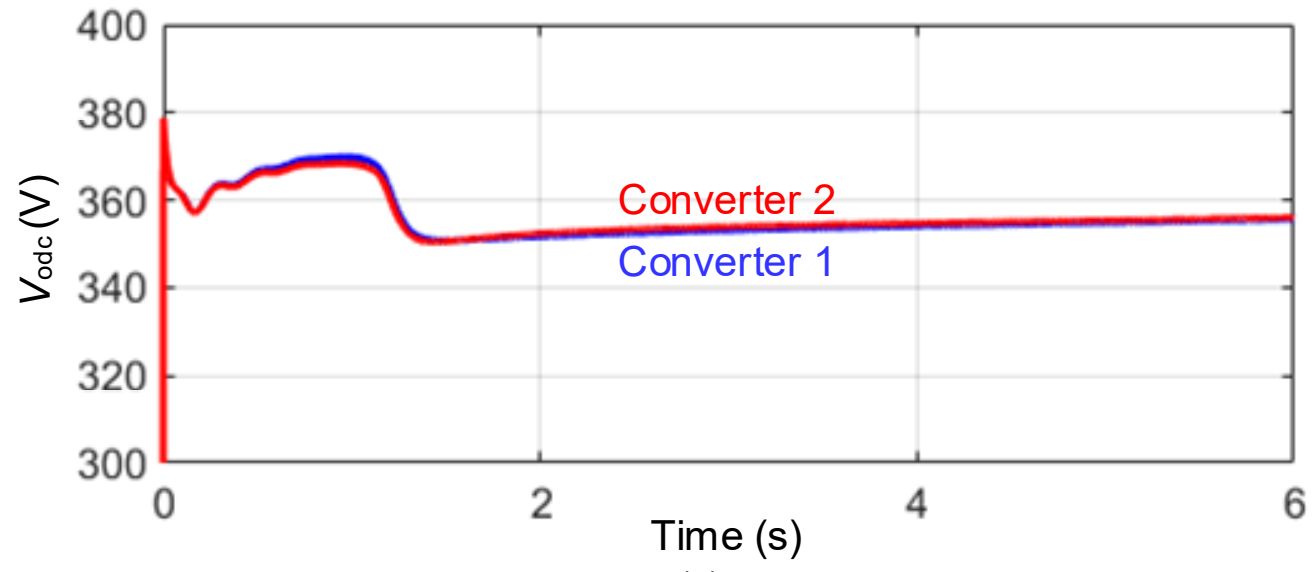

(g)

Fig. 2.4 Unstable operation condition with system for operating Point B. 


\section{Task 3 Develop the alpha-version cost and efficiency assessment tool in AC and DC distribution grids}

Subtask 3.1 Model and calculate the investment cost of hybrid AC and DC grids using the baseline system developed in Subtask 1.1.

Subtask 3.2 Formulate and calculate the operation and maintenance cost of hybrid AC and DC grids using the baseline system developed in Subtask 1.1.

In Subtasks 3.1 and 3.2, we modeled the investment cost, operation, and maintenance cost of the baseline system developed in Subtask 1.1 as a typical example of cost analysis. The component acquisition cost in the hybrid AC and DC grids is quantified along with the estimated initial installation cost. The operation and maintenance cost is estimated based available open to public references.

\subsubsection{Cost Library Build Up}

To build the cost model of the hybrid AC/DC grids, we started with building the component-level cost library based on the available public data set. Selective inverter and multiport inverter prices are concluded in Tables 3.1 and 3.2.

Table 3.1. Inverter Price Conversion (2017, USD) [30]

\begin{tabular}{|c|c|c|c|c|}
\hline Type & Sector (for PV) & USD/Wac & D/A Ratio & USD/Wdc \\
\hline Single-phase string inverter & Residential (non-MLPE) & 0.15 & 1.15 & 0.13 \\
\hline Microinverter & Residential (MLPE) & 4.0 & 1.15 & 0.34 \\
\hline DC power optimizer string inverter & Residential (MLPE) & 0.17 & 1.15 & 0.15 \\
\hline Three-phase string inverter & Commercial (non-MLPE) & 0.12 & 1.15 & 0.1 \\
\hline Central inverter & Utility-scale (fixed-tilt) & 0.08 & 1.3 & 0.06 \\
\hline Central inverter & Utilit-scale (1 axis tracker) & 0.08 & 1.3 & 0.06 \\
\hline
\end{tabular}

MLPE: module-level power electronics

Table 3.2. Multiport inverter price

\begin{tabular}{|c|l|l|l|}
\hline & Product Name & Size & Cost \\
\hline 1 & Ideal Power Stabiliti Multiport (AC/DC-DC) & $30 \mathrm{~kW}$ & $\$ 12,142.86$ \\
\hline 2 & Princeton Power Demand Response Inverter DRI-100 (4-Port) & $100 \mathrm{~kW}$ & $\$ 84,995$ \\
\hline 3 & Princeton Power Battery Integrated Inverter (3 Port) BIGI-250 & $250 \mathrm{~kW}$ & $\$ 118,000$ \\
\hline
\end{tabular}

Apart from inverter cost, we also collect the cost data for the whole PV system with inverter, battery systems; see Fig. 3.1. 


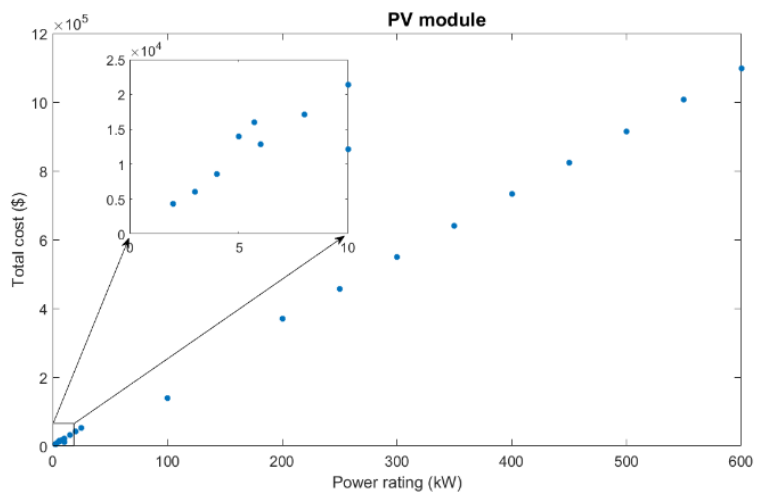

(a)

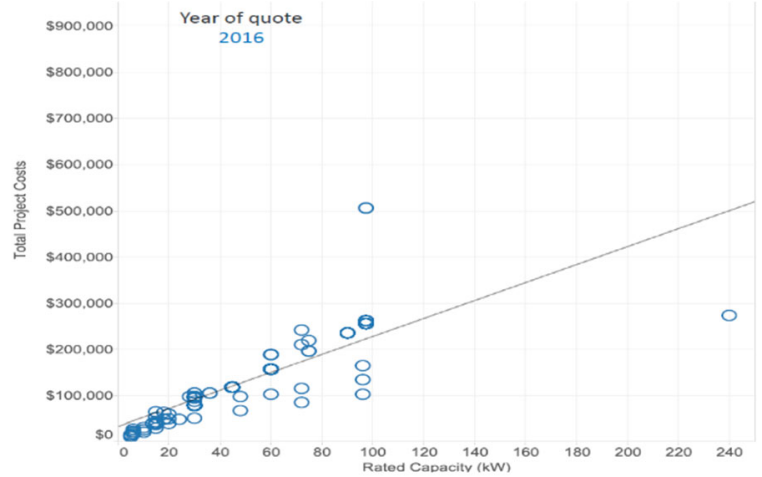

(b)

Fig. 3.1. Cost data for PV systems and battery systems [31]-[33]. (a) PV system; (b) Battery system [34]

\subsubsection{Cost and O\&M model}

Various cost models are considered in our alpha-version cost analysis tool for hybrid AC/DC grids. In this model, we have considered the system total capital cost $\mathrm{C}_{\text {cap }}$, the annualized total capital cost $C_{\text {cap,a, }}$, total annual O\&M costs $C_{O \& M, a}$, disposal and recycling costs $C_{D R}$, annualized life cycle cost $C_{L C C, a}$, and levelized cost of energy. The metrics and methodology of the alpha-version cost analysis tool are presented below.

- Total Capital Cost (TCC): TCC evaluates all costs that should be covered for the purchase, installation, and delivery of an EES unit, including costs of PCS, energy storage related costs, and balance of power (BOP) costs [35]. TCC can be calculated per unit of output power rating, presented as $\left(\mathrm{C}_{\mathrm{cap}}\right)$ in the following equation. While $C_{P C S}, C_{B O P}, C_{P V}$, and $C_{B a t}$ represent unitary costs of power conversion system (PCS), Balance of Plant (BOP), PV arrays, and battery ( $\$ / k W h)$, respectively, ' $h$ ' is the charging/discharging time [35].

$$
C_{c a p}=C_{P C S}+C_{B O P}+C_{P V}+C_{B a t} \times h
$$

where Balance of Plant (BOP) Cost - BOP includes costs for project engineering, grid connection interface and integration facilities (e.g. transformers), construction management including cost of land and accessibility, in addition to other services and assets required that are not included in the scope of PCS and storage related costs [35].

- Life Cycle Cost (LCC): LCC accommodates all the expenses related to fixed operation and maintenance (O\&M), variable O\&M, replacement, disposal, and recycling, in addition to TCC [35]. LCC can be presented in levelized annual costs (\$/kW-yr), which is the yearly payment that the operator should maintain for all services of the system, including repayment of the loan and upfront of the capital costs. LCC calculations can be performed, first, by annualized TCC $\left(C_{c a p}\right)$, presented by $\left(C_{c a p, a}\right)$ in Eq. (3.2). Based on the present value of money, the capital recovery factor $(C R F)$ is calculated by applying Eq. (3.3) [36], subject to the interest rate (i) during the lifetime (T) [35].

$$
C_{c a p, a}=T C C \times C R F
$$




$$
C R F=\frac{i(1+i)^{T}}{(1+i)^{T}-1}
$$

- Total Annual O\&M Costs (Co\&M,a) can be expressed by adding annualized costs of fixed O\&M $\left(C_{F O M, a}\right)$, and variable O\&M ( $\left.C_{V O M}\right)$ multiplied by yearly operating hours, as presented in Eq. (3.4).

$$
C_{O \& M, a}=C_{F O M, a}+C_{V O M} \times n \times h
$$

To accommodate the replacement costs for replaceable systems, e.g. batteries, the future cost of replacement $\left(C_{R}\right)$ in $\$ / \mathrm{kWh}$ and replacement period $(t)$ in years should be known. Annualized replacement costs $\left(C_{R, a}\right)$ can be calculated by using Eq. (3.5), given the number of replacements $(r)$ during the application lifetime [35], [37].

$$
C_{R, a}=C R F \times \sum_{k=1}^{r}(1+i)^{-k t} \times \frac{C_{R} \times h}{n_{\text {sys }}}
$$

- Disposal and Recycling Costs $\left(C_{D R}\right)$ are other cost items that are usually neglected in the LCC analysis of EES in the literature. Annualized disposal and recycling costs $\left(C_{D R, a}\right)$ can be calculated by applying interest rate $(i)$ and the lifetime of the plant $(T)$, as explained in Eq. (3.6).

$$
C_{D R, a}=C_{D R} \times \frac{i}{(1+i)^{T}-1}
$$

- Annualized LCC (ALCC) of the system is presented by $C_{L C C, a}$ in Eq. (3.7), which is determined by stacking the previously discussed cost items.

$$
C_{L C C, a}=C_{c a p, a}+C_{O \& M, a}+C_{R, a}+C_{D R, a}
$$

- Levelized Cost of Energy (LCOE) is the revenue for delivered energy needed to cover all Life-cycle fixed and variable costs, and provides the target rate of return based on financing assumptions and ownership types and it can be calculated as below [35], [38].

$$
L C O E=\frac{A L C C}{\text { yearly operating hours }}=\frac{C_{L L C, a}}{n \times h}
$$

\subsubsection{Cost analysis for AC/DC hybrid baseline system}

The total cost of the IEEE-34 bus system is evaluated in the following section. The total cost of the system comprises of, the cost of transformers, voltage regulators, capacitor banks, conductors and the dc-system connected at the secondary level. The costs of each component are obtained from the various sources available online to evaluate the overall cost of the system at different PV penetration levels. Here, the penetration level of the PV system is broadly classified into two categories (0-10 kW and 10-600 kW) at the secondary voltage level. It is to be noted that the total length of conductor in the IEEE34 bus system, including neutral, is $1031208 \mathrm{ft}$. 
$\mathrm{AC}$ and $\mathrm{DC}$ hybrid distribution grids with solar integration: architecture, stabilization and cost assessment

Table 3.3. System input data for $0-10 \mathrm{~kW}$ system

\begin{tabular}{|c|c|c|c|}
\hline Inputs & Notation & Value & Unit \\
\hline Cost of PV module & $\mathrm{C}_{\mathrm{PVm}}$ & 2700 & $\$ / \mathrm{kW}$ \\
\hline Cost of Power Converter & $\mathrm{C}_{\mathrm{PVC}}$ & 120 & $\$ / \mathrm{kW}$ \\
\hline Cost of Battery & $\mathrm{C}_{\text {Bat }}$ & 1200 & $\$ / \mathrm{kWh}$ \\
\hline Cost of Battery Converter & $\mathrm{C}_{\text {Bat,C}}$ & 140 & $\$ / \mathrm{kW}$ \\
\hline Fixed operational \& maintenance costs PV & Co\&M,PV & 11.5 & $\$ / k W-y r$ \\
\hline Fixed operational \& maintenance costs Battery & Co\&m,Bat & 13.2 & $\$ / \mathrm{kWh}$ \\
\hline Variable operational \& maintenance costs & Cvom & 0.0015 & $\$ / \mathrm{kWh}$ \\
\hline Replacement Costs Battery & $\mathrm{C}_{\text {Bat }}$ & 1200 & $\$ / \mathrm{kWh}$ \\
\hline Discharge Time & $\mathrm{h}$ & 4 & $\mathrm{hr}$ \\
\hline Interest Rate & $\mathrm{i}$ & 5 & $\%$ \\
\hline No. of discharge cycles per year & $\mathrm{n}$ & 300 & $\#$ \\
\hline Lifetime & $T$ & 10 & $\mathrm{yr}$ \\
\hline Replacement Period of Battery & $\mathrm{t}$ & 10 & $\mathrm{yr}$ \\
\hline No. of replacements & $r$ & 1 & \# \\
\hline Cost Transformer 1,1000 kVA & Cxformer1 & 77898 & per unit \\
\hline Cost Transformer 2, 2500 kVA & CXformer2 & 86198 & per unit \\
\hline Efficiency of transformer & $\eta$ & 98 & $\%$ \\
\hline Period of use transformer & $T_{\text {xformer }}$ & 20 & $\mathrm{yr}$ \\
\hline Cost Capacitor, 100 kVAr & $\mathrm{C}_{\mathrm{c} 1}$ & 2000 & per unit \\
\hline Cost Capacitor, 150 kVAr & $\mathrm{C}_{\mathrm{C} 2}$ & 2500 & per unit \\
\hline Cost Voltage Regulator & $\mathrm{C}_{\mathrm{VR}}$ & 1600 & per unit \\
\hline Cost Line Conductor & $\mathrm{C}_{\text {line }}$ & 0.2 & $\$ / f t$ \\
\hline
\end{tabular}

The cost of the fixed components in the AC sector is $\$ 387,037.6$, includes the cost of transformers, capacitors, voltage regulators, and feeders. The cost of the DC sector for the $0-10 \mathrm{~kW}$ system is shown in Table 3.4, including the PV module, battery, and power conversion part.

Table 3.4. Life Cycle Cost Calculation for 0-10 kW System

\begin{tabular}{|l|l|l|l|}
\hline Total Capital Cost (DC sector) & $\mathrm{C}_{\text {cap }}$ & 7760 & $\$ / \mathrm{kW}$ \\
\hline Annualized Total Capital Cost & $\mathrm{C}_{\mathrm{cap}, \mathrm{a}}$ & 1005.0 & $\$ / \mathrm{kW}-\mathrm{yr}$ \\
\hline Total Annual O\&M Costs & $\mathrm{C}_{\mathrm{O} \& \mathrm{M}, \mathrm{a}}$ & 26.5 & $\$ / \mathrm{kW}-\mathrm{yr}$ \\
\hline Annualized Replacement Costs & $\mathrm{C}_{\mathrm{R}, \mathrm{a}}$ & 381.6 & $\$ / \mathrm{kW}-\mathrm{yr}$ \\
\hline Annualized Life Cycle Cost & $\mathrm{C}_{\mathrm{LCC}, \mathrm{a}}$ & 1413.1 & $\$ / \mathrm{kW}-\mathrm{yr}$ \\
\hline
\end{tabular}


$A C$ and DC hybrid distribution grids with solar integration: architecture, stabilization and cost assessment

Table 3.5. System Input Data for 10-600 kW System

\begin{tabular}{|c|c|c|c|}
\hline Inputs & Notation & Value & Unit \\
\hline Cost of PV module & $\mathrm{CPVm}_{\mathrm{P}}$ & 1830 & $\$ / \mathrm{kW}$ \\
\hline Cost of Power Converter & $\mathrm{CPVC}_{\mathrm{P}}$ & 80 & $\$ / \mathrm{kW}$ \\
\hline Cost of Battery & $\mathrm{C}_{\text {Bat }}$ & 700 & $\$ / k W h$ \\
\hline Cost of Battery Converter & $\mathrm{C}_{\text {Bat,C }}$ & 100 & $\$ / k W$ \\
\hline Fixed operational \& maintenance costs PV & Co\&m,PV & 11.5 & $\$ / k W-y r$ \\
\hline Fixed operational \& maintenance costs Battery & Co\&m,Bat & 13.2 & $\$ / k W h$ \\
\hline Variable operational \& maintenance costs & $\mathrm{C}_{\text {Vom }}$ & 0.0015 & $\$ / k W h$ \\
\hline Replacement Costs Battery & $\mathrm{C}_{\text {Bat }}$ & 700 & $\$ / k W h$ \\
\hline Discharge Time & $\mathrm{h}$ & 4 & $\mathrm{hr}$ \\
\hline Interest Rate & $\mathrm{i}$ & 5 & $\%$ \\
\hline No. of discharge cycles per year & $n$ & 300 & $\#$ \\
\hline Lifetime & $\mathrm{T}$ & 10 & $\mathrm{yr}$ \\
\hline Replacement Period of Battery & $\mathrm{t}$ & 10 & $\mathrm{yr}$ \\
\hline No. of replacements & $r$ & 1 & \# \\
\hline Cost Transformer 1, 1000 kVA & Cxformer1 & 77898 & per unit \\
\hline Cost Transformer 2, 2500 kVA & Cxformer2 & 86198 & per unit \\
\hline Efficiency of transformer & $\eta$ & 98 & $\%$ \\
\hline Period of use transformer & $T_{\text {xformer }}$ & 20 & $\mathrm{yr}$ \\
\hline Cost Capacitor, $100 \mathrm{kVAr}$ & $\mathrm{C}_{\mathrm{c} 1}$ & 2000 & per unit \\
\hline Cost Capacitor, 150 kVAr & $\mathrm{C}_{\mathrm{c} 2}$ & 2500 & per unit \\
\hline Cost Voltage Regulator & $\mathrm{C}_{\mathrm{VR}}$ & 1600 & per unit \\
\hline Cost Line Conductor & $\mathrm{C}_{\text {line }}$ & 0.2 & $\$ / \mathrm{ft}$ \\
\hline
\end{tabular}

The cost of the fixed components in the AC sector is also $\$ 387,037.6$, includes the cost of transformers, capacitors, voltage regulators, and feeders. The cost of the DC sector for the 10-600 kW system is shown in Table 3.6.

Table 3.6. Life Cycle Cost Calculation for 10-600 kW System

\begin{tabular}{|c|c|c|c|}
\hline Total Capital Cost (DC sector) & $C_{c a p}$ & 4810 & $\$ / \mathrm{kW}$ \\
\hline Annualized Total Capital Cost & $\mathrm{C}_{\mathrm{cap}, \mathrm{a}}$ & 622.9 & $\$ / \mathrm{kW}-\mathrm{yr}$ \\
\hline Total Annual O\&M Costs & $\mathrm{C}_{\mathrm{O} \& \mathrm{M}, \mathrm{a}}$ & 26.5 & $\$ / \mathrm{kW}-\mathrm{yr}$ \\
\hline Annualized Replacement Costs & $\mathrm{C}_{\mathrm{R}, \mathrm{a}}$ & 222.6 & $\$ / \mathrm{kW}-\mathrm{yr}$ \\
\hline Annualized Life Cycle Cost & $\mathrm{C}_{\llcorner\mathrm{CC}, \mathrm{a}}$ & 872.0 & $\$ / \mathrm{kW}-\mathrm{yr}$ \\
\hline
\end{tabular}


Subtask 3.3 Calculate the energy conversion efficiency from operation simulation using the baseline system.

This subtask contains the simulation work of energy conversion efficiency when having the baseline system under operation in the simulation environment. The energy conversion efficiency is for the entire hybrid $\mathrm{AC}$ and $\mathrm{DC}$ system considering the input and output energy under simulation.

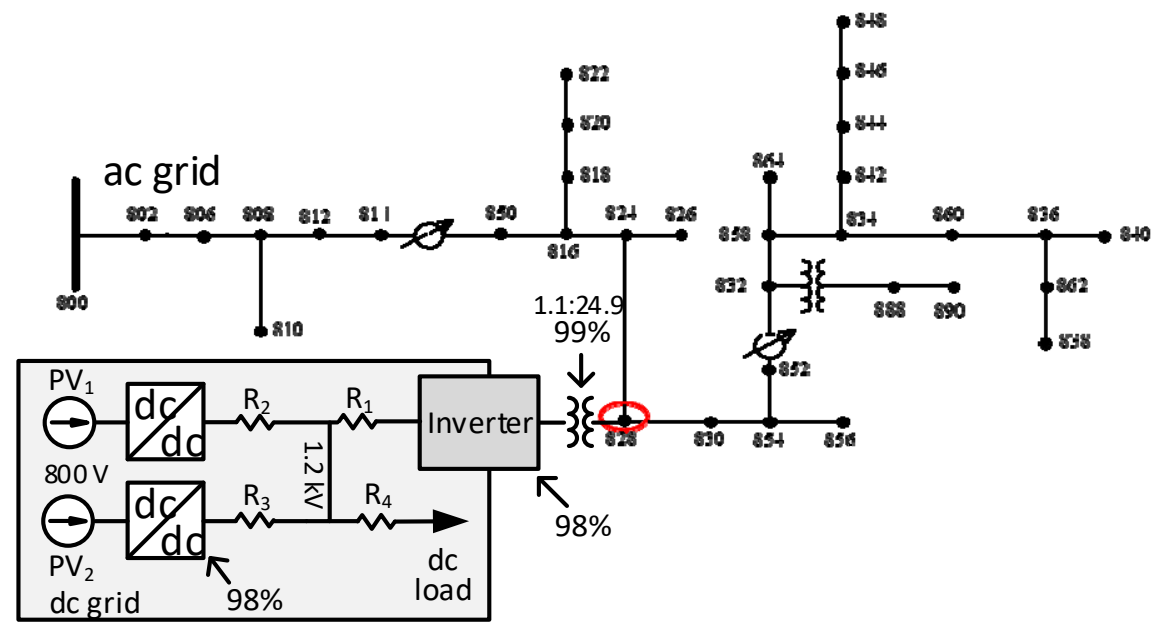

Fig. 3.2. Baseline model of $A C / D C$ hybrid distribution system.

Based on the test system in Subtask 1.1 built in the previous period, the AC/DC hybrid system model has been developed in the Matlab environment with OpenDSS API. The developed model can be used for system-level evaluation purposes; see Fig. 3.2. In the baseline system, we consider the maximum PV output is $1200 \mathrm{~kW}$ and the DC load inside the DC grid is $600 \mathrm{~kW}$. Hence, the DC grid active output power can be adjusted from - $600 \mathrm{~kW}$ to $600 \mathrm{~kW}$. In addition, the converter efficiencies have been considered in the DC grid model. The detailed system parameters are shown in Table 3.7.

Table 3.7. System Parameters of Baseline Hybrid System

\begin{tabular}{|c|c|c|c|}
\hline Parameter & Value & Parameter & Value \\
\hline Voltage of AC microgrid & $24.9 \mathrm{kV}$ & PV converter $\eta$ & $98 \%$ \\
\hline Voltage of DC microgrid & $1.2 \mathrm{kV}$ & Solar panel voltage & $800 \mathrm{~V}$ \\
\hline Stepdown transformer ratio & $24.9 \mathrm{kV}: 0.69 \mathrm{kV}$ & Maximum Solar capacity & $600 \mathrm{~kW}$ each \\
\hline Stepdown transformer $\eta$ & $99 \%$ & Total DC Load $P_{d c, L}$ & $600 \mathrm{~kW}$ \\
\hline Grid-connected inverter $\eta$ & $98 \%$ & Total AC load & $\mathrm{P}=1.8 \mathrm{MW}, \mathrm{Q}=0.29 \mathrm{MVar}$ \\
\hline
\end{tabular}

In this subtask, we first analyze the peak efficiency of the baseline system with updated system parameters. Under this condition, we assume power devices are running at its rated efficiency (highest). Both full loading and half loading conditions are studied by simulations. According to the simulation results shown in Fig. 3.3. The system overall loss is reduced when the PV penetration increases. The reducing rate of the system loss is 
decreasing when the PV output approaches to $1200 \mathrm{~kW}$. When the loading rate is $50 \%$, the system overall efficiency first increases and then reduces. The peak efficiency of the $50 \%$ loaded hybrid system is $91.5 \%$ when the PV output is $632 \mathrm{~kW}$. The peak efficiency analysis of the system ignores the fact that the conversion efficiency of the power device is a function of converted power.

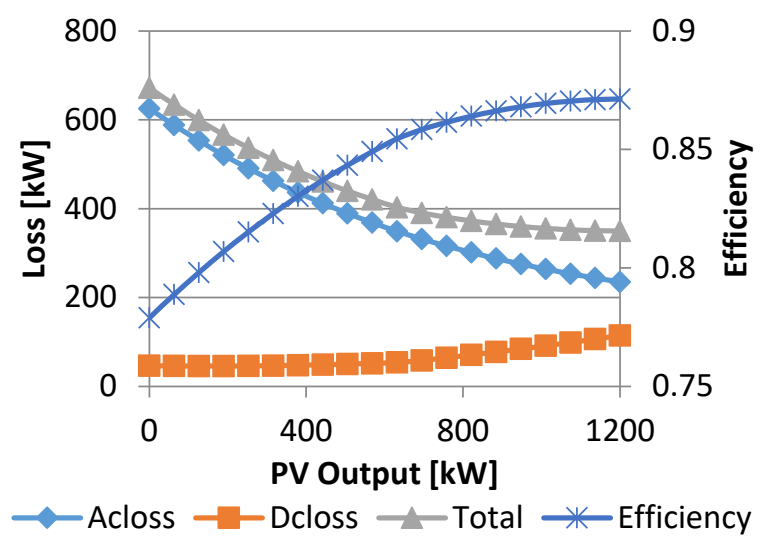

(a)

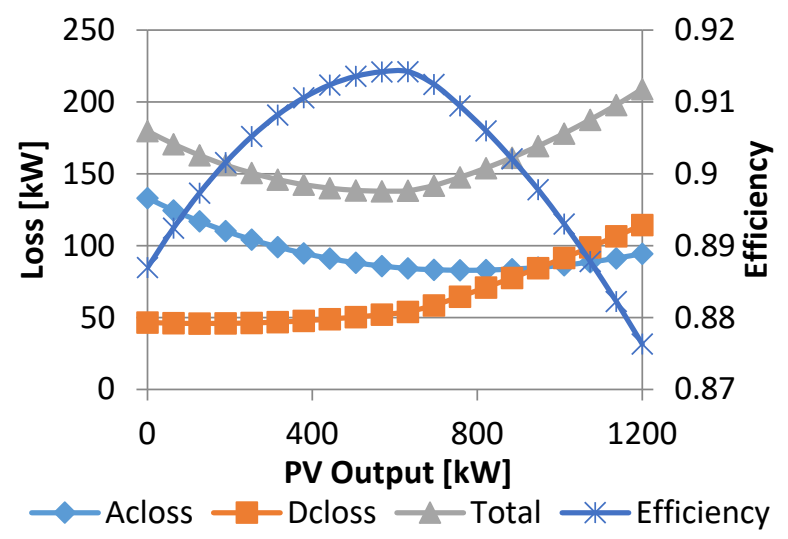

(b)

Fig. 3.3. Peak efficiency analysis of the baseline system: (a) $100 \%$ loading condition; (b) $50 \%$ loading

By considering the nonlinear relationship between the device loading with its efficiency, the converter efficiency model can be obtained by using the polynomial based regression method, as shown in Fig. 3.4.

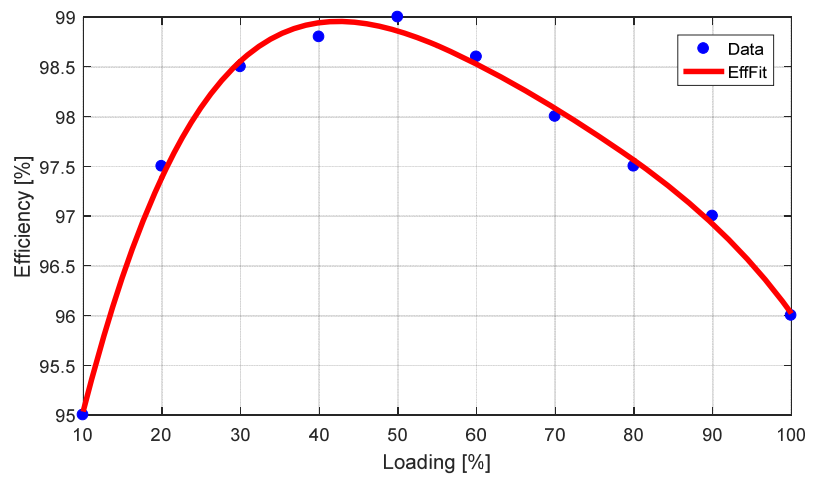

Fig. 3.4. Power converter efficiency curve.

After integrating the converter efficiency model into the Matlab - OpenDSS analysis platform, the simulation results for a fully loaded hybrid system and a half-loaded hybrid system can be found in Fig. 3.5.

With the consideration of the realistic converter efficiency model, the system efficiency curve has been changed in both $100 \%$ loading and $50 \%$ loading condition. The system overall efficiency stops increasing when the PV output reaches to $690 \mathrm{~kW}$ under $100 \%$ loading condition. Meanwhile, the system overall efficiency under $50 \%$ loading condition experiences a slower increase when the PV output changes from 0 to $632 \mathrm{~kW}$. 


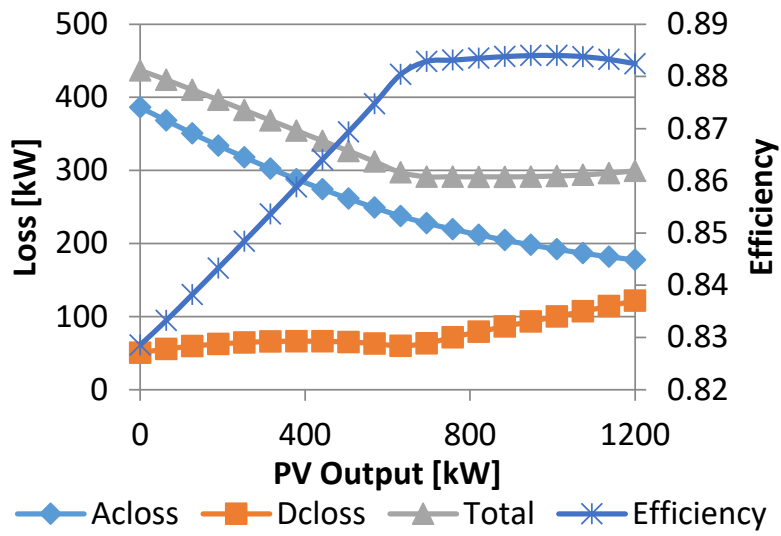

(a)

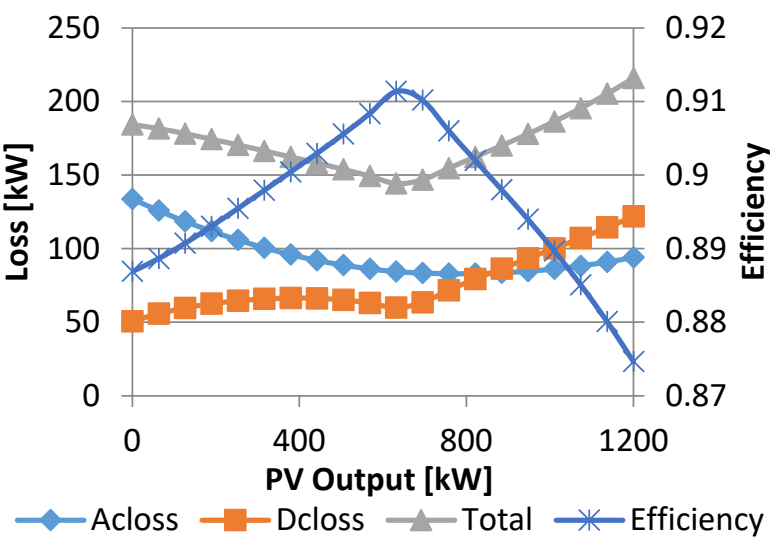

(b)

Fig. 3.5. Power variant efficiency analysis of the baseline system: (a) $100 \%$ loading condition; (b) $50 \%$ loading condition.

According to the simulation study in this subtask, the optimal PV penetration at bus 828 considering the system efficiency is $632 \mathrm{~kW}$. Besides, a detailed efficiency model of the hybrid system has a significant impact on the system-level loss analysis.

Subtask 3.4 Develop the test cases with different load and source power allocation between AC and DC sub-sections, and identify the costs (both investment and operation costs) and energy conversion efficiency in each individual case.

Subtask 3.5 Identify the impacts of multiport converters (developed in Task 1) and impedance-based stabilization approach (developed in Task 2) on cost and efficiency analysis results.

In these two subtasks, we developed representative test cases with respect to load and source power allocation between AC and DC sub-sections, which will be more comprehensive to cover various conditions in addition to the baseline case. Cost and energy conversion efficiency will be calculated using the model and method developed in Subtask 3.1 to 3.3 for all of these test cases. The sensitivity analysis and impact analysis of the multiport converter with respect to its influence on the energy conversion efficiency was also performed during these two subtasks.

During these two tasks, we have developed both ac and dc subsection models utilizing the IEEE 34 bus system. The corresponding alpha version computational tool for calculating the power flow of the hybrid distribution system is also developed. The system one-line diagrams of the system with $\mathrm{AC}$ and DC subsections are shown in Fig. 3.6.

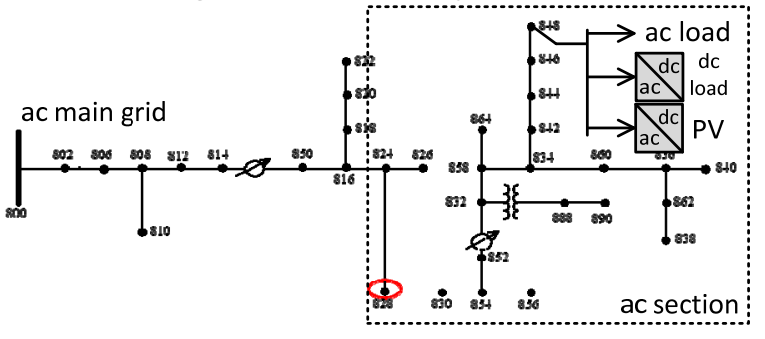

(a)

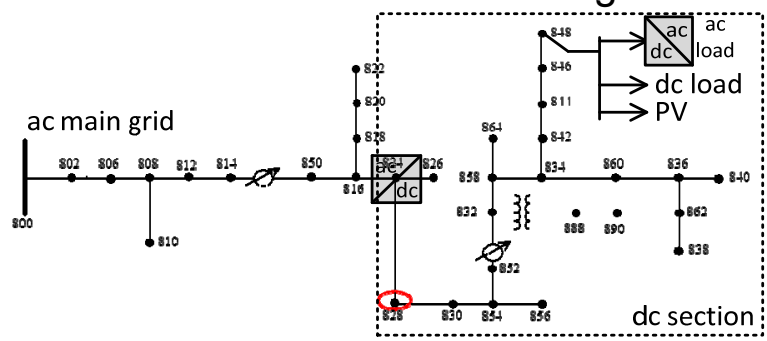

(b)

Fig. 3.6. Distribution systems with ac and dc subsections. 
For comparison purposes, we assume the lines costs for both $A C$ section and DC section are the same. The inverter cost only depends on the power capacity, and the cost does not depend on the power flow directions. Two systems have identical loads, and the PV systems are installed on each bus.

\subsubsection{Cost Analysis}

Based on the develop methodology in Subtasks 3.1 and 3.2, the capital cost and the corresponding O\&M cost for both pure AC system and hybrid AC/DC system are computed and plotted in Fig. 3.7. In this study, we consider the DC load ratio is fixed at $50 \%$ and the PV penetration level changes from $10 \%$ to $100 \%$ (w.r.t. the load in the subsections). According to the cost computation results, the capital investment for both pure AC system and hybrid AC/DC is close. When PV penetration level below $35 \%$, the capital investment cost of the pure AC system is lower than hybrid AC/DC. When PV penetration level higher than $35 \%$, the capital investment cost of the hybrid AC/DC system is lower than pure AC system. For the alpha-version cost analysis tool, the O\&M cost for both systems are identical with each other.

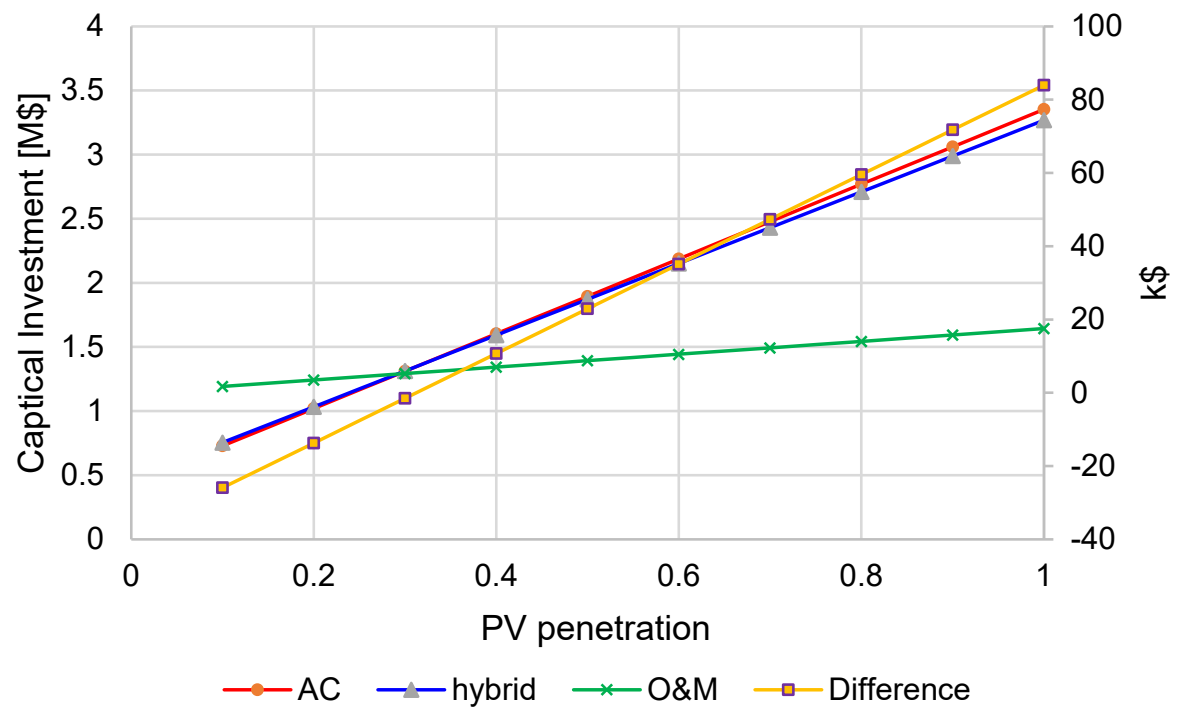

Fig. 3.7. Cost analysis for hybrid AC/DC and pure AC system with O\&M cost.

According to the cost analysis result shown in Fig. 3.7, we found that the cost of the system is very sensitive to the inverter model. We further improve the inverter cost model in this study. One model is used for the quantification of the relationship between power capacity and price. The second model is used for extracting the price trend based on the development of the power electronics technique.

The mathematical power capacity and price model is developed in this period is

$$
C_{I n v}\left(P_{I n v}\right)=a\left(P_{I n v}+b\right)^{0.8}+c
$$

where parameters $a, b$, and $c$ are curve fitting results and can be obtained by using our cost library data developed in the previous tasks; $C_{I n v}$ is the cost of an inverter, $P_{I n v}$ is the power capacity of a inverter. 
The proposed price model has several advantages comparing with other models. First, the proposed price model always returns a positive price. Second, the proposed price model is a sublinear function which is numerical stable. Third, the proposed price model is not sensitive to unbalanced data and will not stop growing. A numerical comparison between different price modes is shown in Fig. 3.8.

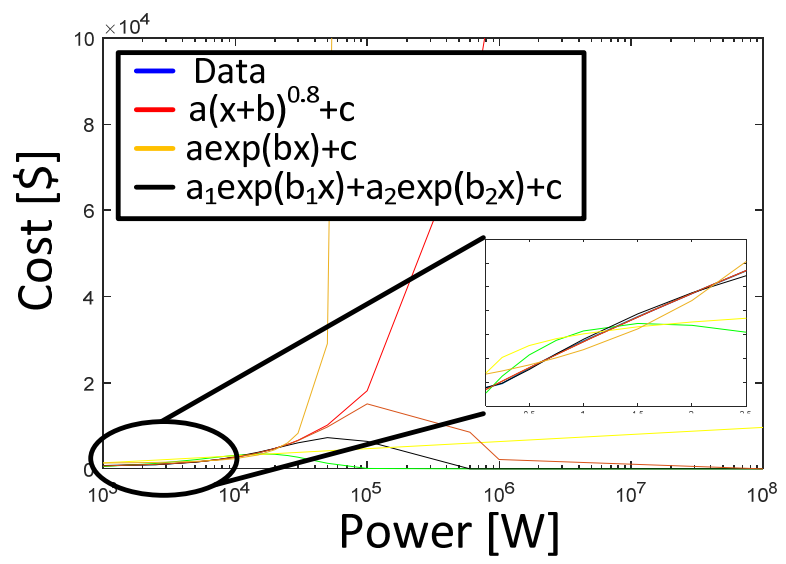

Fig. 3.8. Price model extraction using incomplete data set.

Similarly, the mathematical model for price trend v.s. year is

$$
F_{\text {Inv }}\left(Y_{\text {Inv }}\right)=a \exp \left(b Y_{\text {Inv }}\right)+c
$$

where $F_{I n v}$ is the cost factor of an inverter, $Y_{I n v}$ is the under-investigated year.

According to the price models and the distribution system models, the price comparison without considering the system physical performance is presented in Fig. 3.9.

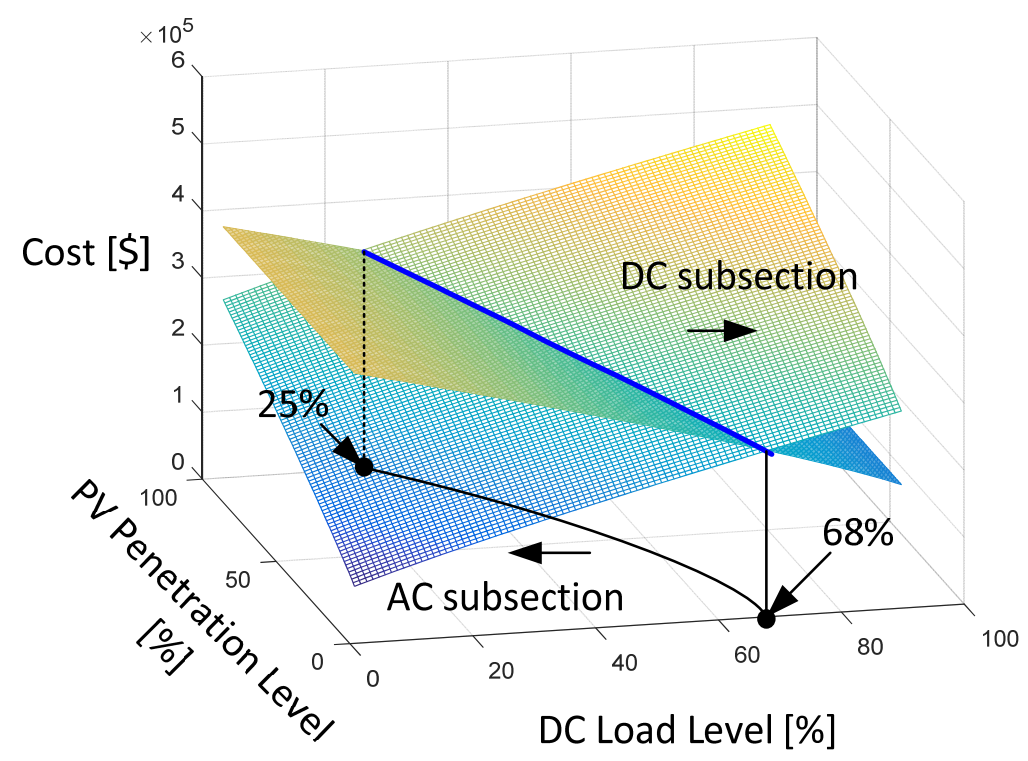

Fig. 3.9. Cost comparison for ac and dc sections considering PV penetration and dc load growth.

Intuitively, the cost of the system with dc section goes down when the PV penetration increases or the DC load level increases. The PV penetration plays a dominant role in 
cost reduction. The cost of the system with $\mathrm{AC}$ section goes up when the PV penetration increases or the DC load level increases. The importance of PV penetration level and DC load level are similar.

According to the cost analysis results shown in Fig. 3.9, we can conclude:

- DC subsection has no advantage in the investment cost for distribution systems when the loads are purely ac load under $0-100 \%$ PV penetration.

- When DC load is presented, the investment cost of the DC subsection is lower than AC subsection when PV penetration level is high, and certain amount dc load exists.

In addition, we extend the dc load with additional battery systems and perform the costbenefit analysis for different distribution systems. Especially, the impact of different battery operating policies on the annualized cost is investigated. A battery degradation model is applied with rainflow counting algorithm is applied to estimate the life of the battery [39]. Figure 3.10 presents the net present O\&M and replacement cost over time when the PV penetration level equals $80 \%$. The discount factor is also presented in this figure. The maximum depth of discharge (DOD) allowed is $80 \%, 70 \%$ and $60 \%$ in cases (a), (b) and (c), respectively. As shown in Fig. 3.10(a), the replacement of the battery is needed starting at year 6 when DOD is $80 \%$. When DOD is restricted to $70 \%$ and $60 \%$, the first replacement can be postponed to years 7 and 8 . Due to the increase in capital cost, the annualized cost does not decrease, even though the replacement cost is reduced. However, this does not indicate that it is not cost-effective to oversize the storage system. The higher the capacity is maintained, the larger reliability and resilience value is. For instance, if the SOC of the storage system is kept in a range between $40 \%$ and $90 \%$, the storage system can discharge $40 \%$ of its capacity to serve the load when a power outage occurs. It would be expected to serve more load when the SOC range is $10 \%$ to $90 \%$. Thus, the further detailed analysis would be necessary to evaluate the comprehensive benefits of different sizing strategies. The nominal, discounted (net present), and the annualized cost of the system with $80 \%$ PV penetration under different cycling constraints are listed in Table 3.8.

Table 3.8 Cost Analysis Result Considering Different Penetration Level

\begin{tabular}{|c|c|c|c|}
\hline PV Penetration & Nominal Cost [\$] & Discounted Cost [\$] & Annualized Cost [\$] \\
\hline $10 \%$ & $1,262,279$ & 975,579 & 70,875 \\
\hline $20 \%$ & $1,775,183$ & $1,433,961$ & 104,176 \\
\hline $30 \%$ & $2,288,087$ & $1,892,342$ & 137,476 \\
\hline $40 \%$ & $2,800,991$ & $2,650,724$ & 170,777 \\
\hline $50 \%$ & $3,313,895$ & $2,809,105$ & 204,078 \\
\hline $60 \%$ & $3,826,799$ & $3,267,486$ & 237,379 \\
\hline $70 \%$ & $4,339,703$ & $3,725,868$ & 270,680 \\
\hline $80 \%$ & $4,852,607$ & $4,184,249$ & 303,981 \\
\hline $90 \%$ & $5,365,511$ & $4,642,631$ & 337,282 \\
\hline $100 \%$ & $5,878,415$ & $5,101,012$ & 370,583 \\
\hline
\end{tabular}




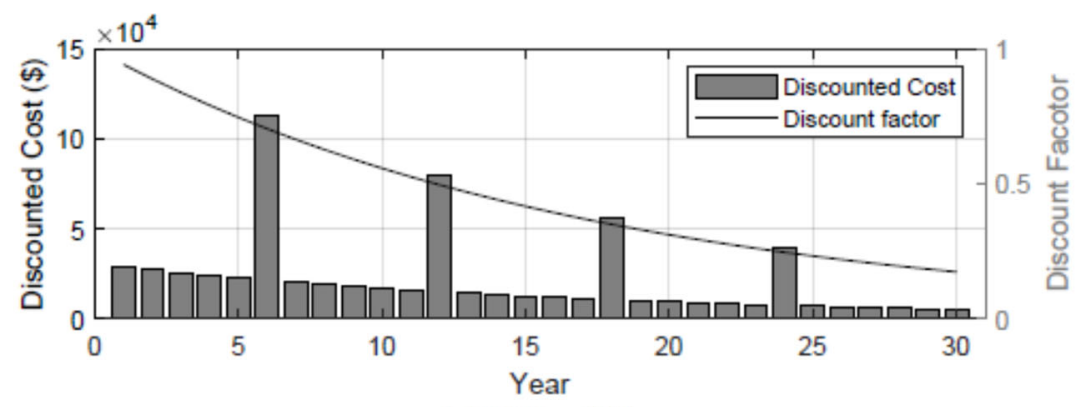

(a) $\mathrm{DOD}=80 \%$

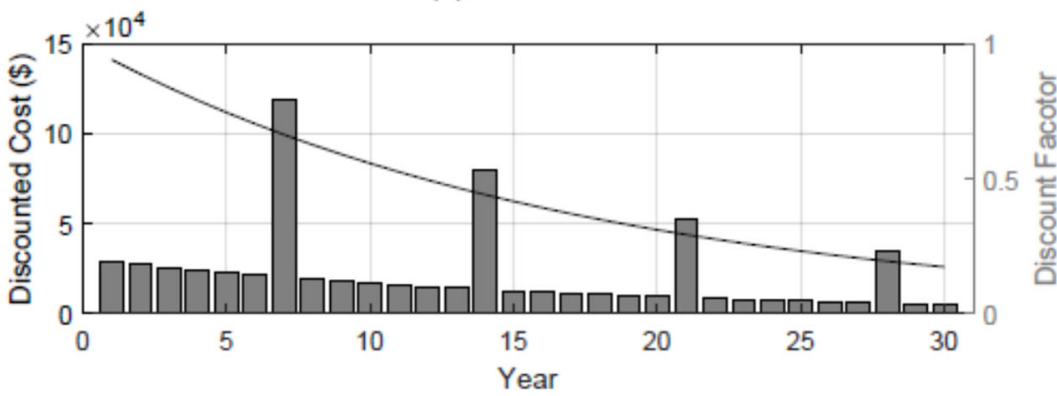

(b) $\mathrm{DOD}=70 \%$

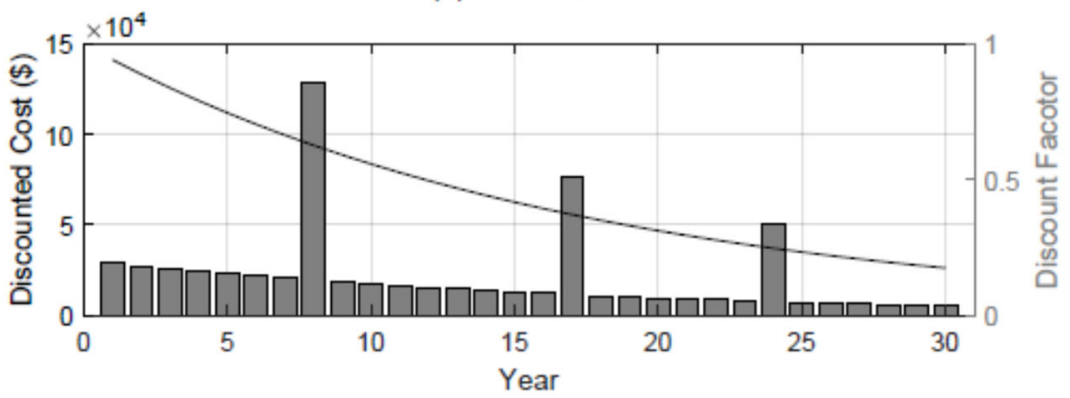

(c) $\mathrm{DOD}=60 \%$

Fig. 3.10. Net present O\&M and replacement cost

\subsubsection{Energy Conversion Efficiency Analysis}

To compute energy conversion efficiency, the tool for computing power flow results of a hybrid distribution system is necessary. In this work, we established a co-computation platform between OpenDSS and the dc system power flow (DCPF) package in Matlab. The OpenDSS is responsible for AC power flow calculation and the developed DCPF is responsible for the sub-DC system power flow calculation. Due to the nonlinearity of the DC system, fix point theory is applied to solve the power flow of a DC subsection.

Any DC system can be presented mathematically as

$$
\boldsymbol{I}_{d c}\left(\boldsymbol{V}_{d c}\right)=\boldsymbol{Y}_{d c} \boldsymbol{V}_{d c}
$$

where $\boldsymbol{I}_{d c}$ is the node current vector normally is function vector related to the terminal voltage, $\boldsymbol{V}_{d c}$ is the node voltage vector and $\boldsymbol{Y}_{d c}$ is the admittance matrix of the DC subsection. Iteratively linearizing $\boldsymbol{I}_{d c}\left(\boldsymbol{V}_{d c}\right)$ term, the final DC voltage vector $\boldsymbol{V}_{d c}^{*}$ can be computed under certain conditions. The corresponding calculation results of the DC subsection are shown in Fig. 3.11. 


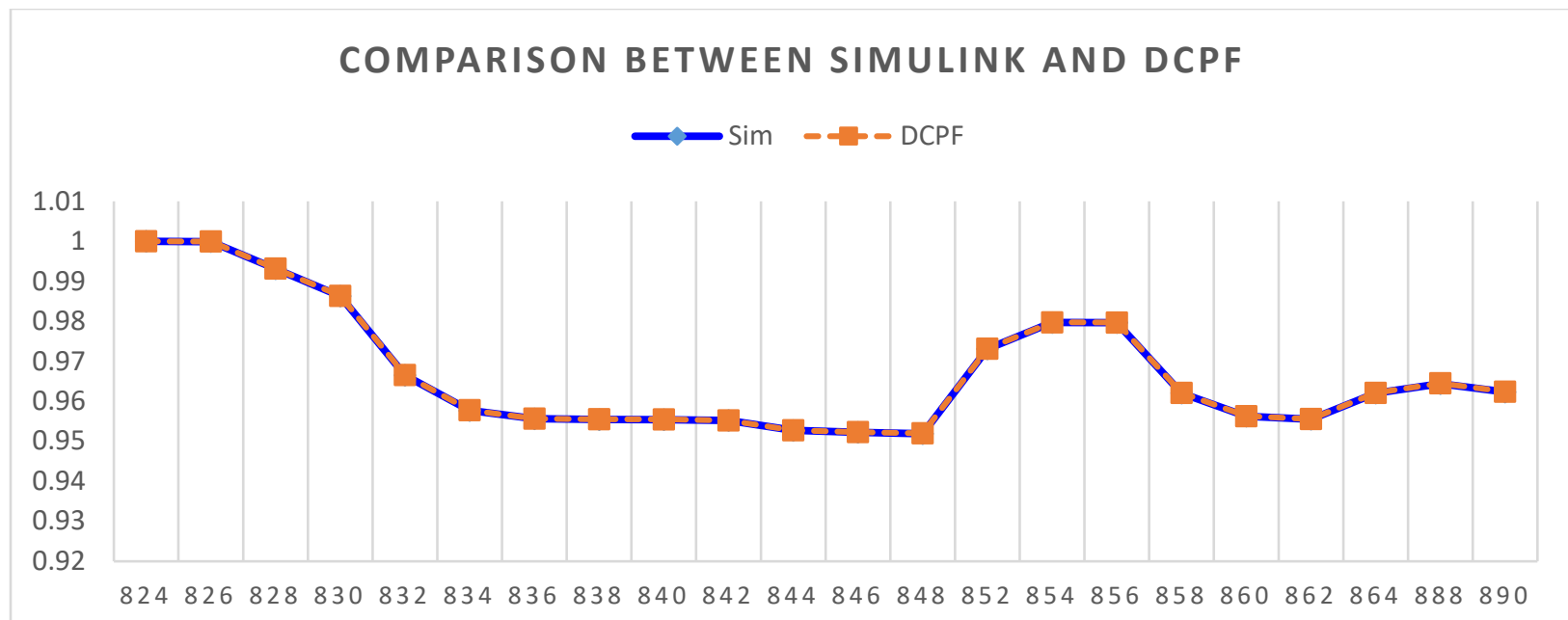

Fig. 3.11. Comparison between the Simulink power flow results and the DC power flow calculation results.

The corresponding DC system loss can be computed as

$$
L o_{d c}=\boldsymbol{V}_{d c}^{T} \boldsymbol{Y}_{d c} \boldsymbol{V}_{d c}
$$

where $L o_{d c}$ is the loss of the DC section.

The load conversion loss is computed as

$$
L o_{\text {load }, i}=P_{\text {load }, i} \frac{1-\eta_{\text {inv }}}{\eta_{\text {inv }}}
$$

where $\eta_{\text {inv }}$ is the inverter efficiency, $P_{\text {load }, i}$ is the AC load at bus $i$. The main AC/DC inverter loss is computed as

$$
L o_{M}=\left(1-\eta_{M}\right)\left(L o_{d c}+\frac{1-\eta_{i n v}}{\eta_{i n v}} \sum_{i} P_{l o a d, i}\right)
$$

where $\eta_{M}$ is the inverter efficiency.

The total system energy conversion loss of a distribution system with DC subsection is

$$
L o_{t d c}=L o_{d c}+L o_{a c}+L o_{M}+\sum_{i} L o_{l o a d, i}
$$

where $L o_{a c}$ is the AC grid loss.

In AC subsection loss calculation, the PV energy conversion loss should be considered and we have

$$
L o_{P V, i}=\frac{1-\eta_{i n v}}{\eta_{i n v}} \sum_{i} P_{P V, i}
$$

Hence, the total system energy conversion loss of a distribution system with ac subsection is 


$$
L o_{t a c}=L o_{a c}+\sum_{i} L o_{P V, i}+\sum_{i} L o_{l o a d, i}
$$

Note that the loads for the load conversion loss calculation are DC loads.

With the developed energy conversion platform, we studied 200 different scenarios considering different PV penetration levels and DC load percentage. The corresponding simulation results are shown in Fig. 3.12.

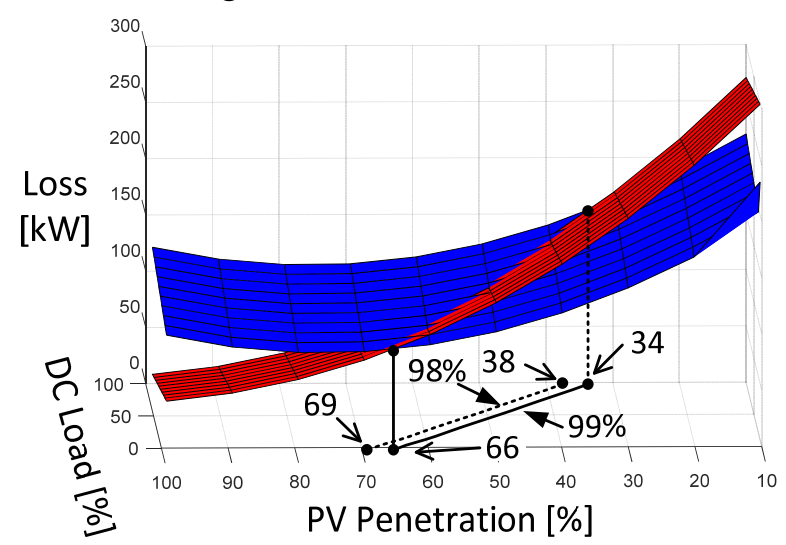

Fig. 3.12. Cost comparison for ac and dc sections considering PV penetration and dc load growth.
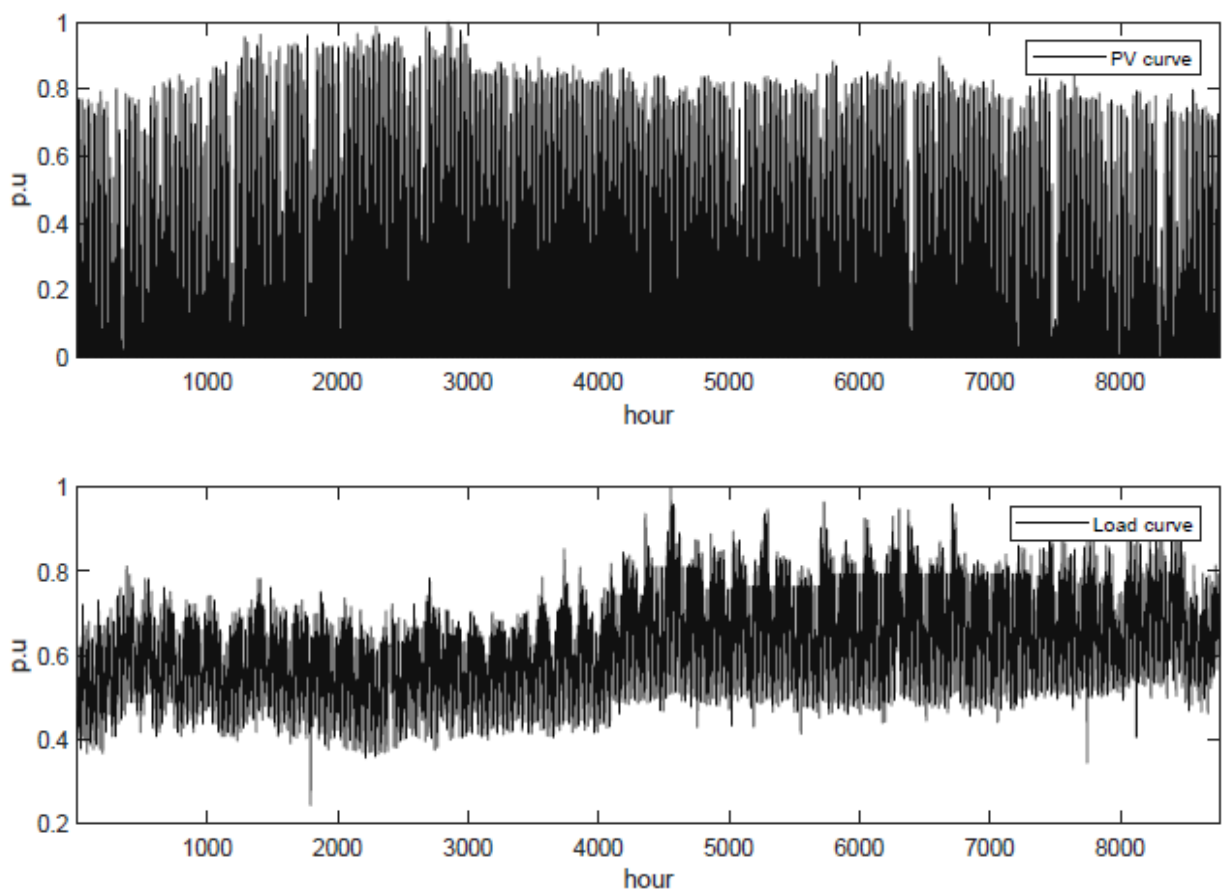

Fig. 3.13. PV output and load curve over a year.

According to Fig. 3.12, the system with DC section has better energy conversion efficiency when the PV penetration is higher than $69 \%$ with zero DC load or the PV penetration is higher than $38 \%$ with $100 \%$ DC load. If the main AC-C inverter efficiency 
increases from $98 \%$ to $99 \%$, the DC section requirements reduced from $69 \%$ to $66 \%$ and $38 \%$ to $34 \%$, respectively.

Besides, we also extend the energy conversion efficiency study by considering whole year operation. In the annualized efficiency study, we only consider three scenarios for DC load percentage in the subsections: Case 1, DC load percentage $=20 \%$; Case 2, DC load percentage $=50 \%$; Case 3 , DC load percentage $=80 \%$. The PV output and load curve over a year are plotted in Fig. 3.13.

By utilizing the analysis tool developed in this task, the averaged loss in the hybrid $A C / D C$ system and conventional $A C$ system is compared and the corresponding results are shown in Fig. 3.14. According to Fig. 3.14, we can observe that the system loss reduces with the increase of $P V$ penetration. While in the conventional system, the system does not change much. Also, the hybrid AC/DC system has better energy conversion efficiency when the PV penetration is more than $30 \%$, but if the system only has a small portion of DC load, e.g., in case 1 with $20 \%$ DC load, the energy efficiency is better in the conventional system.
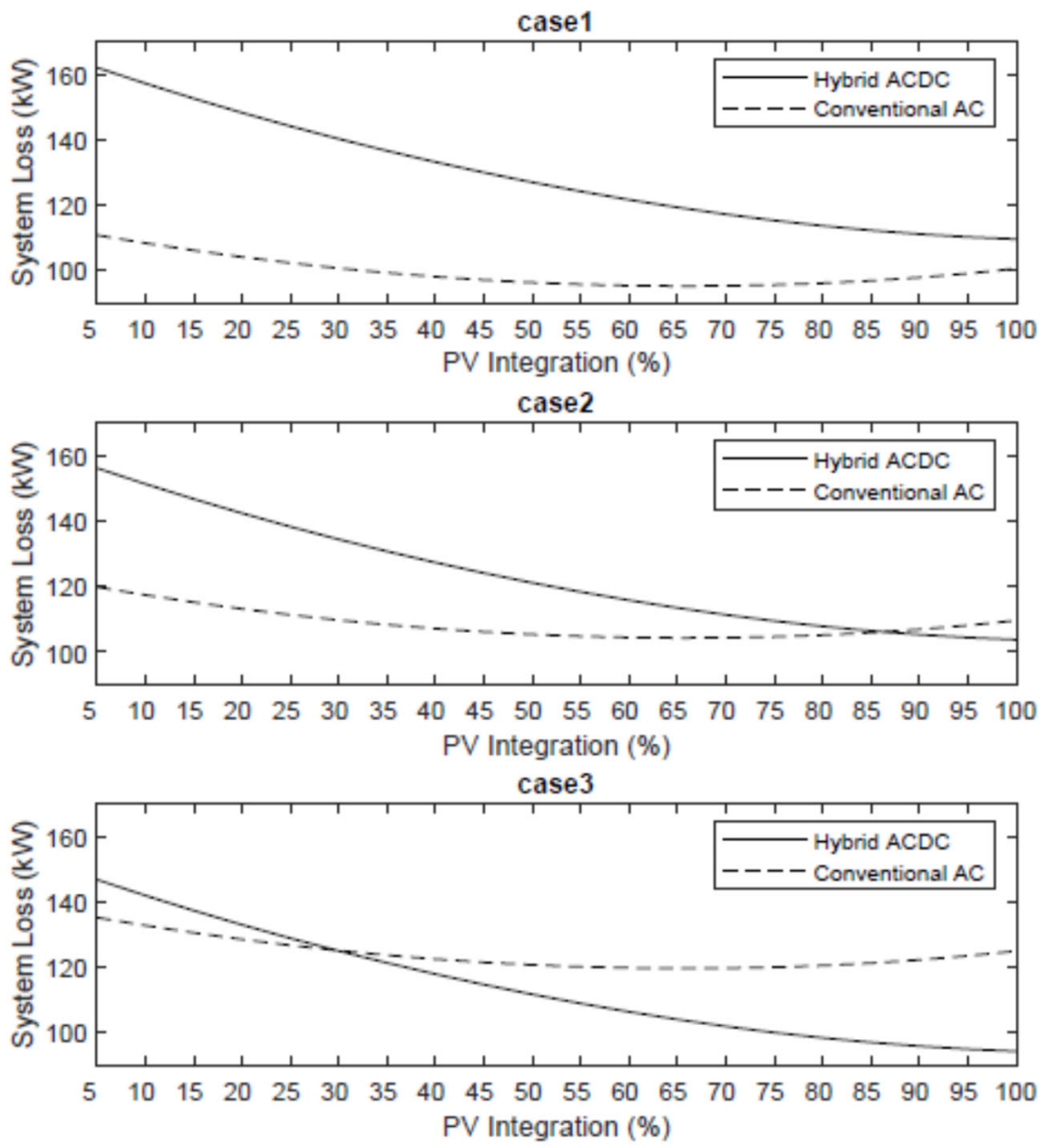

Fig. 3.14. Averaged system loss comparison between hybrid AC/DC and conventional AC system.

Table 3.9 presents the loss that can be reduced in each case in the hybrid AC/DC system with different PV penetration levels. 
Table 3.9 Loss Reduction in Hybrid AC/DC system

\begin{tabular}{|c|c|c|c|}
\hline PV Penetration & Case 1 & Case 2 & Case 3 \\
\hline $10 \%$ & $6.0 \%$ & $6.2 \%$ & $6.4 \%$ \\
\hline $20 \%$ & $11.3 \%$ & $11.7 \%$ & $12.2 \%$ \\
\hline $30 \%$ & $16.1 \%$ & $16.7 \%$ & $17.3 \%$ \\
\hline $40 \%$ & $20.4 \%$ & $21.1 \%$ & $21.9 \%$ \\
\hline $50 \%$ & $24.1 \%$ & $24.9 \%$ & $25.8 \%$ \\
\hline $60 \%$ & $27.3 \%$ & $28.2 \%$ & $29.3 \%$ \\
\hline $70 \%$ & $29.9 \%$ & $31.0 \%$ & $32.1 \%$ \\
\hline $80 \%$ & $32.0 \%$ & $33.2 \%$ & $34.4 \%$ \\
\hline $90 \%$ & $33.5 \%$ & $34.7 \%$ & $36.0 \%$ \\
\hline $100 \%$ & $34.5 \%$ & $35.7 \%$ & $37.0 \%$ \\
\hline
\end{tabular}
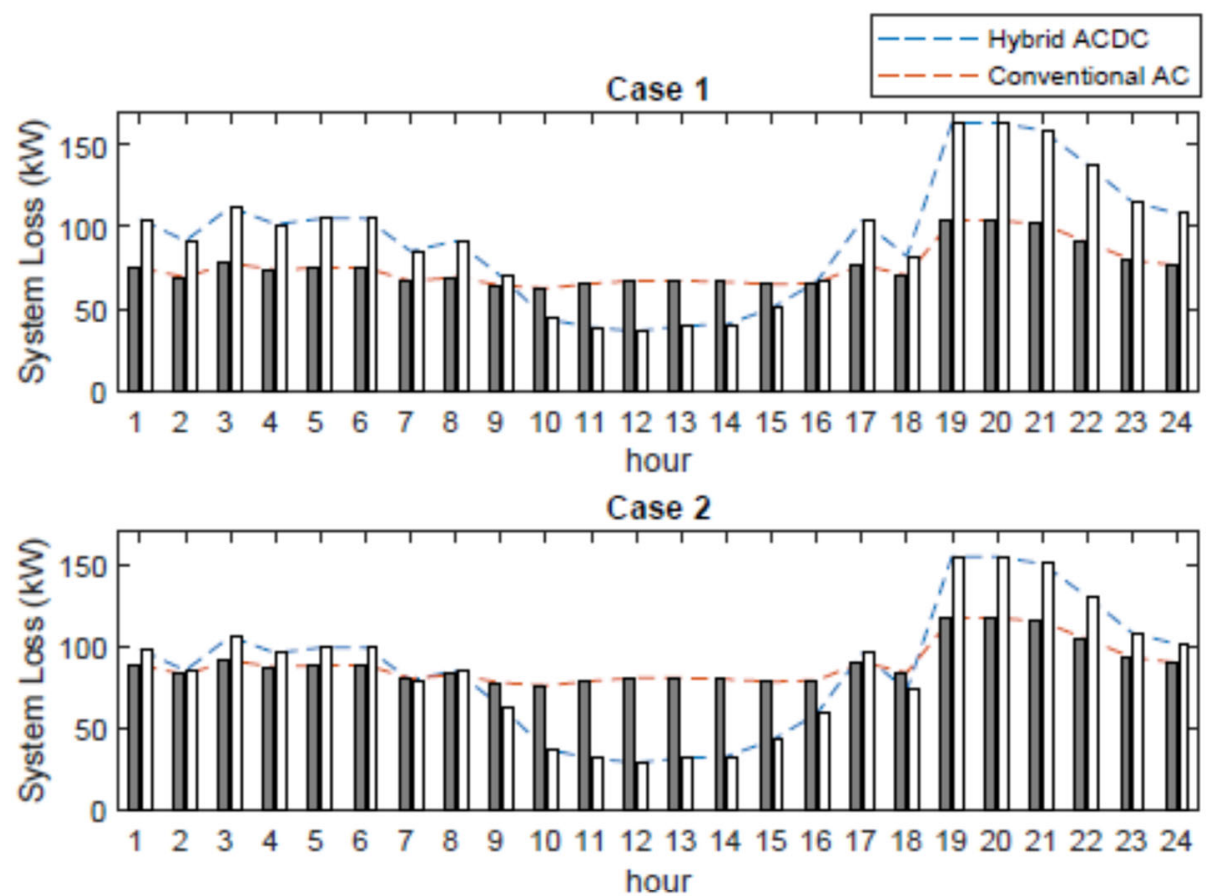

Case 3

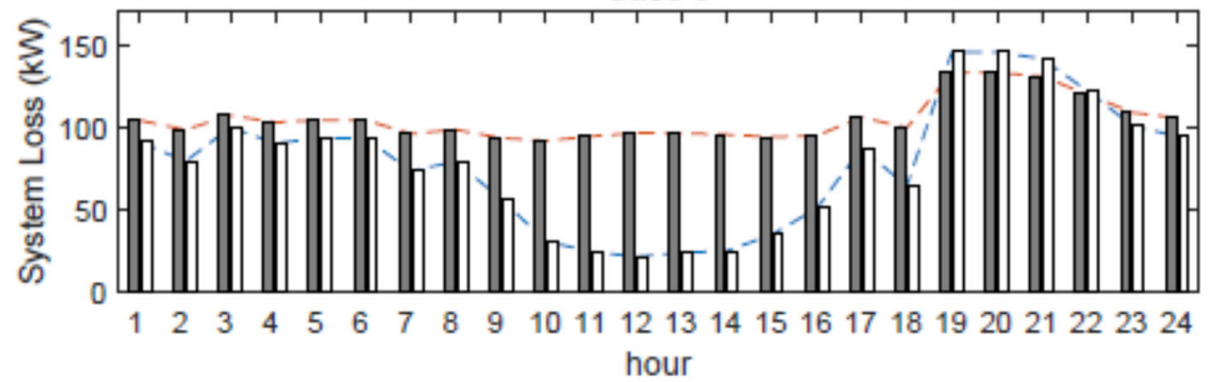

Fig. 3.15. Daily system loss at 50\% PV penetration level. 
According to the comparison results, the advantage of the hybrid AC/DC system in system loss reduction is not as good as the performance in the study shown in Fig. 3.12. The loss reduction performance of the hybrid AC/DC system is mainly impaired by considering daily PV output. In the early morning or late night, the output of the PV system is zero. Hence, an actual loss can be found in the hybrid AC/DC system during the energy conversion process from AC to DC. This phenomenon can also be found by looking at the daily system loss shown in Fig. 3.15. Clearly, the hybrid AC/DC grid has higher efficiency during the noontime.

The cost-effectiveness of the PV and storage integration in the context of a hybrid $\mathrm{AC/DC}$ grid is compared under different $\mathrm{PV}$ penetration levels (when the maximum DOD is $80 \%$ ). Cost-effectiveness is defined as the ratio between the cost and the percentage of loss reduction as shown in Fig. 3.16. From the results, we can observe that

- Among the three cases, Case 3 is more cost-effective than the other two. As to achieve a higher percentage of loss reduction, less cost is needed in Case 3.

- The system is more cost-effective when PV penetration is around $40 \%$ and $50 \%$.

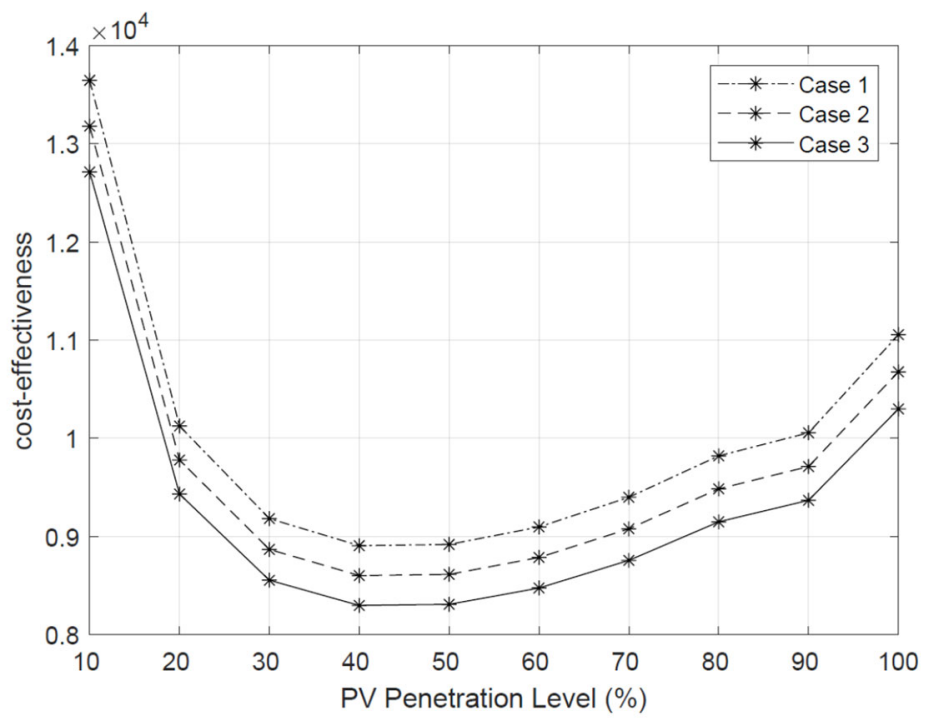

Fig. 3.16. Cost-effectiveness of the PV and energy storage system for hybrid AC/DC grids.

\section{Conclusions}

The major qualitative conclusion of this is concluded in a task-by-task format. The detailed technical conclusions can be found in the previous section.

Task 1: According to the dynamic study of the hybrid AC/DC system, we found that the hybrid AC/DC system can reduce the system harmonic level at all PV penetration levels. When the PV penetration level is high and the actual generation is high, the hybrid $A C / D C$ system offers more loss reduction than the traditional pure AC system with PVs.

However, the hybrid AC/DC system may not benefit the host AC system in loss minimization. With a low PV penetration level, the host system loss when a hybrid AC/DC system exists is higher than the system with a pure AC system.

Task 2: For modeling, control, and active stabilization of hybrid AC and DC distribution feeders, we developed a holistic model considering all the sections included in the hybrid 
framework, including AC subsections, DC subsections, and interlink inverters between $A C$ and DC buses. Meanwhile, both interface inverters, network circuits, and loads are detailed in each subsection for conducting the corresponding large-signal and smallsignal models. Grid-forming(GFM) controls are implemented in both AC and DC subsections, and the coordinated control diagram at the interlink inverters is designed to adapt to the control schemes in both AC and DC sides. An additional virtual impedance loop comprised of virtual inductance and virtual resistance is involved to actively adjust system stability margin. Time-domain testing results and the frequency-domain stability analysis are conducted to verify the developed model and control algorithms.

Task 3: According to the cost-benefit analysis results from this project, we found that the cost-benefit advantages of the hybrid AC/DC system heavily related to (1) the ratio of the DC load; (2) the daily PV generation curve; (3) PV penetration level. The hybrid $A C / D C$ distribution grid is more suitable to the system with a high DC load ratio, more daily PV generation, and a high PV penetration level. The whole range energy conversion efficiency of the multiport converter is the key parameter to reduce the bar of hybrid AC/DC grid adoption.

\section{Budget and Schedule}

All spendings and cost share are as shown in the updated TWP and are all on schedule.

\section{Path Forward}

In the future, we plan to keep improve the performance of the developed control method for the hybrid AC/DC grid. Besides, we will also try to update our alpha version cost benefit analysis tool.

Publications Resulting from This Work

[A] Y. Tian, D. Zhao, T. Hong, B. Cui, "Cost and efficiency analysis for hybrid AC/DC distribution system planning with PV and Battery," Innovative Smart Grid Technologies (ISGT), Feb. 2020.

[B] Y. Men, L. Ding, Y. Du, X. Lu, D. Zhao and Y. Cao, "Holistic Small-Signal Modeling and Al-Assisted Region-Based Stability Analysis of Autonomous AC and DC Microgrids", in Proc. Energy Convers. Congr. Exposit (ECCE), Detroit, MI, USA, 2020.

[C] T. Hong, D. Zhao, Y. Zhang, "A Relaxed PV Bus Model in Linear Power Flow," accepted by IEEE Transactions on Power Delivery, Oct. 2020.

\section{References}

[1] F. Nejabatkhah and Y. W. Li, "Overview of Power Management Strategies of Hybrid AC/DC Microgrid," IEEE Trans. Power Electron., vol. 30, no. 12, pp. 7072-7089, 2015.

[2] X. Liu, P. Wang and P. C. Loh, "A Hybrid AC/DC Microgrid and Its Coordination Control," IEEE Trans. Smart Grid, vol. 2, no. 2, pp. 278-286, June 2011

[3] H. M. A. Ahmed, A. B. Eltantawy and M. M. A. Salama, "A Planning Approach for the Network Configuration of AC/DC Hybrid Distribution Systems," in IEEE Transactions on Smart Grid, vol. 9, no. 3, pp. 2203-2213, May 2018, doi: 10.1109/TSG.2016.2608508.

[4] H. M. A. Ahmed, A. B. Eltantawy and M. M. A. Salama, "A Generalized Approach to the Load Flow Analysis of AC-DC Hybrid Distribution Systems," in IEEE Transactions 
Lab Call FY19-21 34225

$\mathrm{AC}$ and $\mathrm{DC}$ hybrid distribution grids with solar integration: architecture, stabilization and cost assessment

Dongbo Zhao

on Power Systems, vol. 33, no. 2, pp. 2117-2127, March 2018, doi: 10.1109/TPWRS.2017.2720666.

[5] M. Zhou, J. Zhai, G. Li and J. Ren, "Distributed Dispatch Approach for Bulk AC/DC Hybrid Systems With High Wind Power Penetration," in IEEE Transactions on Power Systems, vol. 33, no. 3, pp. 3325-3336, May 2018, doi: 10.1109/TPWRS.2017.2762358.

[6] H. Qiu, B. Zhao, W. Gu and R. Bo, "Bi-Level Two-Stage Robust Optimal Scheduling for AC/DC Hybrid Multi-Microgrids," in IEEE Transactions on Smart Grid, vol. 9, no. 5, pp. 5455-5466, Sept. 2018, doi: 10.1109/TSG.2018.2806973.

[7] C. Qi et al., "A Decentralized Optimal Operation of AC/DC Hybrid Distribution Grids," in IEEE Transactions on Smart Grid, vol. 9, no. 6, pp. 6095-6105, Nov. 2018, doi: 10.1109/TSG.2017.2703582.

[8] Z. Yu, X. Wang, L. Qu, W. Zhou and R. Zeng, "DC Side Over-Voltage Characteristics Analysis of AC/DC Hybrid Distribution Power System," in IEEE Access, vol. 8, pp. 133248-133257, 2020, doi: 10.1109/ACCESS.2020.3010266.

[9] S. Mirsaeidi, X. Dong, S. Shi, D. Tzelepis, "Challenges, advances and future directions in protection of hybrid AC/DC microgrids," IET Renewable Power Generation, vol. 11, no. 12, pp. 1495-1502, Oct. 2017.

[10] C. H. Noh, C. H. Kim, G. H. Gwon, M. O. Khan, S. Z. Jamali, "Development of protective schemes for hybrid AC/DC low-voltage distribution system," Electrical Power and Energy Systems, vol. 105, pp. 521-528, Feb. 2019.

[11] Z. Li and M. Shahidehpour, "Small-Signal Modeling and Stability Analysis of Hybrid AC/DC Microgrids," IEEE Trans. Smart Grid, vol. 10, no. 2, pp. 2080-2095, 2019.

[12] N. Pogaku, M. Prodanovic and T. C. Green, "Modeling, analysis and testing of autonomous operation of an inverter-based microgrid," IEEE Trans. Power Electron., vol. 22, no. 2, pp. 613-625, March 2007.

[13] M. Singh, T. Vishnuvardhan, S. G. Srivani, "Adaptive protection coordination scheme for power networks under penetration of distributed energy resources", IET Generation, Transmission \& Distribution, Vol. 10, Iss. 15, 2016, pp. 3919-3929.

[14] N. Schaefer, T. Degner, A. Shustov, T. Keil, J. Jaeger, "Adaptive protection system for distribution networks with distributed energy resources", in Proc. Of 10th IET International Conference on Developments in Power System Protection, March 2010.

[15] V. Telukunta, J. Pradhan, A. Agrawal, M. Singh, S. G. Srivani, "Protection challenges under bulk penetration of renewable energy resources in power systems: a review", in CSEE Journal of Power and Energy Systems, Vol. 3, No. 4, Dec 2017.

[16] Z. Hadi, A. Mohamed, H. Shareef and M. Mohammadjafari, "A Comprehensive review of protection coordination methods in power distribution systems in the presence of DG," Electrical Review, no. 8, 2011.

[17] H. H. Zeineldin, H. M. Sharaf, D. K. Ibrahim and E. E.-D. A. El-Zahab, "Optimal Protection Coordination for Meshed Distribution Systems With DG Using Dual Setting Directional Over-current Relays," IEEE Transactions on Smart Grid, vol. 6, no. 1, pp. 115123, January 2015. 
[18] X. Bao, P. Tan, F. Zhuo, X. Yue, "Low voltage ride through control strategy for high-power grid-connected photovoltaic inverter", in Proc. Of 2013 28th APEC, March 17212013 , CA, USA.

[19] A. Marinopoulos, F. Papandrea, M. Reza, S. Norrga, F. Spertino, R. Napoli, "Grid integration aspects of large solar PV installations: LVRT capability and reactive power/voltage support requirements", in Proc. Of 2011 IEEE Trondheim PowerTech, June 19-23 2011, Trondheim, Norway.

[20] A. Ghadiri, M. R. Haghifam, and S. M. M. Larimi, "Comprehensive approach for hybrid ac/dc distribution network planning using genetic algorithm," IET Generation, Transmission \& Distribution, vol. 11, no. 16, pp. 3892-3902, 2017.

[21] S. Diaf, M. Belhamel, M. Haddadi, and A. Louche, "Technical and economic assessment of hybrid photovoltaic/wind system with battery storage in Corsica island," Energy policy, vol. 36, no. 2, pp. 743-754, 2008

[22] P. Poonpun and W. T. Jewell, "Analysis of the cost per kilowatt hour to store electricity," IEEE Transactions on energy conversion, vol. 23, no. 2, pp. 529-534, 2008.

[23] L. Qi, A. Antoniazzi, L. Raciti, "DC Distribution Protection - Analysis, Solutions, and Example Implementations", in Proc. Of the 2017 IEEE Industry Application Annual Meeting, Cincinnati, OH, Oct 2017.

[24] L. Qi, A. Antoniazzi, L. Raciti, D. Leoni, "Design of solid state circuit breaker based protection for DC shipboard power systems", IEEE Journal of Emerging and Selected Topics in Power Electronics, Special Issue on Emerging Electric Ship MVDC Power Technology, March 2017.

[25] G. Tang and M. R. Iravani, "Application of a Fault Current Limiter To Minimize Distributed Generation Impact on Coordinated Relay Protection," in International Conference on Power Systems transients (IPST'05), Montreal, Canada, 2005.

[26] M. Khederzadeh, "Application of TCSC to Restore Directional Overcurrent Relay Coordination in Systems with Distributed generation," in 10th International Conference on Electricity Distribution, Prague, June,2009.

[27] A. Agheli, H. A. Abyaneh, R. M. Chabanloo, H. H. Dezaki, "Reducing the impact of DG in distribution networks protection using fault current limiters", in Proc. Of $20104^{\text {th }}$ International Power Engineering and Optimization Conference, June 22-23 2010, Shah Alam, Malaysia.

[28] M. E. Hamidi, R. M. Chabanloo, "Optimal allocation of distributed generation with optimal sizing of fault current limiter to reduce the impact on distribution networks using NSGA-II", IEEE System Journal, Vol: 13, Issue: 2, 2019.

[29] D. Philpott, L. Qi, "Solid-State Fault Current Limiters for Residential Houses and Commercial Buildings", Vol. 55, Issue. 4, IEEE Transactions on Industrial Applications, July-Aug 2019.

[30] Fu, Ran, et al. US solar photovoltaic system cost benchmark: Q1 2017. No. NREL/TP-6A20-68925. National Renewable Energy Lab.(NREL), Golden, CO (United States), 2017. 
[31] Kelsey A. W. Horowitz, Fei Ding, Barry Mather, and Bryan Palmintier, "The Cost of Distribution System Upgrades to Accommodate Increasing Penetrations of Distributed Photovoltaic Systems on Real Feeders in the United States", National Renewable Energy Laboratory, 2018.

[32] Joyce McLaren, Pieter Gagnon, Kate Anderson, Emma Elgqvist, Ran Fu, Tim Remo, "Battery Energy Storage Market: Commercial Scale, Lithium-ion Projects in the U.S.", National Renewable Energy Laboratory, 2016.

[33] https://news.energysage.com/how-much-does-the-average-solar-panelinstallation-cost-in-the-u-s/

[34] P. Denholm, J. Eichman, and R. Margolis, "Evaluating the Technical and Economic Performance of PV Plus Storage Power Plants," August 2017. www.nrel.gov/publications.

[35] Zakeri B, Syri S. Electrical energy storage systems: A comparative life cycle cost analysis. Renewable and sustainable energy reviews. Feb 2015.

[36] Athanasia, A.L., Anastassios, D.P., The economics of photovoltaic stand-alone residential households: a case study for various European and Mediterranean locations. Solar Energy Materials and Solar Cells 62, 411-427, 2000.

[37] Schoenung SM, Hassenzahl WV. Long- vs. short-term energy storage technologies analysis: A life cycle cost study. New Mexico, California: Sandia National Laboratories, 2003.

[38] Akhil, Abbas A., et al. "DOE/EPRI electricity storage handbook in collaboration with NRECA." Sandia national laboratories (2015).

[39] B. Xu, A. Oudalov, A. Ulbig, G. Andersson, and D. S. Kirschen, "Modeling of lithium-ion battery degradation for cell life assessment," IEEE Trans. Smart Grid, vol. 9, no. 2, pp. 1131-1140, March 2016. 


\section{Argonne}

\section{Energy Systems Division}

Argonne National Laboratory

9700 South Cass Avenue

Lemont, IL 60439

www.anl.gov 